\title{
DEHUMANISATION AND ATTITUDES TOWARD THE PUNISHMENT AND REHABILITATION OF CHILD SEX OFFENDERS: A NEW ZEALAND STUDY
}

By

Charis Elizabeth Lister Dixson

A thesis submitted to Victoria University of Wellington in fulfilment of the requirements for the degree of Master of Arts in Criminology Social and Cultural Studies

Victoria University of Wellington 2015 


\begin{abstract}
Child sex offenders are a group often regarded as dangerous and high risk, leading to increased support for offender registration policies which monitor the whereabouts of offenders after release. These policies have the intended aim of increasing public safety, however a wide body of research supports the idea that negative attitudes towards offenders underlie the creation of these policies more than empirical evidence of their success. Dehumanisation is a psychological process that deprives others of characteristics unique to both human beings and human nature, which has been established to predict increased support for punishment and decreased support for rehabilitation for child sex offenders. The current study aimed to examine the role of dehumanisation in support for punishment and rehabilitation of child sex offenders throughout two studies: first via the undertaking of an online survey using a sample of 228 university students and members of the public, second throughout three focus groups containing a total of 22 university students and members of the public. Dehumanising attitudes in relation to preference between the RNR and GLM models, two key frameworks for child sex offender rehabilitation, were also examined for the first time in the current study. Findings indicated that: 1) both moral outrage and dehumanisation predicted support for harsher forms of punishment and withdrawn support for rehabilitation, 2) victim age did not impact dehumanisation scores, 3 ) type of offense impacted both dehumanisation and support for post-release monitoring and 4) dehumanisation did not predict RNR over GLM preference. Limitations of the current study and implications for policy and practice, future research regarding uniquely human characteristics, victim age and RNR/GLM preference are discussed.
\end{abstract}




\section{Acknowledgements}

I would first like to thank my amazing parents, Alan and Amanda Dixson. Dad, you are a role model like no other and I feel so incredibly lucky to be your daughter. Thanks for showing me the world and making me feel like I was capable of whatever I set my mind to. Mum, you are by far one of the kindest and most generous souls on the planet and I appreciate everything you have done to keep me going. Thank you to both of you for encouraging me not to give up. I would also like to thank my three brothers Henry, Barnaby and Alexander Dixson. I am proud of each one of you and thank you for all the support and advice.

I would also like to thank my supervisor, Russil Durrant, for the hours of time spent collaborating and working on this thesis together and for providing excellent supervision. Thank you for the understanding and kindness at times when I was unwell or unable to attend meetings and for all the time spent guiding me through the jungle of SPSS. I really appreciate it.

I would finally like to thank Tony Ward for providing approval of the Good Lives Model and Risk Need Responsivity survey content of the current study. No previous studies investigating GLM and RNR could be retrieved, therefore no previous survey questions existed on which to base my research, so I greatly appreciate Professor Ward lending his time to help me create them 
Dehumanisation and child sex offenders: a New Zealand study

\section{Table of Contents}

$\begin{array}{lll}\text { Abstract } & \text { ii }\end{array}$

$\begin{array}{ll}\text { Acknowledgements } & \text { iii }\end{array}$

Introduction 1

$\begin{array}{ll}\text { Literature Review } & 2\end{array}$

Attitudes Towards Offending $\quad 2$

Public Attitudes and Legislation $\quad 8$

$\begin{array}{ll}\text { Attitudes Towards Rehabilitation } & 12\end{array}$

Risk Need Responsivity (RNR) Model 13

$\begin{array}{ll}\text { Good Lives Model (GLM) } & 15\end{array}$

$\begin{array}{ll}\text { Dehumanisation } & 19\end{array}$

$\begin{array}{ll}\text { Dehumanisation and Collective Violence } & 19\end{array}$

Dual Model of Dehumanisation $\quad 22$

$\begin{array}{ll}\text { Infrahumanisation } & 24\end{array}$

$\begin{array}{ll}\text { The Present Study } & 26\end{array}$

$\begin{array}{lr}\text { Methods } & 29\end{array}$

$\begin{array}{ll}\text { Study } 1 & 30\end{array}$

Participants \& Design 30

$\begin{array}{ll}\text { Materials } & 30\end{array}$

$\begin{array}{ll}\text { Crime Descriptions } & 30\end{array}$

Moral Outrage \& Liking $\quad 31$

$\begin{array}{ll}\text { Dehumanisation } & 31\end{array}$

$\begin{array}{ll}\text { Punishment } & 31\end{array}$

Support for Rehabilitation $\quad 32$

$\begin{array}{ll}\text { RNR/GLM } & 32\end{array}$ 
Study 1: Ethical Considerations 33

$\begin{array}{ll}\text { Procedure } & 34\end{array}$

Data Analysis $\quad 34$

$\begin{array}{ll}\text { Study } 2 & 36\end{array}$

$\begin{array}{ll}\text { Participants \& Design } & 37\end{array}$

$\begin{array}{ll}\text { Materials and Procedure } & 37\end{array}$

Study 2: Ethical Considerations $\quad 39$

$\begin{array}{ll}\text { Data Analysis } & 41\end{array}$

$\begin{array}{ll}\text { Results and Discussion } & 42\end{array}$

$\begin{array}{ll}\text { Study } 1 & 42\end{array}$

$\begin{array}{ll}\text { Discussion } & 50\end{array}$

Study 2

$\begin{array}{ll}\text { Dehumanisation } & 54\end{array}$

'Beast of Blenheim' case study $\quad 54$

Animalistic dehumanisation and denial of uniquely human characteristics $\quad 54$

$\begin{array}{ll}\text { Child pornography offender case study } & 57\end{array}$

Consideration of offense $\quad 59$

Summary: Type of Offense 61

$\begin{array}{ll}\text { Post-release monitoring } & 61\end{array}$

Infrahumanisation and UH characteristics $\quad 63$

$\begin{array}{ll}\text { Infrahumanisation and paedophilia } & 63\end{array}$

Summary of findings: Infrahumanisation 66

Contact Hypothesis 66

$\begin{array}{ll}\text { Summary } & 69\end{array}$

$\begin{array}{ll}\text { General Discussion } & 70\end{array}$ 
$\begin{array}{ll}\text { Type of offense and age of victim } & 71\end{array}$

$\begin{array}{ll}\text { Dehumanisation, punishment and rehabilitation } & 73\end{array}$

$\begin{array}{ll}\text { RNR/ GLM } & 74\end{array}$

$\begin{array}{ll}\text { Infrahumanisation } & 75\end{array}$

Rehumanisation of child sex offenders and the contact hypothesis 76

Limitations of the current study $\quad 77$

$\begin{array}{ll}\text { Implications of the current study } & 78\end{array}$

$\begin{array}{ll}\text { Implications for policy and practice } & 78\end{array}$

Rehumanisation, the contact hypothesis and community education $\quad 78$

$\begin{array}{lr}\text { Implications for future research } & 80\end{array}$

Future investigation of UH characteristics $\quad 80$

$\begin{array}{ll}\text { Victim age } & 80\end{array}$

$\begin{array}{ll}\text { Non-contact offenses } & 81\end{array}$

$\begin{array}{ll}\text { Conclusion } & 81\end{array}$

$\begin{array}{lr}\text { Appendices } & 85\end{array}$

Appendix A: Information sheet: online survey 86

$\begin{array}{ll}\text { Appendix B: copy of online survey } & 87\end{array}$

Appendix C: vignettes used in online survey $\quad 91$

Appendix D: GLM/RNR question from online survey 92

Appendix E: information sheet: focus group participation 93

Appendix F: consent form: focus group participation 96

Appendix G: focus group interviewer guide $\quad 97$

$\begin{array}{ll}\text { Appendix H: Counselling services available in NZ } & 100\end{array}$

$\begin{array}{ll}\text { References } & 102\end{array}$ 


\section{List of Tables and Figures}

\section{Tables}

1. Results of focus group coding

2. Means and Standard Deviations for dehumanisation, moral outrage, punishment and rehabilitation conditions

3. Results of 2-way ANOVA for dehumanisation, moral outrage, punishment and rehabilitation

4. Bivariate relationships between key study variables

5. Results of linear regression analysis: support for punishment

6. Results of linear regression analysis: support for rehabilitation

\section{Figures}

1. Significant interaction effect between type of offense and age of victim for moral outrage

2. Significant interaction effect between type of offense and age of victim for punishment 


\section{Introduction}

Child sex offenders have long been a source of moral panic due to the morally abhorrent nature of their crimes and the public perception that they recidivate at a frequent and unpredictable rate (Levenson, Brannon, Fortney \& Baker, 2007a). Although research has indicated that the re-offending rates of child sex offenders is generally low compared to other groups of offenders (Hanson \& Morton-Bourgon, 2004; 2005) and even further reduced by effective rehabilitation (Harkins \& Beech, 2007) the public remain generally unaware of these findings due to the development of legislation, such as notification policies and registration, which physically and morally distance offenders from the rest of society (Sample \& Bray, 2006). The media also influences moral panic relating to child sex offenses by using eyecatching dehumanising titles for child sex offenders such as "The Beast of Blenheim" (3News, 2014) and consistent use of terms such as 'monster', 'predator' and 'pervert' (Marshall, 1996; Viki, Fullerton, Raggett, Tait \& Wiltshire, 2012). These titles reinforce to the public the belief that animal-like predators walk the streets at night with the aim of sexually victimizing children (Welchans, 2005). Referring to this group of sexual offenders as 'beasts' and 'predators' may create dehumanising attitudes amongst members of the public, clinicians and criminal justice system professionals which may have a detrimental impact on the efforts of clinicians to rehabilitate and successfully reintegrate child sex offenders into society after release (Levenson, D'Amora, Hern, 2007b). Due to the extent of moral outrage towards child sex offenders and their crimes, the public may not deem these individuals worthy of moral concern which in turn provides justification for violations of rights to privacy, safety, housing and employment after release (Levenson \& Cotter, 2005a). It also places the burden of "ex facto" punishment on this group (Petrosino \& Petrosino, 1999), referring to punishment that extends beyond institutional walls and into the public realm. Despite the heterogeneity of offense type, victim age and individual level of risk for re-offending (Levenson et al., 2007b), typically all child sex offenders receive the same label and subsequent treatment from the public (Marshall, 1996).

A number of studies now support a link between public attitudes towards child sex offenders and support for: (a) harsher forms of punishment including post-release monitoring (Bastian, Denson \& Haslam, 2013; Shackley, Weiner, Day \& Willis, 2013; Viki et al., 2012): and (b) withdrawn support for rehabilitation (Viki et al., 2012). Viki et al. (2012) found that dehumanisation was a form of negative attitude which could predict support for forms of punishment as severe as castration and murder. This study also found that dehumanisation 
predicted less support for offender participation in rehabilitation. Those who dehumanise believe that child sex offenders are separated from the rest of society via differences in characteristics unique to humans such as higher cognition, empathy and remorse (Haslam, 2006) therefore child sex offenders are often regarded as uncontrollable 'beasts' or 'monsters' (Marshall, 1996) who pose a high risk of recidivism, leading to an increase in support for harsher forms of punishment and post-release monitoring. The media often contribute to these beliefs, using sensationalised titles such as 'Beast of Blenheim' (3News, 2014) to describe a New Zealand sex offender released on stringent parole conditions.

Very few studies could be retrieved addressing public attitudes toward child sex offenders in a New Zealand context, none of which addressed dehumanisation. Willis, Malinen \& Johnston (2013a) explored demographic differences in attitudes in New Zealand and found that within their sample women held more negative attitudes towards sex offenders than men and were more likely to support monitoring policies. The current study aims to contribute to this growing body of literature with a New Zealand study of public attitudes towards the punishment and rehabilitation of child sex offenders.

Based on previous findings, the current study aims to provide a sample of attitudes from members of the New Zealand public to assess the role of dehumanisation in: (1) support for harsher punishment, (2) support for rehabilitation, (3) preference for a Good Lives Model (GLM) approach to rehabilitation compared to a Risk Need Responsivity (RNR) framework for rehabilitation; and (4) support for inclusion or exclusion of child sex offenders from the community after release. This examination will be conducted through 2 studies, first the online surveying of anonymous members of the public to quantitatively test for levels of moral outrage and dehumanisation towards child sex offenders, and second through three focus groups to allow for better discussion of post-release monitoring and child sex offender rehabilitation. This research will add to the growing body of literature on dehumanising attitudes towards offenders and will provide the first assessment of dehumanising attitudes towards child sex offenders in New Zealand.

\section{Literature Review}

\section{Attitudes Towards Offending}

Attitudes of the public become an important point of focus for research because they can determine support for rehabilitation and underlie the creation of future policy (Brown, 1999). Previous studies have compared the attitudes of different groups in the public domain; 
community samples from both the UK and Australia determined that attitudes can be influenced by demographic differences such as gender (females were found to view sex offenders more negatively than males (Willis et al., 2013a), educational attainment (Shackley et al., 2013), age of victim and parental status (those who have their own children were found to be less in favour of rehabilitation) (Rogers, Hirst \& Davies, 2011). Willis et al. (2013a) used an online New Zealand community sample which produced findings that women and those with lower educational attainment should become target groups for re-education, suggesting that psychoeducational material in a group format could be helpful. Rogers, et al. (2011) used a public sample in the UK and found opposing evidence that female participants of the study viewed child sex offenders in positive terms and supported their rehabilitation, whereas men were more supportive of harsh attitudes and punishment. Rogers et al. (2011) found that other factors influenced public attitudes towards reintegration beside gender; attitudes became more negative as the victim's age decreased, and could be made more positive if the offender had completed treatment before release. Brown's (1999) public sample study of 312 participants in the UK also found that participation in treatment before release could influence public support for offender reintegration as the public sample showed preference for rehabilitation if it was presented alongside a sentence and completed before release.

Brown's (1999) study found evidence that generally the public can be accepting of the rehabilitation and reintegration of child sex offenders, however individuals are often reluctant to allow reintegration of offenders within their own community. The attitudes of the public towards offender reintegration have been established as significantly more negative than the attitudes of those who work in close proximity with child sex offenders, such as clinicians and probation workers (Willis, Levenson \& Ward, 2010). This difference in attitude can primarily be attributed to the contact hypothesis, which states that contact between two social groups can increase prosocial attitudes whilst decreasing prejudice by reinforcing the shared values of both groups (Willis et al., 2013a). Therefore those in closest contact with child sex offenders are able to base their opinions on their own personal interactions with offenders, rather than rely on the media for information on which to form an opinion (Willis et al., 2010). Willis et al. (2010) have suggested that clinicians and academics should become more heavily involved with the media so that the public may be able to build more factual perceptions of child sex offenders despite the lack of contact.

Knowledge of sexual abuse was determined by Sanghara \& Wilson (2006) to be the factor which explained differences in attitude between criminal justice professionals and public 
school teachers. School teachers endorsed more negative attitudes due to a lack of knowledge of the behaviour, whereas more experienced criminal justice system professionals were more in favour of a rehabilitative approach. As previously noted, Willis et al. (2013a) identified women and those with lower educational attainment as the demographic groups which would benefit most from education about child sex offenders. It has been established by multiple researchers that these attitudes result from a lack of education about child sex offenders and their rehabilitation, therefore community education can reduce negative attitudes toward the rehabilitation of sex offenders by providing accurate and evidence based information (Opotow, Gerson \& Woodside, 2005; Shackley et al., 2013; Willis et al., 2013a). Consistent with the contact hypothesis, education about other social groups can reduce 'othering' and therefore reduce prejudice by promoting shared values and human needs (Willis et al. 2010).

Higgins \& Ireland (2009) found support for the contact hypothesis by comparing the attitudes of prison staff, forensic staff and members of the public towards child sex offender rehabilitation. Forensic staff were found to have the most positive attitudes, viewing offenders as having high potential for rehabilitation, whereas prison staff had the harshest most untrusting attitudes. Amongst the public sample it was found that women more typically viewed the offenders in positive terms and supported their rehabilitation, whereas men were more supportive of harsh attitudes and punishment. Other studies have compared the attitudes of criminal justice professionals with those of the public such as Johnson, Hughes \& Ireland (2007) who examined a sample of 174 probationer police officers and community members in the UK. Community members were found to hold significantly more negative attitudes than police. A similar study was conducted in Norway (Kjelsberg \& Loos, 2008) comparing the attitudes of prison employees (professionals) to students (the public). Students were found to hold significantly more negative attitudes than prison employees. Ferguson \& Ireland (2006) similarly found that students held more negative attitudes than forensic staff in their sample of 139 forensic staff and students. Regardless of offense type, students endorsed the most negative attitudes toward child sex offenders compared to criminal justice system professionals. As previously suggested, these attitudes likely result from a lack of both education and contact between child sex offenders and the public (which serves to foster negative attitudes and prejudice), compared to that of justice system professionals who experience a high amount of contact and personal understanding.

The attitudes of clinicians is of importance because professionals who display dehumanising attitudes will further hinder the ability of the offender to successfully reintegrate 
into society and possibly contribute to re-offending via creation of negative emotional states for offenders (Ward \& Brown, 2004). This is an important finding when considering that negative emotional states have been established as precursors to reoffending (Mercado, Alvarex \& Levenson, 2008). Child sex offenders will eventually be released into the community, therefore it is important they are motivated towards living a productive life without re-offending and positive and effective delivery of rehabilitation is of paramount importance. Other researchers have found that motivation based - opposed to confrontation based - therapy is the most effective for offender rehabilitation, reinforcing the idea that care is needed regarding the emotional states of offenders for successful reintegration (Kear-Colwell \& Pollock, 1997) which dehumanising attitudes of both clinicians and the public can greatly hinder.

Throughout Marshall's (1996) clinical interactions with child sex offenders, he notes that enhancing the self-esteem of clients reduces risk factors for re-offending whereas negative emotional states are established to be a precursor to sexual offending. Clients who felt attacked and belittled were the most likely to end treatment early. Therefore, the most effective form of therapy would help offenders to better clarify these goals via therapeutic focus on: restoring educational attainment to full potential, matching career goals consistent to their individual abilities, enjoying leisure activities and expanding the range of social interaction available to offenders. For example many child sex offenders hold functioning consensual relationships with adult women (Durrant, 2013) and effective therapy should help child sex offenders to redirect intimacy towards functioning adult relationships.

An interesting finding uncovered by research is that attitudes vary within categories of justice system professionals: Hogue \& Peebles (1997) found that amongst a sample of criminal justice professionals in Canada, police held the most negative attitudes. Hogue (1993) also identified police as having the most negative attitudes towards sex offenders in a UK study of criminal justice employees. Kjelsberg \& Loos (2008) found in their sample of 517 students and prison employees in Norway that amongst the prison employees, prison officers endorsed the most negative attitudes toward offenders. Day, Boni, Hobbs, Carson, Whitting \& Powell (2014a) also found in their study that police officers tended to hold more negative attitudes towards offenders than allied health workers who delivered treatment. Police officers in the study were more likely to view offenders as unchangeable and support harsher forms of punishment. This difference in opinion could be attributed to the fact that other criminal justice professionals - such as clinicians or probation workers - establish a more personal relationship 
with offenders through being involved in their rehabilitation and reintegration, whereas prison officers are more involved in the punitive enforcement of prison routine and control.

Multiple studies have found that negative attitudes towards child sex offenders are associated with punitive responses such as longer jail sentence, harsher forms of punishment or support for offender registration policies (Kernsmith, Cruan \& Foster, 2009; Rogers et al., 2011; Willis et al., 2010). Viki et al. (2012) found that negative attitudes directly correlated to less support for rehabilitation and endorsement of harsher punishment for offenders. Participants who held the most negative attitudes were also likely to support the violent ill treatment and overall social exclusion of offenders from society.

Negative, uninformed approaches towards sex offender reintegration can lead to the development of legislation that does not effectively address child sex offending and is ineffective at reducing recidivism rates. Kernsmith et al. (2009) did a study in the USA to examine the relationship between fearful attitudes of the public towards different types of sexual offenses and subsequent support for offender registration using a telephone survey of 733 participants. The offenses presented for consideration were: incest, statutory rape, marital rape, paedophilia, date rape, and an offense committed ten years ago. Responses indicated that the public experienced some level of fear for each offense and that fearful emotions determined support for registration requirements. The offence type most feared by the public was for crimes involving paedophilia: $80 \%$ were afraid/very afraid to have a paedophile live nearby, 97\% supported paedophiles registering their whereabouts with the criminal justice system, compared to only $65 \%$ stating they would prefer a statutory rapist to be registered. This study indicates a direct link between the level of fear experienced by the public and support for sex offender registries, suggesting that a lack of understanding of the behaviour leads to increased fear and subsequent support for legislation that makes the public feel secure even if it hasn't been empirically established to increase public safety (Levenson et al., 2007b). Whitting, Day \& Powell (2014) mention in their review that empirical evidence for notification policies achieving their intended aim of reducing recidivism has only been established in two studies using samples of high risk offenders whereas a wide body of research indicate negative consequences of the legislation. Whitting et al. (2014) also state that registration policies are premised on flawed logic and designed to prevent attacks from strangers, which may leave children open to potential victimization from family members and acquaintances. 
A large contributing factor to the stigmatization of child sex offenders is a lack of knowledge and understanding of the behaviour by the public, leading researchers to suggest community based education to aid offenders in reintegration after release (Viki et al., 2012). The diagnostic label of 'paedophile' is broadly attributed to most offenders placed on community notification, however paedophile is a term created by the DSM referring to prolonged sexual interest for children 13 and below (American Psychiatric Association, 2013). The DSM-5 now considers paedophilia under the broader diagnostic term 'paraphilic disorders' as 'paedophilic disorder' (American Psychiatric Association, 2013). Those who victimise children above age 13 would be labelled as a 'hebephile' which can lead to alternate forms of prosecution in different parts of the world (Durrant, 2013), however in terms of offender registration policies 'hebephiles' and 'paedophiles' are typically subjected to homogenous application of law (Levenson et al., 2007b) regardless of the difference in victim typology and risk of re-offending, because sexual contact with any person below the legal age of consent is considered coercive. Many studies include hebephiles and paedophiles in the same sample when examining re-arrest patterns, sexual victimisation in childhood, and the role of fantasy in offending (Greenberg, Bradford \& Curry, 1993; Neutze, Grundmann, Scherner \& Beier, 2012; Sample \& Bray, 2006). In a correctional setting, an offender who had sexual contact with anyone under the age of consent would be referred to as a child sex offender (Durrant, 2013).

Despite receiving a homogeneous correctional label, child sex offenders are a heterogeneous group who differ greatly in offence and victim type as well as overall sexual preference (Marshall, 1996). Durrant (2013) explains the various categories of child sex offenders and their overlapping qualities: extra-familial, familial, victimisation of boys, girls, or both and child sex offenders who offend against both adults and children. Neutze et al. (2012) found that in their sample of 345 self-referred hebephiles and paedophiles that $42 \%$ committed an offense of more than one type and only $7 \%$ had been detected by law enforcement for both offenses. Cann, Friendship \& Gonza (2007) conducted a study of 1,345 male sex offenders who had been discharged from both England and Wales between 1992-1996, finding that $8 \%$ of the sample had offended against both adults and children. These findings reinforce the heterogeneous nature of child sex offenders and support the need for therapy that addresses variability of different types of offending.

Shackley et al. (2013) conducted a study of attitudes in Australia which found evidence that the public endorse a large number of myths towards child sex offenders (high rates of 
Dehumanisation and child sex offenders: a New Zealand study offenses by strangers and high re-offense rates) and generally have a poor understanding about their likelihood of being rehabilitated. In Shackley et al.'s (2013) study it was found that those with children were most likely to support notification policies and sex offender registries, not based on any evidence that the policies increased public safety, but rather based on the false belief that sex offenders recidivate frequently and abduct their victims at random from the public places, therefore monitoring their whereabouts is necessary. In actuality, the recidivism rates of child sexual offenders have been empirically established to be low and can be reduced even further through effective therapy. Hanson, Harris, Helmus \& Thornton (2014) found in a sample of 7,740 released offenders that the 5 year recidivism rate for offenders deemed 'high risk' was $22 \%$ from the time released, however for offenders that remained offense-free in the community within 10 years the rate of recidivism dropped to $4.2 \%$. Low risk offenders in the sample had a consistently low re-offense rate of $1-5 \%$. These findings reinforce the idea that offenders and their habits do change over time, and reoffending will decrease the longer an individual lives a prosocial offense-free life within the community, leading them to entitle their article "High Risk Offenders May Not Be High Risk Forever". Sample \& Bray (2006) used arrest data from Illinois to produce findings that offenders with child or adolescent victims had lower recidivism rates than adult sex offenders over an 8-year period after release (1990 1997). Child pornographers were more frequently re-arrested at $10 \%$, leading the researchers to conclude that notification policies like registries exaggerate the amount of threat that is actually present when in fact recidivism for sexual crimes is relatively low and varies across offense types. The researchers also concluded that notification policies adopted far too homogenous of an approach for a group of offenders who vary individually in risk.

Hanson \& Morton-Bourgon (2005) found that violent non-sexual recidivism rates were higher than that of sexual recidivism, which was also supported in other studies by Hanson \& Morton-Bourgon (2004). Another interesting finding by Hanson \& Morton-Bourgon (2005) was that sexual offenders were most likely to recidivate with a non-sexual offense, which could relate to the strain created by notification policies after release. When offenders cannot obtain housing, employment, or enjoy fulfilling social interactions due to the social stigma placed on them, then they may be forced to recidivate in non-sexual ways to obtain these needs.

\section{Public Attitudes and Legislation}

Notification policies were created in the United States as a response to the murder of a young girl, Megan Kanka, who was killed by a released child sex offender that lived in her neighbourhood (Levenson \& Cotter, 2005a). Registries listing the name and whereabouts of 
convicted child sex offenders were then placed online and/or printed on paper and distributed to the community (Welchans, 2005). Some forms of registration also include disclosure of photographs (Day, Carson, Boni \& Hobbs, 2014b) home addresses of offenders, and the addresses of employers (Mercado et al., 2008). Child sex offender registries were created (and typically placed online for public access) with the assumption that knowing the physical whereabouts of offenders will allow parents to protect their children from future victimization, insinuating Megan Kanka's death could have been avoided had a register existed at the time of her death (Levenson et al., 2007b; Welchans, 2005). Notification policies were created in response to the murder of a child - a context in which the public's concern and moral panic toward child sex offending was at an all-time high - and were therefore assumed to deter these crimes from occurring again, creating a sense of security for the public by constantly monitoring the whereabouts of offenders (Whitting et al., 2014). Notification policies are also based on the assumption that public disclosure will deter future offending and aid in investigation and prosecution of future offenses (Day, Carson, Newton \& Hobbs, 2014c; Powell, Day, Benson, Vess \& Graffam, 2014).

Legislation involving community notification and online registration are born out of public fear for an unexplainable crime, or as Levenson \& Cotter (2005a) explain, notification policies are built on the concept of 'stranger danger' in which child sex offenders are perceived to be members of the public who have uncontrollable sexual urges towards children and therefore hide in public places such as schools or parks waiting to abduct children opportunistically. Researchers have counteracted these myths with empirical evidence displaying that much like adult sex offences, sexual offenses against children are more likely to occur when the victim and offender have a pre-existing relationship (Whitting et al., 2014). This misconception could be potentially harmful to parents trying to protect their children; victimisation is assumed to occur at the hands of a 'predator' (anonymous member of the public) whereas research indicates great care should also be taken when leaving children in the care of close acquaintances, family, and neighbours (Levenson et al., 2007a; Whitting et al., 2014).

Kernsmith et al. (2009) drew a valuable link between public fear and support for registration, determining that the more afraid the public felt, the more comfort was provided by placing an offender on a registry. This illustrates both the moral panic surrounding sexual offending and the lack of knowledge held by the public as there is little evidence to support the claim that sex offender registries increase public safety or reduce sexual victimization (Levenson \& Cotter, 2005a; 2005b; Whitting et al., 2014). Rather, these policies provide a false 
sense of security for the public with no basis in evidence. Support for a sex offender registry therefore originates from the false idea that: 1) child sex offenders re-offend at a frequent and uncontrollable rate; 2) child sex offenders pose the same amount of risk after release and/or treatment as they did at the time of offending; and 3) knowing their whereabouts can both reduce recidivism and protect neighbourhood children from further sexual victimization (Levenson \& Cotter 2005a; 2005b; Mercado et al., 2008). The consequences of online sex offender registration, as previously discussed, are far from those that deter offending and instead create consequences conducive to reoffending such as strain on employment, living, and mental health (Levenson et al., 2007b; Whitting et al., 2014).

Once a community becomes notified of the whereabouts of a child sex offender, that individual's right to peaceful living, employment, and personal safety are placed in jeopardy (Levenson et al., 2007b). Researchers have documented the barriers to reintegration placed on registered offenders, such as Levenson \& Cotter (2005a) who recorded collateral consequences faced by 183 registered male sex offenders in Florida. Most respondents of the study felt that it was unfair to receive this label for life, especially as it overlooked those who participated in therapeutic programs and/or those who ceased offending after being released. Those on the registry felt that they should have an opportunity for redemption and that remaining offense free in the community for an extended period of time should guarantee their removal from the data base. Many participants noted the homogeneous approach of the registry to sex offenders; those who had offended once or committed non-contact offenses were registered alongside those who committed violent, serial sexual offenses. Some countries adopt a policy where only offenders determined as 'high risk' are placed on the registry (Mercado et al., 2008), however more commonly the registry is applied broadly to all child sex offenders with no distinction of risk-level, offense type or victim type (Whitting et al., 2014; Levenson et al., 2007b; Powell et al., 2014).

Powell et al. (2014) performed a study using a sample of 24 Australian police professionals who worked in roles associated with sex offender registration schemes to provide a thorough analysis of police officers' perceptions of registration policies. The professionals included in the sample frequently reported that the broad application of the notification policy to a wide range of sexual offenses was a limitation of the legislation and a better tools to assess the individual level of risk of each offender and guide police practice are required for the future. Day et al. (2014c) used a sample of experienced practitioners in Western Australia to discuss criticisms of notification policies and uncovered similar findings to Powell et al. (2014) 
wherein notification laws were reported to be over-inclusive and place unfair strain on some offenders. The researchers concluded that notification policies would be more effective if refined into "...tiered systems of registration based on empirically derived levels of risk, with varied application, scope, registration periods, and monitoring requirements" (Day et al., 2014c, p. 183). These findings reinforce that the selection criteria for offender notification is in most cases too broad and an evidence-based approach to risk management could better benefit the intended legislative aim of notification policies to reduce re-offending.

The consequences of notification policies have been considered by researchers in terms of a human rights violation (Esmeir, 2006; Ward, Gannon \& Birgden, 2007a). However community notification policies and registries are based on the assumption that offenders forfeit human rights via the crimes they commit (Ward et al., 2007a). Considering these offenses involve sexual victimisation of children, offenders are not considered worthy of moral consideration or deserving of human rights after offending (Esmeir, 2006). Therefore the "loneliness" and "isolation" (Levenson \& Cotter 2005b, p. 173) inflicted by notification policies is not worthy of moral concern to the public, in fact it appears justified (Marshall, 1996). Media titles such as "Beast of Blenheim" (TV3, 2014) serve to further separate child sex offenders from the rest of society, turning them into a group divest of human qualities and therefore not worthy of moral concern. Notification policies reflect the wider attitudes of the public: that child sex offenders are not functioning, autonomous members of society but rather a lower life-form with no self-control or moral restraints, quite like an animal or a 'beast' (Marshall, 1996).

Whitting et al. (2014) conducted an integrative review appraising the rational underlying community notification policies and their impact on offender reintegration. They found evidence from a range of studies to establish that the factors known to impede successful reintegration (loss of social ties, unemployment, and homelessness) were often increased as a consequence of notification policies suggesting that registration could increase risk for re- offending, therefore failing to achieve its intended legislative goal. These findings have been re-iterated throughout similar studies on the effect of notification policies (Day et al., 2014b; Levenson et al., 2007b; Willis et al., 2010). Whitting and colleagues (2014) also mention that the only studies which have found registration to be successful in reducing reoffending included samples of offenders classified as high risk, indicating that notification policies could possibly be effective if registration criteria was reduced to this category of offenders. They conclude that subjecting offenders who pose a 
Dehumanisation and child sex offenders: a New Zealand study relatively small risk of reoffending to policies which stigmatise them and create barriers to their reintegration is not an efficient use of public resources. It can be suggested that notification policies are created out of fear for an unexplainable, morally abhorrent crime (Kernsmith et al., 2009) and negative attitudes towards offenders which provide justification for exclusion (Viki et al., 2012) rather than empirical and evidence based approaches to reducing sexual recidivism.

\section{Attitudes Towards Rehabilitation}

Negative attitudes towards child sex offenders can lead to the development of ineffective legislation - such as notification policies - whilst detracting attention and public support for offender participation in cognitive behavioural therapy (CBT) programs, a form of rehabilitation program that can effectively reduce recidivism (Ward \& Gannon, 2006 ; Willis et al., 2010). Kernsmith et al. (2009) found that public fear of sexual recidivism underlay support for the creation of sex offender registries within their sample and this fear of recidivism also lead participants to withdraw support for rehabilitation programmes. Brown (1999) found that members of the public in Britain would accept the creation of treatment facilities for child sex offenders, however rehabilitation was preferred to be accompanied by a punishment, and participants were less accepting of offender rehabilitation and reintegration occurring in their own community. Rogers et al. (2011) found using a UK community sample that members of the public were far more accepting of the reintegration of child sex offenders who had successfully completed a treatment program while incarcerated.

Marshall (1996) argues that clinicians, as well as members of the public, sometimes view their clients as unchangeable monsters and therefore their approach can become confrontational with little regard to offender dignity, which Marshall does not believe is "appropriate and effective" (p. 321) and often leads clients with damaged self-esteem to leave rehabilitation prematurely. Therapy sessions often involve facing emotionally distressing memories and information, therefore therapy needs to be undertaken in a motivationally enhancing and encouraging manner without damaging the dignity of the offender. A clinician who embodies dehumanising attitudes, is unsympathetic, or displays disrespectful behaviours will create an anti-therapeutic environment for clients. Throughout his study Marshall (1996, p.327) notes that clients have felt "attacked and belittled" by clinicians who take a harshly confrontational approach and often dreaded their next therapy session. Also, phallometric assessment carried out by hostile clinicians added to feelings of humiliation for clients. Marshall (1996) goes on to state that focusing on client's self-esteem has a lot of potential to 
aid rehabilitation because it is often unclear to clients what treatment goals they are capable of and therefore they underestimate their own future performance. Marshall concludes that it is possible to have repugnance for the offending behaviour but still maintain compassion for the offender, therefore effective therapy should strike a balance between acknowledging harm that is caused by sexual behaviours and motivating offenders to live a life free of offending behaviour. Kear-Colwell \& Pollock (1997) similarly found that motivational approaches to offender rehabilitation were more effective than confrontation-based approaches, because offenders must see a personal responsibility to change and that change must be beneficial (lead to a better life) in order for it to occur.

\section{Risk Need Responsivity (RNR) Model}

The Good Lives Model of Offender Rehabilitation (GLM) and the Risk Need Responsivity (RNR) model are two important frameworks for child sex offender rehabilitation (Andrews, Bonta \& Wormith, 2011) in New Zealand and worldwide.

In 1990 Andrews, Bonta and Hogue published a framework for effective offender rehabilitation that was built on the process of assessing individual level of risk, targeting of criminogenic needs (needs functionally related to criminal behaviour) and response in the form of intervention tailored to fit the individual needs and risk of each offender. The RNR has a therapeutic goal of engaging offenders with the treatment process to ensure behavioural change and has been empirically established to be an effective method of offender rehabilitation (Andrews et al., 2011). The RNR model is developed based on the underlying assumption that recidivism can be reduced by targeting dynamic risk factors and attempting to either reduce or eliminate them, leading to criticism that there is too much focus on the deficits of offenders and 'problem focused' therapy (Ward \& Brown, 2004, p. 245). This form of approach has been referred to as a 'pin cushion' method in which a deficit is located and removed, leading to neglect of other factors or issues that could relate to offending (Ward, Gannon \& Mann, 2007b). Studies have found that sex offenders are low in self-esteem and higher in emotional loneliness and personal distress than non-sexual offenders (Fisher, Beech \& Browne, 1999) reinforcing the need for therapy that not only identifies criminogenic needs related to offending but also motivates offenders to live a productive life without harming others. Focusing on the sexual deficits of offenders has been established to hinder the rehabilitative process: Harkins \& Beech (2007) note the lack of recognition for the therapeutic alliance between client and clinician in the RNR model despite the large body of evidence that supports its importance in the therapeutic process. Other studies such as 
Dehumanisation and child sex offenders: a New Zealand study Olver \& Wong (2013) note that treatability is a function of the clinician's ability to deliver required needs to the offender during rehabilitation.

Ward \& Brown (2004) state that the RNR places an emphasis on identifying and targeting deficits within the offender, which may divert rehabilitative efforts from multiple behaviours and psychological variables associated with offending such as intimacy deficits, cognitive distortions, substance abuse and difficulty regulating emotional states. Although the RNR model includes components which address cognitive distortions, other researchers have suggested that the model focuses too much on deficits and downplays the context and etiological factors which contribute to offending (Ward \& Brown, 2004).

It is important that rehabilitation includes effective and equal targeting of deficit, risk, and the cognitive distortions which underlie offending. Yang \& Ahn (2007) found in their sample of sexual offenders that the majority of participants were aroused due to underlying cognitive distortions related to knowledge of sex. Cognitive distortions - thought patterns that often justify offending behaviour - are described by Keenan \& Ward (2000) as possible 'theory of mind' deficits. Theory of mind refers to the understanding and perception of both one's own mental state and that of others. For example, the ability to feel empathy for another requires the ability to gauge the mental state of another and therefore requires a functioning theory of mind. In the case of child sex offenders, cognitive distortions which create the view that children are willing sexual partners or prevent intimate relationships with other adults could be due to a theory of mind deficit. This is important when considering research that establishes the high occurrence of cognitive distortion in child sex offenders. Blumenthal, Gudjonsson \& Burns (1999) found that child sex offenders - compared to adult sex offenders - endorse more cognitive distortions to support their offending. Ward \& Keenan (1999) identify 5 implicit theories of child sex offenders used to justify offending behaviour, which effective rehabilitation should address and redirect: the view of children as sexual beings, entitlement (harm to the victim ignored or secondary), nature of harm (disregarding sexual activity as harmful), dangerous world and uncontrollability (the world is a generally unsafe place in which sexual crime is inevitable and the view that sexual desires are external and uncontrollable). For the offenders who endorse these implicit theories of offending, effective rehabilitation should address the presence of theory of mind deficit in each offender and attempt to challenge and change the cognitive distortions that support offending behaviour. Harkins \& Beech (2007) found that those who chose to participate in treatment freely (compared to reasons relating to 
parole or sentencing) displayed the most significant reduction in cognitive distortions by the end of treatment.

\section{Good Lives Model (GLM)}

The GLM was developed by Ward and colleagues (Ward \& Brown, 2004; Ward \& Gannon, 2006; Ward et al., 2007b) as a strength-based addition to RNR principles which provides a focus on motivation to live a better life without offending (Willis, Prescott \& Yates, 2013b). The RNR model - which emphasises assessment of risk and removal of deficit - has been regarded as overlooking the component of motivation needed for effective therapy (Ward \& Brown, 2004). Ward \& Brown (2004) explain that the GLM is constructed on the belief that equipping offenders with the necessary tools and motivation to live better lives will serve as a more effective method of rehabilitation than a narrow focus on the management of risk factors.

It is assumed by the GLM model that human beings are goal-oriented and live in pursuit of primary human goods which are described as: actions, states of affair, characteristics, experiences and states of mind that benefit human beings (Ward \& Brown, 2004). Examples of primary goods include: happiness, relationships, friendships, and experiencing mastery in work and/or leisure activities (Willis et al., 2013b). Ward \& Gannon (2006) state that child sex offenders are therefore regarded by the model as attempting to attain the primary human good of relationships and/or intimacy through maladaptive means (sexual contact with children). Therefore from this perspective humans are goal oriented beings and effective rehabilitation should target how these means can be better achieved through non-offending behaviour. Primary human goods are also sometimes achieved through use of instrumental or secondary goods, for example a history of theft can relate to attaining the primary human good of life if the stolen funds were used to pay for housing or food. Commonly child sex offenders use alcohol or drugs as an instrumental good to justify sexual offending against children and reports of offending due to being under the influence are common (Keenan \& Ward, 2000; Ward \& Gannon, 2006).

Ward \& Gannon (2006) detail the components of both the GLM-C (good lives model comprehensive: the theoretical basis for treatment) and the GLM-O (values and principles to guide clinicians in treatment), which provide the guidelines for clinicians that the RNR was noted as lacking. The GLM-O instructs clinicians that therapy should not focus on deficits but rather human health, wellbeing and strength building. The GLM-C lists the theoretical assumptions that underlie and guide treatment, for example psychological wellbeing is the aim 
of the model therefore a good lives plan must incorporate and address all the primary and secondary goods needed to achieve this. Also, human beings are contextually dependent beings therefore the most effective good lives plan should consider both the characteristics of the offender and the environment they will be released into. Every plan should be formed in the conceptualisation of a good life with emphasis on personal preferences and strengths, and what agencies are required to achieve these goods. Clinicians should be supportive and take an indepth approach when aligning the personal strengths and capabilities of the client with a role specific to their skill-set in the community after release.

Ward \& Gannon (2006) also suggest that the GLM assumes there are both direct and indirect pathways which lead to sexual offending. The direct pathway to offending is implicated when sexual offending is used as a means to directly secure primary goods but the individual is unaware of the primary good being attained via offending. For example aggression or sexual behaviour could be for the goal of intimacy, for which sexual contact is a factor. The GLM aims to help offenders identify the primary human good that is being attained through offending and teach socially acceptable non-harmful ways of attaining that good in the public realm. Indirect pathways to offending occur when pursuit of a good or set of goods is frustrated in some way and unanticipated effects can lead to an increased chance of sexual offending occurring again. For example, the break-up of a valued relationship may lead to loneliness or stress (Ward \& Gannon, 2006). Alcohol may be used to relieve this turmoil, which leads to an overall loss of self-control and results in sexual offending. Another example is that of an individual who controls their sexual thoughts via masturbation and alcohol abuse, lives in isolation and is detached from intimate others, and experiences a period of loneliness during which they become intoxicated and sexually abuse a child. This is an example of an indirect pathway to offending, because the primary human good of intimacy or relationships is blocked and achieved through other indirect means.

Willis, Ward \& Levenson (2014) conducted a study of offender treatment programs in the United States and Canada that reported the GLM as one of three main theories that informed treatment. The purpose of the study was to examine how well the GLM was being integrated in a treatment setting and if there were any factors that hindered the application of the model using semi-structured interviews with program directors and managers. It was found that the majority of treatment settings used the GLM as a module at the end of treatment to help form life management plans to aid reintegration. The use of a 'good lives wheel' was found to be useful in helping offenders identify needs and goals to prevent offending after release. 
Clinicians reported preference for the GLM because the properties of the program were clearly communicated and established that the offender could be motivated to live a better life, which further improved the therapeutic alliance between clinicians and offenders. Clinicians also reported that the model had an easy and respectful form of delivery, which allowed clients to be treated as fellow human beings endowed with dignity and respect. Some participants even reported that they could make the therapeutic environment more fun and positive by emphasising the building of skills. One respondent said they had more positive attitude towards life in general through motivating others to live a more healthy life. One of the most important noted findings was that GLM framework had allowed clinicians to place greater emphasis on the social environment: outside support from families, volunteers and professionals was brought in for briefing on GLM principles before the release of the offender, ensuring that the environment outside the working group would continue to foster treatment goals. Considering that human beings are assumed by the GLM to be contextually dependent individuals, it is of paramount importance that the environment an offender is released into will allow them to maintain treatment principles instead of creating further frustration which may lead to reoffending.

Factors noted as hindering the application of the GLM in Willis et al.'s (2014) study included the qualities of probation and parole requirements, which did not match up with the holistic, strength-based approach of the GLM. One participant was noted as saying that parole and probation workers "have the final say and take a hard approach" (p. 68) and they are "non- treatment oriented and don't like to see sex offenders released" (p. 68). Another participant noted that laws - particularly notification laws and effects on employment and housing - were greatly damaging to GLM principles after release. Clients cannot attain suitable employment and appropriate housing if those in the environment around them block them from doing so. The attitudes of clinicians were also noted as being damaging, particularly the opinion that "clients are unchangeable" (p. 68). The GLM was noted as needing further establishment as an effective model in the therapeutic community - alongside better funding for materials such as GLM manuals - for it to gain further success and popularity in treatment settings, however the study by Willis et al. (2014) largely yielded results that the GLM has been effectively implemented across the US \& Canada, yielding satisfaction from both clients and clinicians regarding effectiveness for treatment.

Child sex offenders typically lie outside the boundaries of social and moral concern due to the nature of their crimes and perceived unpredictability of re-offending (Marshall, 
Dehumanisation and child sex offenders: a New Zealand study 1996 ). This perspective is reflected via the creation of notification policies, which place constant strain on the ability of offenders to reintegrate after release by placing barriers to employment, housing, and social interaction with others (Levenson \& Cotter, 2005a). The current study therefore predicts that those who hold negative, dehumanising attitudes towards offenders will be less likely to support the strength-based approach of the GLM model. Negative attitudes are predicted to support forms of punishment and exclusion (Viki et al., 2012). Opotow (1990, p. 1) defines the psychological mechanism underlying the 'othering' of social groups as 'moral exclusion', during which members of the community who violate social norms are placed "outside the boundary in which moral values, rules, and considerations of fairness apply". This could provide possible justification for the harsh and unforgiving nature of notification policies inflicted on child sex offenders, because lying outside the boundaries of moral concern provides justification for the infliction of harsh and unforgiving policies.

One component to the process of moral exclusion is defined by Opotow (1990) as 'dehumanisation', wherein a member of the social community violates group norms to such an extent that they are viewed as subhuman or lacking human-like characteristics, which leads to justification for further exclusion from the moral community. Opotow's ideas are clearly supported through references to child sex offenders as 'beasts' throughout the media (Marshall, 1996), reinforcing the idea that due to the nature of their crimes this group is no longer worthy of moral concern or empathy in the moral community. Notification policies then provide dehumanising methods of tracking and monitoring their whereabouts, as if their deviant sexual urges are uncontrollable and animal-like. Viki et al. (2012) found in their study that participants who dehumanised sex offenders were more likely to: a) support the exclusion of the offender from society: b) endorse violent ill treatment during incarceration (such as castration or murder): and c) withhold support for participation in rehabilitation programs. Viki and colleagues (2012) also assessed dehumanising attitudes in a study of correctional staff finding that where there is good quality contact, correctional staff are more likely to perceive offenders as human which lead to a more successful rehabilitative environment. Dehumanisation is therefore one possible mechanism for moral exclusion and harsh treatment of offenders and needs to be further explored in a New Zealand context as New Zealand is in the stage of discussing whether to create a child sex offender registry in 2015 (SST, 2014). The current study aims to build on the findings of Viki and colleagues (2012) by examining the role of dehumanising attitudes towards the punishment and rehabilitation of child sex offenders in a 
New Zealand context (whilst also examining preference for RNR/GLM rehabilitation frameworks).

\section{Dehumanisation}

Livingstone Smith (2011, p.28) explains that to dehumanise is to deprive another of human-like qualities therefore regarding them as subhuman, and that the term originated from Abraham Lincoln's final debate against Stephen Douglas regarding slavery. Douglas asserted that the founding fathers did not account for inferior races when they spoke of equality of men. Lincoln responded that Douglas displayed "the tendency to dishumanise the man" therefore taking "away from him all right to be supposed or considered as human". When the New York Tribune printed his speech they changed the term to the more formally phrased "dehumanise".

Bandura, Barbaranelli, Caprara \& Pastorelli (1996) explain that the process of dehumanisation removes the human qualities of an individual and replaces it with bestial attributions, often likening an individual or group to animals, insects or machines. Once a person has been dehumanised they are no longer viewed as having hopes, dreams, or concerns and are therefore not worthy of moral consideration by other human beings. As stated by Opotow (1990), dehumanising an individual places them outside the boundaries of moral concern therefore justifying their mistreatment or exclusion from the moral community. Dehumanisation has also been referred to as a pattern of prejudicial attitudes in which typically in-group members withhold uniquely human characteristics and characteristics of human nature from out-group members (Bandura, 1999; Dutton, Boyanowsky \& Bond, 2005; Haslam, Loughnan, Reynolds \& Wilson, 2007). Haslam et al. (2007) state that denying others their human qualities has the effect of "weakening moral restraints on violent behaviour" (p. 410), therefore dehumanisation has been frequently used as a factor to explain acts of inhumanity in collective violence.

\section{Dehumanisation and Collective Violence}

Albert Bandura's (1999) model of moral disengagement includes dehumanisation as a mechanism for weakening moral restraint and self-sanctions that normally prevent one person from brutalising another, making it possible to commit inhumanities during instances of collective violence. Bandura (1999) states that interpersonal experiences during the formative years of life create social bonds through perceived similarities, whereas perceived distance through the euphemistic labelling of others as less than human (common examples include being likened to an animal, insect or machine) strips them of their status as a human worthy of 
moral concern from others. The perception of a victim as a fellow human being with shared values and traits creates a mental barrier to inflicting harm because perceived similarity activates emotional reactions such as empathy (Bandura et al., 1996).

Frequently cited examples of dehumanisation include treatment of victims during collective violence such as the holocaust, Rwandan genocide and Bosnian genocide because in wartime propaganda the enemy is frequently referred to in less than human terms (Bandura et al., 1996; Bandura, 1999; Dutton et al., 2005). During the Rwandan genocide, in which an estimated 800,000 Tutsi were slaughtered by their Hutu neighbours, dehumanisation of victims was a clear contributor to the perpetration of violent, inhumane acts (Dutton et al., 2005). Hutu officials used radio broadcasting to insist that 'work' must be done in the form of 'cutting the tall trees' with 'tools' (machete, provided to the public by the Hutu militia) and that the 'Tutsi cockroaches' must be eliminated because they were "enemies of the people" (Dutton, et al., 2005, p. 447). By euphemistically labelling the ethnic group of Tutsi as 'cockroaches' and referring to their slaughter as 'work', the Hutu experienced both moral justification and a diffusion of responsibility whilst conducting mass slaughter (Bandura, 1999; Dutton et al., 2005). As Bandura et al. (1996, p. 365) explain, euphemistic labelling provides a tool for justifying and masking inhumane activities, because "language shapes people's thought patterns on which they base many of their actions". In this instance, Tutsi were euphemistically labelled as subhuman, leading to thought patterns even more conducive to their slaughter. By labelling the Tutsi in this manner and perpetuating the label through media outlets, a level of dehumanisation was created that existed at an implicit, subconscious level in the minds of the Hutu, in which Tutsi victims were a lower life form not capable of higher thought or emotion which therefore must be exterminated like a form of vermin or pest. Loughnan, Haslam \& Kashima (2009) found that dehumanising perceptions of others can exist below conscious awareness at implicit levels, which can be influenced by historically rooted prejudice such as that exhibited by the Tutsi and Hutu. Tutsi victims were not only slaughtered but killed via degrading and brutal methods; some were killed in front of family members, some forced to perform sexual acts on family members before death, others forced to kill each other (Dutton et al., 2005). These unnecessary forms of overkill were perpetrated because the Tutsi had been so frequently represented by Hutu politicians and media as subhuman beings or 'cockroaches' that in the minds of the Hutu they were no longer humans of equal moral value, therefore Hutu perpetrators felt morally justified in inflicting brutality (Bandura et al., 1996). 
During the holocaust of WWII, Nazi officials conducting the mass slaughter of predominantly Jewish victims in gas chambers were noted as dehumanising their victims through euphemistic labelling whilst displacing responsibility with the justification of "just following orders" (Bandura, 1999, p. 196). David Livingstone Smith describes the extent of dehumanisation implicated during the holocaust to allow for the mass extermination of millions:

The Nazis were explicit about the status of their victims. They were Untermenschen subhumans - and as such were excluded from the system of moral rights and obligations that bind humankind together. It's wrong to kill a person, but permissible to exterminate a rat. To the Nazis, all the Jews, Gypsies and others were rats: dangerous, disease-carrying rats. (Livingstone Smith, 2011, p. 15)

One commander of the gas chambers was asked why victims were dehumanised to such a large extent, to which the commander responded that it was not a matter of "purposeless cruelty" but rather dehumanising attitudes were directed on purpose towards concentration camp victims so that officials would be burdened by less distress whilst running the gas chambers and conducting the mass slaughter of thousands (Bandura, 1999, p. 200). This leads Albert Bandura (1999) to suggest that individuals are not inherently good or bad, rather "...it requires conducive social conditions rather than monstrous people to produce atrocious deeds. Given appropriate social conditions, decent, ordinary people can be lead to do extraordinarily cruel things" (p. 200). Dehumanisation therefore becomes a mechanism for disengagement when harming others, allowing everyday people to justify heinous acts.

Zimbardo's (1973) 1971 Stanford prison experiment is commonly cited as evidence that ordinary people placed in roles of authority over others in a consequence free environment can begin exhibiting cruel and dehumanising behaviour. A selection of members of the public were separated into two groups: a group of participants played the role of prisoners and experienced 24-hour incarceration, whilst the other group was assigned the role of guards and allowed to exercise control and domination over the inmates. The study - intended to last two weeks - was terminated early because prisoners were subjected to dehumanisation and ill treatment at the hands of the guard participants and began to show serious signs of distress. As Zimbardo (1973, p. 243) himself explains, "volunteer prisoners suffered physical and psychological abuse hour after hour for days while volunteer guards were exposed to the new self-knowledge that they enjoyed being powerful and had abused this power to make other human beings suffer." Prisoners were taunted, insulted, and forced to complete humiliating and dehumanising tasks whilst video footage of the guards displayed an enjoyment for power and 
brutality. The sadistic and dehumanising actions of the guards have been likened to the actions of soldiers assigned to prison guardianship at the Abu Ghraib facility in Iraq: Zimbardo himself drew a connection between the prison study and the events at Abu Ghraib in 2007, coining the term 'the Lucifer effect' to describe how being placed in a position of power and authority over other human beings creates a transformation in values that can lead to degrading, dehumanising behaviour (Zimbardo, 2007).

\section{Dual Model of Dehumanisation}

Dehumanisation has been further dissected by Haslam (2006) in the 'dual model of dehumanisation' which addresses the denial of uniquely human characteristics (UH) and characteristics of human nature (HN) (Haslam, 2006). Bastian, Laham, Wilson, Haslam \& Koval (2011) describe UH characteristics as qualities relating to higher cognition that are uniquely associated with humans over animals such as refinement, civility, empathy and other socially learned qualities. When individuals are deprived of UH traits they will be seen as uncultured, irrational, amoral and animal-like (Haslam et al., 2007; Haslam \& Loughnan, 2014). The reference towards Tutsi in Rwanda as 'cockroaches' and victims of the holocaust as 'rats' is a form of animalistic dehumanisation which deprives victims of their UH characteristics by likening them to animals (Livingstone Smith, 2011). HN characteristics are described by Gwinn, Judd \& Park (2013) as characteristics that distinguish humans from automata or machinery via innate characteristics that machines lack such as emotionality, agency, and depth of character. Typically when characteristics of human nature are denied to an individual they are likened to machinery, therefore this form of dehumanisation is referred to as mechanistic dehumanisation. Those deprived of $\mathrm{HN}$ qualities will be portrayed as cold, passive, rigid and superficial (Haslam et al., 2007).

Haslam \& Loughnan (2007) conducted a study that found the public perceived those who worked in business professions to be cold and mechanical, like robots (denied HN qualities) whereas artists were attributed higher cognition but still likened to animals (denied UH qualities). Being deprived of HN qualities and likened to a robot or machine can also cause damage to interpersonal control: Moller \& Deci (2009) found that interpersonal control and tendencies towards interpersonal violence were partially mediated by mechanistic dehumanisation. More simply stated, feeling more like an autonomous human being rather than a machine can help to mediate interpersonal control and prevent antisocial behaviours such as violence and aggression. 
Where UH characteristics are withheld the individual is typically likened to an animal, therefore the denial of UH has also been referred to as animalistic dehumanisation (Bastian et al., 2011; Haslam, 2006). A widely cited example of the denial of UH qualities is that of the treatment of Africans by the United States during the period of slavery (Costello \& Hodson, 2009; Haslam, 2006; Haslam et al., 2007). The very first article of the United States constitution declares that when determining state populations, "all other persons" (African slaves) should be counted as three-fifths of a human being (Goff, Eberhardt, Williams \& Jackson, 2008, p. 292). Goff et al. (2008) explain that the first contact between Europeans and West Africans had predominantly likened Africans to apes rather than human beings, and proceeded to conduct a study at Stanford University examining the implicit association of blacks and animals by members of the American public. The researchers found evidence that the historically rooted perception of Africans as apes had created implicit dehumanising attitudes towards African Americans in the present day, which lead to the association between blacks and higher rates of crime. The association between blacks and crime further provided justification for harsher treatment and greater endorsement of violence against a black criminal suspect, supporting the idea that dehumanising attitudes can exist at implicit levels and influence punitive outcomes.

A small body of literature has examined specifically the effects of dehumanisation towards women due to the fact that a heavier societal focus is placed on the physical appearance of women which can lead to objectification and reduced perception of humanness (Heflick, Goldenberg, Cooper \& Puvia, 2011). Heflick et al. (2011) have addressed the objectification of women via forms of media and pornography as a form of dehumanisation because when women are objectified sexually they are denied qualities of morality, warmth, and competence. Across three studies performed by Heflick and colleagues, women were perceived as lacking competency, warmth, and morality when participants were asked to focus on their appearance. This finding states that factors which attract attention to a woman's appearance reduce perceptions of her competence. Heflick and colleagues state that the denial of HN traits (selfcontrol and morality) to women could be partly attributed to evolutionary reasoning: appearance is a direct cue to fertility which could lead to the overlooking of other characteristics like morality. Rudman \& Mescher (2012) conducted the first study that found evidence linking men's implicit dehumanisation of women to sexual aggression. Across two studies the researchers found that men who implicitly dehumanise women by likening them to either animals or objects were also more likely to sexually victimise them (including both assault and rape) and report negative attitudes towards female rape victims. This study 
suggested that the denial of both UH \& HN characteristics lead to overall dehumanisation of women which contributed to justifications for violence against women. Rudman \& Mescher (2012, p. 735) reinforce the importance of this finding with the reminder that the pornography industry reinforces the objectification of women, leading men to attend "more to their bodies than their intellect or personality, usually for sexual purposes". As the link has now been established that this representation leads to rape-supportive attitudes, the content and impact of the pornography industry should become a larger matter of public concern.

\section{Infrahumanisation}

As suggested through the studies of Zimbardo (1973) and Bandura (1999) dehumanisation of the victim can be a powerful mechanism for breaking moral restraints and self-sanctions which usually prevent an individual from committing violent, abusive behaviour against others. These findings can be rephrased to describe in-group and out-group interactions, more specifically, that members of the out-group are divest of human qualities to weaken self- sanctions against harming them, whilst human-like qualities are reserved for members of the in-group. This process of reserving human characteristics for a person's own ingroup is referred to by researchers as infrahumanisation (Haslam, 2006; Haslam et al., 2007; Waytz \& Epley, 2012). Waytz \& Epley (2012) state that being socially connected satisfies an important human need, however individuals become so heavily connected to their own group that it creates a disconnection from other groups which can lead individuals to dehumanise more socially distant others. As Haslam et al. (2007) detail, primary emotions (sadness, fear and happiness) are shared with other animal species whereas secondary emotions are less observable and more dependent on cognition, therefore secondary emotions (UH qualities) are reserved for the in-group and withheld from the out-group during infrahumanisation.

In their study Waytz \& Epley (2012) predicted that infrahumanisation - feeling socially connected to one's own group - would lead to increased dehumanisation of out-group members. This prediction was supported and evidence of infrahumanisation was found across four studies. In addition it was found that those who felt more socially connected to their own group attributed less human-like mental states to out-group members, participants were likely to recommend harsher punishment for out-group members, and social connection actually enabled dehumanisation of distant out groups. Further evidence is provided by Landegaard's (2013) study of foreign domestic helpers (FDHs: predominantly immigrants from the Philippines and Indonesia who become live-in maids) in Hong Kong. It was found that the 
media in Hong Kong created "positive us presentation and negative them presentation" (p.137) which lead to infrahumanisation amongst Hong Kong citizens, excluding FDHs from moral concern which justified abuse, assault and starvation. Bain, Park, Kwok \& Haslam (2009) also provided evidence of infrahumanisation in their study of inter-group relations between Chinese and Australian individuals. Their study found that Chinese participants denied Australians qualities of $\mathrm{HU}$ which in turn provided justification for harsher punishment.

Hackel, Looser \& Bavel (2014) found that social group membership effected mind perception of out-group members. Specifically, individuals had trouble perceiving members of the out-group as having autonomous, working minds because those qualities were heavily reserved for members of the in-group. Having a functioning mind can be considered a UH quality involving higher cognition than that of non-human animals, therefore Hackel et al.'s (2014) study supports the idea that infrahumanisation can lead to the denial of uniquely human characteristics from others. The previously stated findings provide evidence that infrahumanisation is prevalent and can exist at an implicit, subconscious level, similar to the study of Goff et al. (2008) where members of the American public held a historically rooted implicit association between blacks and apes that originated through slavery.

Zhang, Chan, Teng \& Zhang (2015) suggest an alternate explanation to infrahumanisation in which interpersonal security (a sense of belonging and protection from the in-group) can make individuals less likely to dehumanise others because a feeling of belonging promotes connection with others and facilitates "appreciation for all human beings as fully human" (p. 170). Although this is a possible result of in-group bonding, research has established infrahumanisation as a robust phenomenon in group perception (Bain et al., 2009; Hackel et al., 2014; Haslam et al., 2007; Waytz \& Epley, 2012).

Viki et al. (2012) reinforce the importance of the contact hypothesis to reduce infrahumanisation: if public community based education forums on offender rehabilitation and reintegration were made to be a priority, members of the public could be educated on both offending behaviour and the success of rehabilitation on recidivism, leading to reduction of perceived social and moral distance from offenders and thus a reduction in infrahumanisation. Costello \& Hodson (2009) reinforce this point by recommending that drawing the out-group closer to the in-group by lessening the amount of perceived moral distance is helpful in reducing infrahumanisation. One method of reducing perceived difference is to educate about shared values between two groups. Research has identified women, those with low educational 
attainment and those who have children (Shackley et al., 2013) as target groups for education about sex offender rehabilitation. Education on the qualities and characteristics of the out-group and increased contact with members of the out group in a personal or professional setting could break down the prejudicial barriers that contribute to infrahumanisation.

\section{The Present Study}

Attitudes toward child sex offenders therefore become an important point of focus for research because attitudes of the public have been established to underlie the creation of future policy (Marshall, 1996), determine support for rehabilitation (Bastian et al., 2013; Willis et al., 2010), hinder the eventual reintegration of offenders into society after release (Levenson \& Cotter, 2005b), and determine support for harsher forms of punishment (Bastian, Denson \& Haslam, 2013). However, there is only a small body of research addressing attitudes toward child sex offenders in a New Zealand context. Willis et al. (2013a) conducted a study of public attitudes in New Zealand using an online community sample of 401 participants and found that fear of sex offenders living nearby was related to support for monitoring and notification policies, which was more supported by females than males throughout the community. Willis et al. (2013a) conclude by stating the limitation that relatively few studies of public attitudes have been conducted in New Zealand, therefore their study may not be an accurate representation of the population. The current study aims to contribute to this small body of existing research by examining a sample of public attitudes towards the punishment and rehabilitation of child sex offenders with an overarching aim of providing assessment of dehumanising attitudes in New Zealand, and how these attitudes influence preference toward punishment and rehabilitation for child sex offenders.

Rogers et al. (2011) used a community sample of 235 participants in the UK to test whether attitudes of participants became more negative toward offenders as the age of the victim decreased. The study used vignettes describing sexual offenses against female victims aged 10, 15 and 20. Results found that participants supported post-release monitoring and other forms of punishment more as the age of the victim decreased. Offenders were also deemed to be less capable of change and less willing to interact with others when the victim in the vignette was prepubescent (10 years old). Two more conditions were added to the study to test for rehabilitation: vignettes describing an offender who chose to participate in a rehabilitation program while incarcerated, and vignettes describing an offender who chose to participate in an auto mechanics course rather than rehabilitation. It was found that participants held more 
negative attitudes towards offenders who chose not to participate in rehabilitation. The study revealed that the most support for punishment was gained for an offense involving the youngest victim (10 years old) which was not accompanied by rehabilitation.

Viki and colleagues (2012) also examined how the age of victim impacted support for punishment and exclusion from society, however these researchers chose to use a prepubescent victim (6 years old) compared to a pubescent victim (15 years old) to test if the victim's age being closer to the legal age of consent resulted in less dehumanisation. The study found no significant result for age of victim and concluded that "offenders who commit sex offenses against children of different age groups are equally negatively evaluated" (p. 2359). Results indicate that dehumanisation predicted support for exclusion from society, support for violent ill treatment of the offender such as castration or murder, and a reduction in support for offender rehabilitation. These findings support a relationship between dehumanising attitudes, support for harsher forms of punishment, and reduced support for rehabilitation, which the current study aims to examine in a New Zealand context. Viki and colleagues used a UK sample of students and the public and online survey methodology to attain dehumanisation scores on seven-point Likert scales. Study 1 of the current study adopts a similar methodology to obtain a measure of dehumanising attitudes in a New Zealand context.

Bastian et al. (2013) used survey methodology in Australia and the United States to present participants with vignettes portraying offenses which varied in type (child molestation, violent and white collar crime) and severity then asked them to report their scores on moral outrage and dehumanisation scales. It was found that dehumanisation and moral outrage predicted punishment independent from the effects of crime type or crime severity. These findings reinforce the role of dehumanisation in punishment decisions, which could be important when considering the development of new legislation for child sex offenders in New Zealand such as a sex offender registry. There is potential for dehumanising attitudes to underlie support for the creation of a sex offender registry in New Zealand, however there is no existing literature on the topic. The current study aims to fill this gap in research, using similar approach to Bastian et al. (2013) including survey methodology to present different crime types (contact and non-contact child sex offenses) to participants, to test for moral outrage and dehumanisation in relation to punishment decisions.

Shackley et al. (2013) used an Australian community sample in their study to find support for a link between negative attitudes towards sex offenders and support for community 
notification policies. It was found that participants who did not support community notification policies also held less negative attitudes towards child sex offenders. Based on previous findings which establish a link between attitudes and preferences for post-release monitoring, Study 2 of the current study aims to generate discussion on the creation of a sex offender registry in New Zealand, to examine findings relating to attitudes and post-release monitoring in a New Zealand context.

Dehumanising attitudes have been established to be damaging to the reintegration of child sex offenders by predicting support for punishment (Bastian et al., 2013; Rogers et al., 2011; Shackley et al., 2013; Viki et al., 2012) and reducing support for rehabilitation (Viki et al., 2012), however no studies could be retrieved measuring dehumanising attitudes of the New Zealand public towards offenders. An overarching aim of the current study is to further investigate the relationship between dehumanising attitudes and attitudes towards the punishment and rehabilitation of child sex offenders in New Zealand. The second aim is to investigate if dehumanisation plays a role in preference between two types of rehabilitative approaches, the RNR and the GLM. There are no current studies investigating the role of dehumanisation in preferences between RNR and GLM frameworks therefore there are no previous findings on which to base assumptions. The current study predicts that those who dehumanise offenders will be less likely to support the strength-based, motivational approach of the GLM and more likely to support the deficit-focused approach of the RNR model.

Study 1 aimed to examine the role of dehumanisation in public attitudes towards the punishment and rehabilitation of child sex offenders. As summarised, previous research has found that dehumanisation can predict: support for harsher punishment (Bastian et al., 2013; Rogers et al., 2011; Viki et al., 2012) and reduced support for rehabilitation (Viki et al., 2012). In addition, previous researchers have found that dehumanisation varies by characteristics of the offense such as age of victim (Rogers et al., 2011; Viki et al., 2012) and the type of offense (Bastian et al., 2013). Based on the previous research, 6 hypotheses were formed:

1. Participants who are presented with vignettes depicting offenses against prepubescent children - compared to those who read about offenses against pubescent children - will (a) experience greater moral outrage; and (b) dehumanise the offender to a greater extent.

2. Participants who are presented with vignettes depicting contact offenses (sexual assault) against children - compared to those who read about non-contact offenses 
against children - will (a) experience greater moral outrage; and (b) dehumanise the offender to a greater extent.

3. Participants who are presented with vignettes depicting offenses against prepubescent children - compared to those who read about offenses against pubescent children - will (a) favour more punitive responses; and (b) be less in favour of rehabilitation.

4. Participants who are presented with vignettes depicting contact offenses against children -compared to those who read about non-contact offenses against children - will (a) favour more punitive responses; and (b) be less in favour of rehabilitation.

5. Participants who dehumanise the offender to a greater extent will (a) experience more moral outrage; (b) favour more punitive responses; and (c) be less in favour of rehabilitation.

6. Participants who dehumanise the offender to a greater extent will be more in favour of an RNR rather than a GLM approach to rehabilitation.

Although study 1 provided a way to investigate the role of dehumanisation and moral outrage in preferences for rehabilitation and punishment, study 2 was designed to better address the topic of post-release monitoring in New Zealand and dehumanisation of sex offenders at explicit and implicit levels. There was no distinct set of hypotheses attached to study 2 , as focus group questions were designed to further gauge participant's attitudes toward child sex offenders, their rehabilitation and punishment (including post-release monitoring such as sex offender registries).

The overall aim of study 2 was to explore how people viewed child sex offenders and their beliefs about the importance of rehabilitation and post-release monitoring. More specifically the study was designed to investigate to what extent people used concepts and ideas that suggested people were implicitly or explicitly dehumanising sex offenders.

\section{Methods}

In order to address the hypotheses, two studies were conducted using a mix methods approach by combining quantitative and qualitative methodologies to gather information. Study 1 involved the undertaking of an online survey to allow for an anonymous sample of New Zealanders and the generation of quantitative data. Study 2 contained three focus groups to allow for further assessment of dehumanising attitudes of the New Zealand public towards child sex offenders at implicit and explicit levels, whilst generating discussion regarding postrelease monitoring and rehabilitation. The focus groups provided qualitative data for the study, 
which was thematically coded for relevant themes (dehumanisation \& post-release monitoring). A mixed method approach was selected to better address the aims and hypotheses of the current study. Online survey methodology allowed for a larger sample of public attitudes and generated statistical analysis for the topic, whereas the focus groups further elaborated on these findings by allowing for in-depth discussion with members of the public regarding child sex offender punishment, rehabilitation and post-release monitoring in New Zealand.

\section{Study 1}

Participants and Design. To test for variables such as type of offense and age of victim, vignettes of hypothetical offenses were constructed and programmed to alternate via Qualtrics so that every survey presented a vignette of a different type of offence and age of victim. The study employed a 2 (Victim age: prepubescent and pubescent) X 2 (type of offense: contact and non-contact) between subjects design to create four separate vignettes for an online survey, creating a design wherein four different groups of participants were exposed to one vignette each. These vignettes tested for attitudes on contact- vs. non-contact offenders (sexual assault offense vs. a child pornography offense) involving prepubescent vs pubescent victims (age 7 and below vs ages 11-14).

A total of 242 University students and members of the public participated in the online survey, however after deleting false responses (responses that did not meet the participation criteria for age or residency and incomplete survey responses) only 228 members of the public were included in final analysis. The final 228 participants were aged 18-65 $(\mathrm{M}=25.36, \mathrm{SD}=$ 9.42 $)($ Females $=63.2 \%$, Males $=34.2 \%$, other $=2.6 \%)(\mathrm{NZ}$ European $/$ Pakeha $=89.9 \%$, Maori/Pacific Islander $=10.1 \%$ ).

\section{Materials}

Crime descriptions. Each vignette was distinguished by the name of a different offenderWalter, Robert, James and Simon - to allow for easier distinction between the vignettes when the researcher later performed data analysis (see Appendix C). The contact offender was described as a 30 year old male who kidnapped a young girl (either age 7 or age 14) as she walked the neighbourhood one day. He grabbed her, removed her clothing and sexually assaulted her in a nearby bathroom. The non-contact offender was described as a 30 year-old male recently convicted for having a collection of 500 computer images of nude children (either ages 7 and below or 11-14 years old), which took months to collect and was eventually discovered by a friend who accessed his computer. 
Moral outrage and liking. Based on the methodology of Bastian et al. (2013), after the vignettes a moral outrage scale was presented $(\alpha=.755)$ asking the participants to rate what emotions they felt while reading about the crime with questions regarding levels of anger, disgust and contempt. Responses were indicated via an 11-point Likert scale where $10=$ experiencing extreme moral outrage and $0=$ no moral outrage experienced (see Appendix B). Following the moral outrage scale, participants were presented with a scale of how much they 'liked' the offender (also obtained from Bastian et al. (2013) $(\alpha=.667)$. These questions are included so that the effect of dehumanisation can be considered after controlling for liking. Questions include: "how much do you respect the offender?":"how much do you like the offender?":“Does he make a positive impression on you?" Participants were then asked to rate their response ranging from $1=$ not at all to $5=$ extremely.

Dehumanisation. Participants were presented with questions that measure dehumanisation obtained from Bastian et al., 2013 ( $\alpha=.604)$. They were asked to consider the offender in the vignette and rate their agreement with 8 statements $(1=$ strongly disagree, $7=$ strongly agree) (see Appendix B). Questions include: "I felt like the person in the story was mechanical and cold, like a robot": "I felt the person in the story lacked self-restraint, like an animal": and "I felt like the person in the story was refined and cultured". These questions created by Bastian et al. (2013) assess the denial of qualities that relate to human nature (HN) and human uniqueness (HU) and previous research has demonstrated that this dehumanisation scale possesses good internal reliability. Some of the dehumanisation questions needed to be reverse-coded for analysis so that $7=$ support for dehumanising attitudes. Questions which needed to be reverse coded include: "I felt like the person in the story was open minded, like they could think clearly about things": "I felt like the person in the story was emotional, like they were responsive and warm": "I felt like the person in the study was refined and cultured": and "I felt like the person in the story was rational and logical, like they were intelligent".

Punishment. Two questions related to punishment of offenders followed $(\alpha=.826)$. First participants were asked "do you believe the offender should receive a prison sentence for his crime?" and provided 8 possible points of response: (1) not at all: (2) receive a fine: (3) community sentencing: (4) less than one year prison sentence: (5) 1-5 year prison sentence: (6) 6-10 year prison sentence: (7) 11-15 year prison sentence and: (8) life imprisonment without parole. The second punishment question followed, asking "How severe do you think the punishment for this crime should be?" with an 11 point Likert scale provided for assessment 
$(0=$ not severe, $5=$ moderately severe and $10=$ extremely severe $)$. Punishment questions were constructed so that higher scores reflected support for more severe forms of punishment.

Support for Rehabilitation. 5 questions were provided addressing to likelihood of reoffending and support for participation in rehabilitation (see Appendix B). 2 questions addressed likelihood of re-offending: the first asked "How likely do you perceive that the offender will commit a similar offense within 5 years of completing their sentence (without rehabilitation)?" The second re-offending question asked "How likely do you perceive that the offender will commit a similar offense within 5 years of completing rehabilitation?" Scores were rated on an 11 point Likert scale $(0=$ not at all and $10=$ extremely). 2 Questions regarding support for participation in rehabilitation were also rated on an 11-point Likert scale including, "how suitable do you think that the offender that you have just read about would be for a rehabilitation program?" and "To what extent do you support the offender's participation in a rehabilitation program?" The final rehabilitation question asked "How effective do you think a rehabilitation program would be in reducing the likelihood of this individual offending again" and provided 5 options for response ranging from $1=$ not at all to $5=$ extremely. High scores represented support for rehabilitation, therefore the question "how likely do you perceive that the offender will commit a similar offense within 5 years of completing rehabilitation" needed to be reverse coded. Three questions were selected to combine into a total score category for analyses: "how suitable do you think the offender would be for a rehabilitation program?", "how effective do you think a rehabilitation program would be in reducing the likelihood of this individual offending again?", and "To what extent do you support the offender's participation in a rehabilitation program". These questions were selected as they measure support for rehabilitation $(\alpha=.822)$.

$\boldsymbol{R N R / G L M . ~ P r e f e r e n c e ~ f o r ~ R N R ~ o r ~ G L M ~ r e l a t e d ~ t r e a t m e n t ~ o p t i o n s ~ ( s e e ~ A p p e n d i x ~ D ) . ~}$ Two carefully designed descriptions - one of each programme - were presented to participants. They were asked to carefully read through each example and select the treatment program that they would prefer to see the offender participate in.

Rehabilitation option 1 was designed to reflect the rehabilitative aims and components of the Risk need Responsivity (RNR) framework for offender rehabilitation. The RNR model has been criticized for being too heavily 'deficit focused' and not focusing on many of the noncriminogenic needs that can lead to offending therefore the description tried to reflect this approach clearly (Ward \& Gannon, 2006). The current study hypothesizes that participants 
who dehumanise child sex offenders more are more likely to show support for an RNR based rehabilitation program over a Good Lives Model (GLM) framework because the GLM approach regards child sex offenders as human beings of equal moral worth who need motivation, compassion and planning to live a more prosocial, non-offending life. Those who dehumanise child sex offenders will typically not regard them as humans of equal value and stature within their moral community, therefore they are hypothesized to be less supportive of a rehabilitation program like the GLM which attempts to aid reintegration back into the community by building strengths and motivation. Due to the nature of their crimes, child sex offenders are also often deemed as undeserving of clinical time and attention, instead those who dehumanise them tend to prefer extreme forms of punishment or exclusion (Bastian et al., 2013). The second rehabilitation program - based on GLM principles - was designed to describe the more holistic, strength-based approach that the GLM takes towards rehabilitation. The description of the two rehabilitation programs - one that represented RNR principles, the other GLM - was evaluated by clinical psychologist and GLM researcher Tony Ward, who approved that the descriptions accurately represented the treatment aims of each model.

Political orientation. The study concluded with a one-item question about political orientation, asking "In thinking about your political attitudes, which of the groups below would you most identify with?" which offered seven options for response: (1) People whose views are extremely liberal: (2) People whose views are very liberal: (3) People whose views are moderately liberal: (4) People whose views are moderate (neither liberal or conservative): (5) People whose views are moderately conservative: (6) People whose views are very conservative: (7) People whose views are extremely conservative. Political orientation adds another relevant demographic variable that could influence attitudes towards sex offenders.

Study 1: ethical considerations. The online survey presented hypothetical offenses involving sexual abuse and child pornography that could be potentially triggering to some, therefore ethical considerations were related to the mental health and wellbeing of participants. The survey had an age restriction of age 18 and older due to the nature of the content, however the online survey cannot ensure the age of participants, so a descriptive warning was placed on the first page - the information sheet - of the survey indicating the nature and content of the study. The information sheet also stated that participants would be considering a hypothetical offense but at no point would they be required to discuss or reveal any personal experiences or information, and for those who experienced any distress, a list of counselling options would be made available at the end of the survey. Upon completing the survey and reading the debriefing 
page, a page of counselling services - both public and private - was provided, including support for victims, their families and friends available via 24-hour phone hotline, webpage or e-mail. Details of a trust designed specifically for male survivors of sexual abuse were made available as well.

Procedure. The current study obtained approval from the Victoria University Ethics committee. Restrictions for participation in the online survey were that participants needed to be age 18 and over and either a New Zealand citizen or resident. The age restriction was imposed due to the nature of the content of the study. Descriptions of sexual assault can be potentially upsetting or triggering to some. The information sheet of the study also indicated adult content and explained to participants that they would be presented with a hypothetical scenario involving sexual assault of a minor (see Appendix A). The NZ citizen/residency restriction was put into place to ensure the study retrieved a sample of attitudes from those recognised as New Zealanders only. This was done to achieve focus on the attitudes of New Zealanders only, but also the attitudes of those from other countries where forms of punishment such as sex offender registries already exist could be significantly different from those of New Zealanders who have no experience with notification policies, therefore these opinions should not be included in the current study.

Qualtrics was used to generate the survey before it was distributed across various social media sites (Facebook, Twitter, and Tumblr) to obtain participants. The link for the study was also placed on the Victoria University webpage 'blackboard' for the Criminology course CRIM326 to obtain participants with the permission of the course co-ordinator. The conclusion of the survey thanked participants for their time and invited them to contact the researcher if they wished to participate in further discussion on the topic by attending a 1-hour focus group on Victoria University Kelburn campus. Participants were told they would be reimbursed for their focus group attendance with either a \$20 iTunes or petrol voucher.

Data Analysis. SPSS version 22 was obtained from Victoria University to conduct the quantitative analysis of this study. Before analyses could be undertaken, several changes were made to the data set. First, incomplete survey responses and responses from participants who did not meet participation criteria (age 18 and older and a New Zealand permanent resident/citizen) were erased. Next SPSS was used to assign labels to demographic data for the gender category ('cisgender' and 'gender fluid' participants were assigned to the 'other' category alongside 'male' and 'female' categories). Next, new categories were generated to 
code the responses from the vignettes named 'Victim Age' and 'Offense Type'. SPSS was then used to assign values to a number of variables: victim age ( $1=$ pre-pubescent, $2=$ pubescent): offense type ( $1=$ contact, $2=$ non-contact): gender ( $1=$ female, $2=$ male and $3=$ other): ethnicity (1= NZ European/Pakeha, 2= Maori/Pacific Islander): and RNR/GLM (RNR=1, GLM=2).

Before conducting ANOVA new variables needed to be computed using SPSS to represent the sum of scores for the various scales: dehumanisation, moral outrage, punishment, rehabilitation and liking. SPSS was also used to recode variables from the dehumanisation scale so that all values were proportionate to $7=$ support of dehumanising attitudes and $1=$ nondehumanising attitude. Categories of total scores for dehumanisation, moral outrage, punishment, rehabilitation and liking were used for comparison throughout analyses of the study.

The Cronbach alpha score for the dehumanisation scale revealed low but acceptable internal reliability $(a=.604)$. This low alpha score could possibly be due to the wording of the questions on the scale; questions were designed to measure perceptions of emotion, warmth and intelligence of the offender in the vignette and responses depend on the perception of the participant, therefore the phrasing of the questions can generate varying responses between participants. However this score could still allow the scale to be regarded as a useful measure of dehumanising attitudes.

Before performing more analysis on data set a variety of steps were taken to ensure normal distribution and test homogeneity of variance for all of the main dependent variables of the current study (dehumanisation, moral outrage, liking, punishment and rehabilitation). The data was visually examined using box plots, stem and leaf plots, and normal Q-Q plots. The data for the sample was explored both as a whole and by conditions with similar findings. Histograms revealed the distribution of the dehumanisation scale to be normal however the distribution for moral outrage was slightly skewed. Box plots later revealed that 4 outliers existed in the data set for responses on the moral outrage scale. An alternate SPSS data set was created by the researcher with the outliers removed: 2 way ANOVA was performed on both data sets for all dependent variables and descriptive statistics were compared for each to ensure that the presence of the outliers was not significantly skewing analysis of moral outrage. The removal of the outliers had no effect on the results of 2-way ANOVA or descriptive statistics of the data, therefore the outliers were included in the final analyses of the study. 
Kolmogorov-Smirnov scores reported significant outcomes for dehumanisation, moral outrage, liking, punishment and rehabilitation $(\mathrm{P}<.05)$ as did Shapiro-Wilk scores $(\mathrm{P}<.001)$ implying that the main variables of the study had violated assumptions of normality. However Levene's test for homogeneity of variance found no significant variances for any of the dependent variables used to perform 2-way ANOVA so the assumption of homogeneity of variance was not violated. The researcher ran $\log$ transformations and square root transformations on all the data. These transformations did not eliminate the violation of normality. Tests were ran with and without transformed data generating the same pattern of significant results, therefore untransformed data is presented throughout the current study. ANOVA - which is performed for analyses of the current study - is generally recognised as a robust test and the violation of normality does not significantly affect results, particularly when there are equal sample sizes among groups and the variances are not significantly different from each other (Field, 2009). The data of the current study meets these assumptions, therefore there are no undue concerns about the normality of the data for subsequent analyses.

\section{Study 2}

Although study 1 provided a way to investigate the role of dehumanisation and moral outrage in preferences for rehabilitation and punishment, study 2 was designed to better address the topic of post-release monitoring in New Zealand and dehumanisation of sex offenders at explicit and implicit levels. Study 2 involved the undertaking of three focus groups, two on Victoria University campus and one at a home residence in Paraparaumu. This form of analysis allowed for deeper discussion of sex offender treatment in New Zealand with members of the public, who agreed to participate on terms of confidentiality and were debriefed on the nature of the content before consenting to participate. The topics of sex offender rehabilitation and reintegration were discussed via examples of two case studies: (1) the Beast of Blenheim, a New Zealand child sex offender who has received a lot of media attention and is therefore a well-known example: and (2) a vignette from the survey read aloud involving a child pornography offender and the collection of images of prepubescent children ages 7 and below. Support for post release monitoring and offender registration can also be integrated into the conversation via use of these two case studies, providing the current study with further investigation into implicit and explicit levels of dehumanisation and support for post-release monitoring. The proposed creation of a sex offender registry in New Zealand also provided a relevant topic through which post-release monitoring can be discussed in a focus group setting. 
Participants and Design. Three focus groups were held, two on Victoria University campus in tutorial rooms and one in Paraparaumu for locals who wished to participate but could not travel to Wellington CBD. Permission was obtained from the Victoria University ethics committee to hold the focus group off site in Paraparaumu after the safety of both the researcher and participants could be ensured. Permission was also obtained from the Victoria University Ethics committee to hold the other two focus groups on Victoria University campus. In order to participate participants had to meet the same criteria as study 1: New Zealand residency or citizenship was required and participants must be age 18 or older.

The first focus group in Paraparaumu beach was held on the $10^{\text {th }}$ of October, 2014. 6 participants attended, 1 male and 5 females, participants aged 30-65. The other two focus groups were held at Victoria University on the $31^{\text {st }}$ of October and $5^{\text {th }}$ of November, 2014, with a combined total of 22 participants, 12 male and 10 females, with an age range of $19-63$. Each group was 60 minutes long each and had a semi-structured format following an interviewer guide (see Appendix G) that had been approved by the Victoria University Research Ethics Committee.

Materials and Procedure. Advertisements for participation were also placed on posters around Victoria University, on the student-run webpage for the university known as 'Vic deals' and the Victoria University blackboard page for a 300-level criminology course (with permission from the course co-ordinator/supervisor). The invitation to participate in the study was also distributed across social media sites Facebook, Twitter and Tumblr. All advertisements included the invitation to discuss the punishment and rehabilitation of child sex offenders on Victoria University campus for one hour with a reimbursement of either a $\$ 20$ iTunes or petrol voucher.

Participants contacted the researcher regarding attendance via e-mail then date, time and form of reimbursement was arranged prior to attending the group. Upon arrival, participants were checked off a roll kept private to the researcher, handed a name tag and told they may assign any name of their choosing to their name tag because all conversation would remain confidential and no names would be included in the results. Participant responses were later transcribed and quoted throughout the current study using letters unrelated to their actual names.

After all participants were present, information sheets, consent forms and counselling contacts were distributed to participants. At this time the researcher began recording the 
conversation via electronic audio recorder provided by the faculty of the researcher. The information sheet included details about the current study, contact information for the researcher and supervisor, and a mention of the nature and content of the study. Participants were told that punishment and rehabilitation of child sex offenders would be discussed, however there would be no mention of personal experiences or information. Participants were told that if at any point they felt distressed they were welcome to leave, however data recorded until the point they left may still be used in the study. Focus group rules were then read aloud, which reinforced that by signing the consent form to participate they agreed to adhere to the following rules: participation from every member of the group, respect for each group members and their opinions, confidentiality of the material and members of the group, and ensured anonymity for all members of the group.

After consent forms were collected, the focus groups began with a brief personal introduction and description of the current study and its aims. The first topic to be introduced was that of the proposed creation of a child sex offender registry in New Zealand. The registry was explained as a form of punishment that would track and monitor the offender's whereabouts in the community, possibly harming their ability to find employment or housing after release. Participants were told that if the registry was created it would allow them to access via the internet a list of offenders living nearby and what offenses they had committed. It was hypothesised that participants who held dehumanising attitudes towards child sex offenders would support use of post-release the most, because support for a registry denotes support for social and moral exclusion of offenders from the rest of the community.

A non-contact offender scenario vignette from the online survey was read aloud from the survey (see appendix C) involving a 30 year old male offender who collected 500 images of nude children ages children ages 7 and below (prepubescent victim). Age of victim could not be addressed as well in a focus group setting because of A) time constraints - one hour was not long enough to present all four conditions and allow for free-flowing discussion, and B) presenting the same scenario twice with different age victims would not elicit a strong reaction in a focus group setting, and is better addressed via survey methodology where reactions to different ages of victim can be compared.

After having the description of the child pornography offender read aloud to them, participants were asked if they would prefer: (A) the offender to be placed on a sex offender registry: (B) the offender receive a lengthy sentence or harsher punishment: or (C) to see the 
offender participate in a rehabilitation program. Participants were asked what qualities they believed underlie a successful rehabilitation program for child sex offenders and if they would feel safer allowing offenders to reintegrate having participated in a rehabilitation program, adapted from Viki et al.'s (2012) social exclusion questions.

Participants were also presented with a New Zealand case study of Stewart Murray Wilson, also nicknamed 'the Beast of Blenheim' by the New Zealand media. The Wilson case study was chosen for focus group discussion for three reasons: 1) it provides a case study in a New Zealand context that would provoke further thought and discussion around the treatment of offenders in New Zealand, 2) both the media title 'Beast of Blenheim' and the public perception of Stewart Murray Wilson reflect elements of dehumanisation that the current study aims to examine, and 3) it is a high-profile case of a New Zealand child sex offender that is likely to be well known to participants and should elicit a strong reaction. Referring to a child sex offender as a 'beast' implies that they are an animal-like, uncontrollable being who withhold different characteristics from the in-group, denying them UH characteristics and leading to animalistic dehumanisation of the offender.

Regarding the Beast of Blenheim, participants were first asked why titles such as 'beast' were used more often towards child sex offenders than for other types of offenders such as murderers. They were also asked if they supported use of the term 'beast' and if not what term or representation would they choose. Then similar questions used for the noncontact offender based on Viki et al.'s (2012) research were asked relating to rehabilitation, reintegration, and exclusion vs. inclusion of the offender from society after release. Participants were also asked if they would support this offender being placed on a sex offender registry and if not what would be their preferred response from the criminal justice system. They were asked if they would feel comfortable allowing the offender to reintegrate back into the community and resume their original employment to examine support for post release monitoring and evidence for infrahumanisation (participants reserving human qualities for their own in-group members and withdrawing them from child sex offenders). Participants were also asked if offenders such as Wilson would benefit from rehabilitation and would they feel safer allowing the offender like Wilson to reintegrate if they had participated in a rehabilitation program.

Study 2: ethical considerations. The focus groups contained in-depth discussion of child sex offenders, their behaviour and rehabilitation/reintegration, therefore ethical considerations related toward the psychological health and wellbeing for participants who may 
find the content to be potentially triggering. Before beginning the focus group, information sheets and consent forms were distributed to participants. The information sheet described the topic and content of the study and provided a set of 'focus group ground rules' which included: participation from every member of the group, respect for each group members and their opinions, confidentiality of the material and members of the group, and ensured anonymity for all members of the group. It was made clear to participants that punishment and rehabilitation of child sex offenders would be discussed, however no discussion of personal information or experiences would take place. It was also made clear that if any participant felt unconformable they were free to leave the focus group at any point, however the data recorded to the point they left would be used in the study. By signing the consent form to participate in the focus group, members acknowledged that they had read and agreed to adhere to the rules of the group. Along with the consent and information sheets participants were also handed a sheet of the same list of counselling options attached to the end of the online survey, to provide avenues for counselling for anyone who left the focus group feeling distressed.

Great care was taken to ensure the anonymity and wellbeing of participants during the focus groups. Participants were required to wear a name tag to help the researcher guide conversation, however participants were told they did not have to place their full name on the name tag if they did not wish to do so, therefore some participants chose to write only their initials to ensure further anonymity after leaving the focus group. During the groups occasionally conversation would stray into more personal or private subject matter so the researcher took great care and attention to guide the conversation back to the topic and remind participants of the rules of the group. The researcher had to also frequently remind participants to be mindful of explicit language, as the topic of child sex offenders is triggering to some and must be treated delicately to ensure their wellbeing. The topic of child sex offenders also triggered extreme emotions for some participants leading them to make comparisons to other emotionally fuelled areas of topic such as sexuality and religion, therefore the researcher took great care guiding the conversation and ensured all discussion related to the study at hand and was respectful towards all participants.

Considerations were also made to reimburse focus group participants for their time and attendance. Participants were given a choice between a $\$ 20$ petrol or iTunes voucher for reimbursement. 
Data Analysis. The focus groups were recorded via audio recording device before being transcribed by the researcher and uploaded into Nvivo 10 for coding analysis. Responses from the three groups were coded thematically based on the types of dehumanisation described by Haslam (2006) in 'the dual model of dehumanisation': Uniquely human characteristics $(\mathrm{HU})$, and characteristics of human nature $(\mathrm{HN})$. Thematic coding analysis also revealed evidence for infrahumanisation and rehumanisation so these two concepts were coded for as well. The general aim of the current study was to provide assessment of dehumanising attitudes in New Zealand. Coding was used to produce qualitative evidence for the current study by addressing: implicit and explicit levels of dehumanisation in the attitudes of participants, support for rehabilitation, and support for post-release monitoring.

The Nvivo coding was done based on thematic coding for dehumanisation and organised into hierarchical and non-hierarchical nodes (which can be viewed in Table 1). Base nodes were: Beast of Blenheim (New Zealand example of a contact offender), non-contact offender (child pornography offender). infrahumanisation (participants who denied human-like qualities to the out-group of child sex offenders), Rehumanisation (qualities required in order to restore humanness of the offender and allow for reintegration), Human Nature (a category that culminates all mention of qualities related to human nature) and Human Uniqueness (a category that covers all mention of qualities related to human uniqueness).

Table 1

Results of focus group coding

\begin{tabular}{llcc}
\hline \multicolumn{1}{c}{ Node } & \multicolumn{1}{c}{ Sub-node } & $\begin{array}{c}\text { Focus groups } \\
\text { coded at node }\end{array}$ & References \\
& & 3 & 99 \\
\hline Beast of Blenheim & Attributed Qualities (UH \& HN) & 3 & 23 \\
& Denied Qualities (UH \& HN) & 3 & 56 \\
& Comments about the media & 3 & 59 \\
Non-contact (child & & 3 & 69 \\
pornography) offender & & 3 & 43 \\
& Attributed qualities (UH \& HN) & 3 & 41 \\
& Denied Qualities (UH \& HN) & 3 & 67 \\
Human Nature (HN) traits & Consideration of offense & 3 & 38 \\
& & 3 & 14 \\
& Child sex offenders attributed HN & 3 & 35 \\
Uniquely Human (UH) traits & Child sex offenders denied HN & 3 & 111 \\
& & 3 & 52 \\
& Child sex offenders attributed UH & 3 & 72 \\
Infrahumanisation & Child sex offenders denied UH & 3 & 168 \\
Rehumanisation & & 3 & 120 \\
& & 2 & 10 \\
& HN traits & 3 & 54 \\
\hline
\end{tabular}


Each node was divided into hierarchical nodes to allow for further coding of the data. The beast of Blenheim node had three hierarchical nodes: attributed qualities (when participants attributed qualities of either $\mathrm{HN}$ or $\mathrm{HU}$ to the beast of Blenheim), denied qualities (either HN or HU denied to the beast of Blenheim) and comments about the media (due to the significant amount of responses from participants that mentioned the role of the media in the case - see results section for further elaboration).

The HN and HU nodes were collections of quotes that related directly to attribution or denial of qualities unique to human beings or part of human nature (e.g. warmth, compassion, civility, higher cognition). A node for rehumanisation was created to code for the mention of characteristics that needed to be restored in offenders in order for participants to support their reintegration back into the community. The node for rehumanisation was divided into two subnodes: UH traits and $\mathrm{HN}$ traits.

The non-contact child pornography offender node was also divided into denial and attribution of UH and HN traits however it also included a sub-node addressing 'consideration of the offense' because of the overwhelming response from participants regarding the details of child pornography offenses in general, including legal considerations of the offense and impacts on child trafficking. Due to the free-flowing nature of focus group conversation, the non-contact offender scenario branched out to topics of conversation which related to attitudes towards offending, therefore these topics were coded for under the 'consideration of offense' node.

\section{Results and Discussion}

\section{Study 1}

In order to test the first four hypotheses a series of two (offence type: contact vs. noncontact) X two (Victim age: pubescent vs. pre-pubescent) independent ANOVAs were carried out. Means and standard deviations for all of the relevant dependent variables, by condition, are depicted in Table 2.

In support of hypothesis 2(a) there was a significant main effect of offense type on moral outrage: participants were significantly more morally outraged at a contact offender $(\mathrm{M}$ $=21.31)$, compared to the non-contact offender $(\mathrm{M}=18.10)$ (see Table 2 for details). However, contrary to hypothesis 1 (a) there was no significant effect of victim age on moral outrage, as pre-pubescent victims $(M=19.83)$ did not invoke greater moral outrage compared to pubescent 
victims $(M=19.28)$. There was, however, a significant interaction effect between the age of the victim and the type of offence. As illustrated in Figure 1 for contact offences there was substantially greater moral outrage reported for the pre-pubescent $(\mathrm{M}=22.62)$ compared to a pubescent victim $(M=20.00)$, but for non-contact offences the patterns was reversed, with more moral outrage reported for the pubescent victim $(\mathrm{M}=19.15)$ compared to the prepubescent victim $(\mathrm{M}=17.03)$.

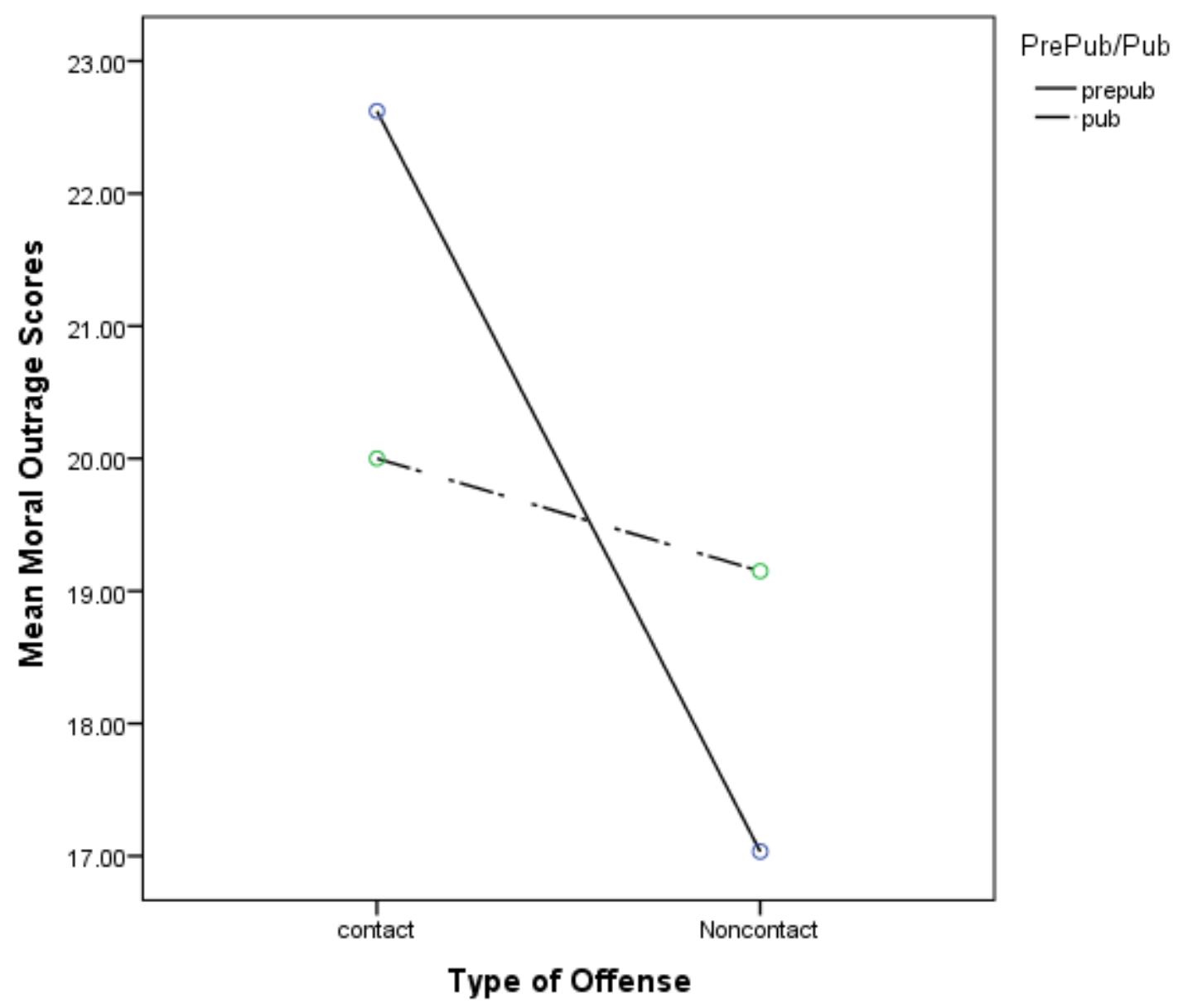

Figure 1

Significant interaction effect between type of offense and age of victim for moral outrage 
Table 2

Means and Standard Deviations for dehumanisation, moral outrage, punishment and rehabilitation conditions.

M (SD)

Dehumanisation (7-56)

Prepubescent Victim

Pubescent Victim

$\begin{array}{rr}\text { Contact Offender } & 41.17(7.77) \\ \text { Non-Contact Offender } & 35.50(7.21) \\ & \\ \text { Contact Offender } & 37.71(8.36) \\ \text { Non-Contact Offender } & 35.19(8.05)\end{array}$

Moral Outrage (0-30)

Prepubescent Victim

$\begin{array}{rr}\text { Contact Offender } & 22.62(5.57) \\ \text { Non-Contact Offender } & 17.03(7.44)\end{array}$

Pubescent Victim

Contact Offender $20.00(5.93)$

Non-Contact Offender $19.15(6.68)$

Punishment (2-18)

Prepubescent Victim

$\begin{array}{rc}\text { Contact Offender } & 16.38(2.99) \\ \text { Non-Contact Offender } & 9.55(4.23) \\ & \\ \text { Contact Offender } & 14.32(3.67) \\ \text { Non-Contact Offender } & 10.94(4.52)\end{array}$

Prepubescent Victim

Contact Offender

$22.37(7.34)$

Non-Contact Offender 22.56 (4.93)

Pubescent Victim

Contact Offender $23.49(6.06)$

Non-Contact Offender $24.36(4.43)$ 
Table 3

Results of 2-way ANOVA for dehumanisation, moral outrage, punishment and rehabilitation

df $\quad$ F $\quad p \quad \eta 2$

Dehumanisation (7-56)

$\begin{array}{ccccc}\text { Offense Type } & 1 & 14.16 & .00 & .07 \\ \text { Victim Age } & 1 & 2.98 & .09 & .01 \\ \text { Offensetype*Victimsage } & 1 & 2.09 & .15 & .01\end{array}$

Moral Outrage (0-30)

$\begin{array}{ccccc}\text { Offense Type } & 1 & 14.02 & .00 & .06 \\ \text { Victim Age } & 1 & .09 & .77 & .00 \\ \text { Offensetype*Victimsage } & 1 & 7.59 & .01 & .03\end{array}$

Punishment (2-18)

$\begin{array}{ccccc}\text { Offense Type } & 1 & 87.75 & .00 & .30 \\ \text { Victim Age } & 1 & .38 & .54 & .00 \\ \text { Offensetype*Victimsage } & 1 & 155.82 & .00 & .05\end{array}$

Rehabilitation (0-45)

$\begin{array}{lcccc}\text { Offense Type } & 1 & 1.69 & .19 & .01 \\ \text { Victim Age } & 1 & 1.45 & .23 & .01 \\ \text { Netype*Victimsage } & 1 & .04 & .84 & .00\end{array}$


Hypothesis 1(b) predicted victim age would have an effect on dehumanisation, specifically that offenses involving prepubescent victims would receive higher scores for dehumanisation. Results did not provide support for this hypothesis and no significant interaction between dehumanisation and victim age was found (see Table 3), indicating that participants did not dehumanise the offender to a greater when the offense included a prepubescent victim $(M=38.33)$ compared to a pubescent victim $(M=36.46)$. A significant effect was found, however, for the type of offense and dehumanisation (see Table 3) providing support for hypothesis 2(b). Participants who were presented with a contact offence $(M=41.17)$ tended to dehumanise the offender to a greater extent than those who were described a noncontact (child pornography) offense ( $\mathrm{M}=35.35)$.

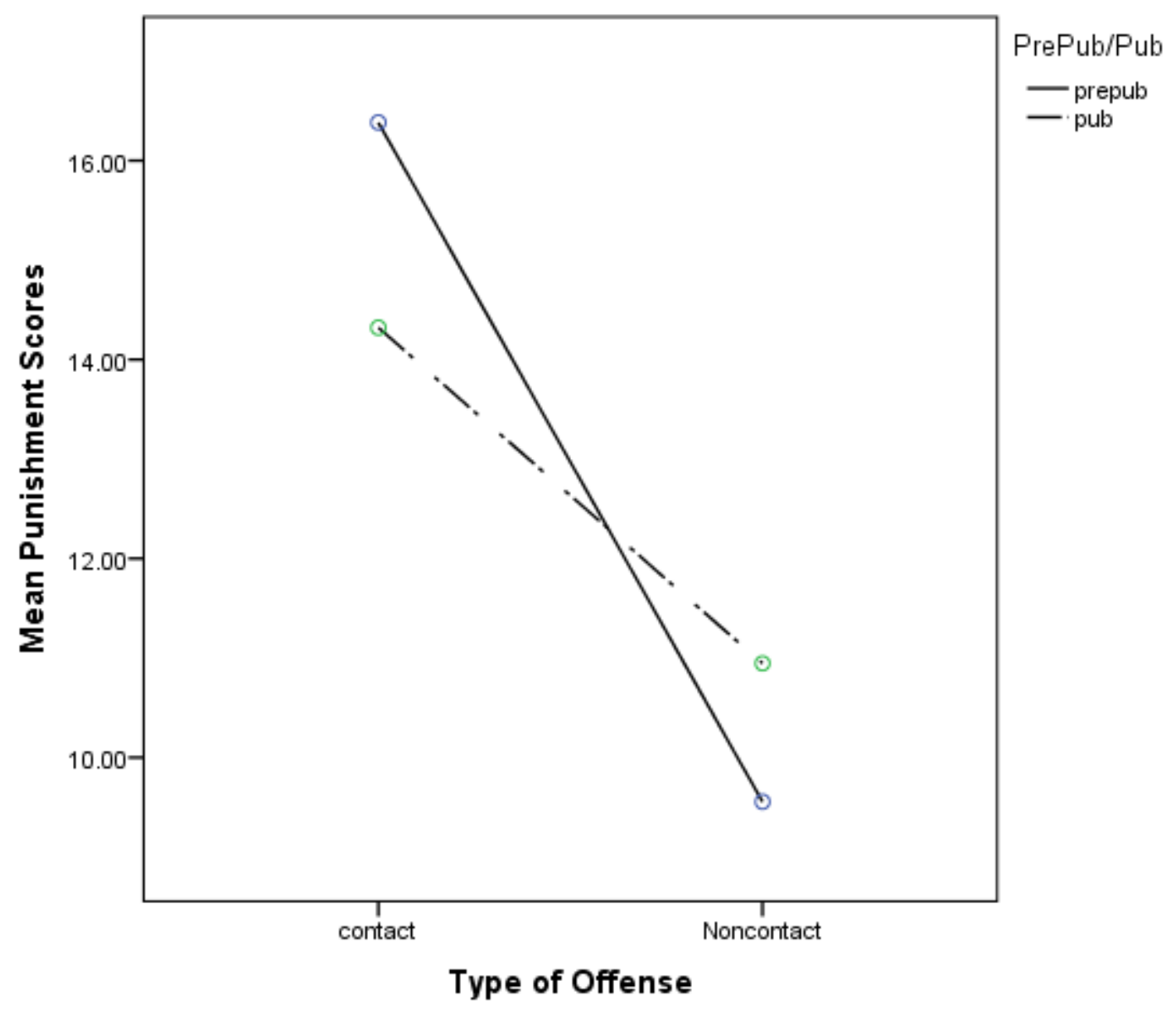

Figure 2

Significant interaction effect between type of offense and age of victim for punishment 
In support of hypothesis 4(a), a significant effect was found between preference for punishment and the type of offense (see Table 3). Participants presented with a contact offense $(M=15.35)$ were more likely to recommend harsher forms of punishment than those who were presented with a less harmful non-contact offense $(M=10.25)$. Conversely, no significant effect was found for the age of victim and punishment (see Table 3). Support for punishment did not significantly differ between participants who were presented a scenario involving sexual assault against a prepubescent victim $(M=12.97)$ compared to a pubescent victim $(M=12.63)$. Findings did however produce a significant interaction effect between the age of victim and type of offense. As illustrated in Figure 2 for contact offences there was more recommendation for punishment for a contact offense involving a prepubescent victim $(M=16.38)$ however for non-contact offenses the pattern was reversed and more punishment was recommended for older (pubescent) victims $(\mathrm{M}=10.94)$.

Type of offense and age of victim were found to have no significant effect on support for rehabilitation (see Table 3) leaving hypotheses 3(b) and 4(b) unsupported. Results indicate that participants were not less likely to support rehabilitation for contact offenses $(M=22.93)$ compared to less harmful non-contact offenses $(M=23.96)$ whether the offense was committed against a prepubescent $(M=22.97)$ or pubescent $(M=23.92)$ victim.

In summary, mixed support was found for the first four hypotheses. Participants were found to experience greater moral outrage when presented with scenario involving a contact offense (hypothesis 2a) however not for offenses involving younger prepubescent victims as predicted (hypothesis 1a). Participants tended to dehumanise the offender more when they had committed a contact offense (hypothesis $2 b$ ) however victim age was found to have a nonsignificant effect in predicting dehumanising attitudes leaving hypothesis 1(b) unsupported. Participants supported punishment significantly more for an offender who committed a contact offense (hypothesis 4a) however offenses involving younger victims did not receive more support for punishment (hypothesis 3a). In summary, the type of offense was found to have an impact on dehumanisation, moral outrage and punishment, but victim age did not.

Hypotheses 3(b) and 4(b) predicted that type of offense and age of victim would impact support for rehabilitation and both were unsupported. Participants did not withdraw support rehabilitation less for a contact offense involving a prepubescent victim, implying that the type of offense and age of victim did not play a significant role in determining support for 
rehabilitation. Possible explanations for the unsupported findings of Study 1 will be further discussed later in the study.

In Table 4 the zero-order correlations for the main independent and dependent variables are depicted. Hypothesis 5 (a) was supported as there was a significant bivariate relationship between moral outrage and dehumanisation, $r=.29, p$ (one-tailed) <.01, as participants who were more morally outraged at the offence also dehumanised the offender to a greater extent. Similarly, hypotheses 5 (b) was supported and there was a significant bivariate relationship between dehumanisation and punishment $r=.33, p$ (one-tailed) <.01. Finally, hypothesis 5 (c) was supported as there was a significant relationship between dehumanisation and support for rehabilitation $r=-.23, p$ (one-tailed) <.01, indicating that increased dehumanisation leads to a reduction in support for rehabilitation.

One of the main aims of this study was to explore to what extent dehumanisation predicted attitudes towards the punishment and rehabilitation of sex offenders while controlling for other relevant variables. In order to test this aim two regression models were constructed. In the first model, punishment was regressed on moral outrage, dehumanisation, age, gender, liking, political orientation and the question 'how likely do you perceive that the offender will commit a similar offense within 5 years of completing rehabilitation?' In total these predictors account for $41 \%$ of the variance in punishment responses $\left(\mathrm{R}^{2}=.41\right)$, and the overall model was significant, $F(7,192)=18.99, p<.001$. The significant predictors of punishment were dehumanisation $(\beta=.10, \mathrm{p}<.01)$ moral outrage $(\beta=.32, \mathrm{p}<.001)$ and age $(\beta=-.09, \mathrm{p}<.01)$. Expectantly, the question 'how likely do you perceive that the offender will commit a similar offense within 5 years of completing rehabilitation?" also predicted punishment as high scores indicated belief of likelihood of reoffending. The hypothesis that dehumanisation would predict punishment responses was overall supported (hypothesis 5b) (see Table 5). 
Table 4

Bivariate relationships between key study variables

$$
2
$$

3

4

$4 \quad 5$

$\begin{array}{llll}5 & 6 & 7 & 8\end{array}$

1. Dehumanisation

2. Moral Outrage $.29^{* *}$

3. Liking

$-.25^{* *} \quad-.21^{* *}$

4. Punishment

$.33^{* *}$

$.58^{* *}$

$-.26^{* *}$

5. Rehabilitation

$-.23^{* *}$

$-.17^{* *}$

$.13^{*}$

$-.28^{* *}$

6. RNR/GLM

$-.19^{* *}$

.10

$-.20^{* *}$

$.14^{*}$

7. Age

.05

$-.09$

.01

$-.21^{* *} \quad-.05$

$-.08$

8. Gender

$-.01$

$-.02$

$-.00$

$-.02$

.01

$-.07$

.03

**. Correlation is significant at the 0.01 level (1-tailed). *. Correlation is significant at the 0.05 level (1-tailed). 
Rehabilitation was also regressed on moral outrage, dehumanisation, age, gender, liking, political orientation and the question 'how likely do you perceive that the offender will commit a similar offense within 5 years of completing rehabilitation?' In total these predictors account for $13 \%$ of the variance in rehabilitation responses $\left(\mathrm{R}^{2}=.13\right)$, and the overall model was significant, $\mathrm{F}(7,192)=4.13, p<.001$. The two significant negative predictors of support for rehabilitation were dehumanisation $(\beta=-.13, p<.05)$, and political orientation $(\beta=-1.28$, $\mathrm{p}<.001)$ indicating that the more participants dehumanised an offender the less they supported their rehabilitation, thus supporting the hypothesis that dehumanising attitudes would predict less support for rehabilitation of child sex offenders (hypothesis 5c) (see Table 6).

In sum, the results provide support for hypothesis five. Participants who dehumanised the offender to a greater extent were more likely to experience heightened moral outrage, support harsher forms of punishment and withdraw their support for offender rehabilitation.

Finally, it was hypothesised that dehumanisation may be related to preference for a GLM approach to rehabilitation over an RNR approach. As illustrated in Table 6 there were significant bivariate correlations between preference for GLM over RNR and several of the variables including moral outrage $(r=-.19, \mathrm{p}<.001)$, support for rehabilitation $(r=.14, \mathrm{p}$ $<.05)$, and punitiveness $(r=-.20, p<.001)$. This suggests that individuals who are more morally outraged and believed that more punitive responses are warranted are less likely to favour a GLM approach, whereas those that are more favourable towards the use of rehabilitation and perceived the offender to be reformable are more likely to favour a GLM approach, however further research is required to better establish these findings.

Logistic regression was also performed to see if dehumanisation, moral outrage, liking, punishment, rehabilitation, age or gender significantly predicted preferences between GLM and RNR approaches to rehabilitation. None of the variables were found to significantly predict preference for GLM over RNR. Overall, hypothesis 6 of the current study was unsupported and dehumanisation did not predict preference for an RNR rather than a GLM approach to rehabilitation.

Discussion. Participants were found to experience more moral outrage, increased punitive stances, and dehumanise to a greater extent an offender who committed a contact offense compared to a less harmful non-contact offense providing support for hypotheses 2 and 3(a). None of these variables were influenced, however, by the age of the victim in the study. 
Table 5

Results of linear regression analysis: support for punishment

\begin{tabular}{|c|c|c|c|c|}
\hline & $\beta$ & SEB & $\beta^{*}$ & $\mathrm{p}$ \\
\hline Dehumanisation & .10 & .03 & .17 & .00 \\
\hline Moral Outrage & .32 & .05 & .44 & .00 \\
\hline Liking & -.42 & .27 & -.09 & .13 \\
\hline Age & -.09 & .03 & -.17 & .00 \\
\hline Gender & .01 & .48 & -.00 & .98 \\
\hline Political Orientation & .25 & .25 & .06 & .31 \\
\hline $\begin{array}{l}\text { How likely do you perceive that the } \\
\text { offender will commit a similar offense } \\
\text { within } 5 \text { years of completing } \\
\text { rehabilitation? }\end{array}$ & .35 & .13 & .16 & .01 \\
\hline
\end{tabular}

Table 6

Results of linear regression analysis: support for rehabilitation

\begin{tabular}{lcccc}
\hline & $\beta$ & SEB & $\beta^{*}$ & $\mathrm{p}$ \\
\hline Dehumanisation & -.12 & .05 & -.18 & .01 \\
Moral Outrage & -.08 & .07 & -.09 & .26 \\
Liking & .33 & .40 & .06 & .40 \\
Age & -.03 & .04 & -.04 & .53 \\
Gender & -.33 & .70 & -.03 & .64 \\
$\begin{array}{l}\text { Political Orientation } \\
\begin{array}{l}\text { How likely do you perceive } \\
\text { that the offender will commit }\end{array}\end{array}$ & -1.28 & .36 & -.24 & .00 \\
$\begin{array}{l}\text { a similar offense within 5 } \\
\text { years of completing } \\
\text { rehabilitation? }\end{array}$ & & .19 & -.07 & .35 \\
& & & & \\
\end{tabular}


Hypotheses $1 \& 3$ were found to be unsupported; participants did not experience more moral outrage, dehumanisation, increased support for punishment or decreased support for rehabilitation when presented with vignettes of offenses against prepubescent children. Other studies have found a similar lack of effect for victim age against attitudes. Viki et al. (2012) found in their study that participants did not significantly dehumanise an offender who had offended against a prepubescent victim ( 6 years old) compared to a pubescent victim (15 years old), leading the researchers to suggest that child sex offenders are equally negatively perceived by the public regardless of the age group to which the victim belongs. It is also possible that the phrasing of the online survey questions did not clearly describe the non-contact offender's behaviour (see Appendix C). The offender was described as having a collection of "nude" images of children, which may not convey sexualised images of children. A suggested rephrasing could be "sexualised images of children" or "children posed in sexual positions" to better clarify the context of the images.

Type of offense and age of victim were not found to have a significant effect on support for offender rehabilitation, therefore hypotheses 3(b) and 4(b) of the study were unsupported. It was found support for rehabilitation was, however, significantly reduced dehumanisation and preference for punishment (hypotheses $5 \mathrm{~b} \& 5 \mathrm{c}$ ) indicating that participants who supported rehabilitation were less likely to dehumanise the offender or support more severe forms of punishment. The findings of the current study reflect those of Viki et al. (2012), who also found that dehumanising attitudes predicted withdrawn support for rehabilitation.

2-way ANOVA also revealed a significant interaction between type of offense and age of victim for punishment and moral outrage scores (see Figures $1 \& 2$ ). Contact offences received greater moral outrage reported for the pre-pubescent $(M=22.62)$ compared to a pubescent victim ( $M=20.00)$, but for non-contact offences the patterns was reversed, with more moral outrage reported for the pubescent victim $(\mathrm{M}=19.15)$ compared to the prepubescent victim $(M=17.03)$. Contact offenses involving a prepubescent victim $(M=16.38)$ were also recommended harsher punishment, however for non-contact offenses the pattern was reversed and more punishment was recommended for older (pubescent) victims $(M=10.94)$. This interesting interaction reinforces the lack of effect for victim age because less harmful non-contact offenses with older (pubescent) victims were recommended more punishment than contact offenses involving younger (prepubescent) victims. It was predicted by the current study that both types of offenses would receive increased moral outrage and support for punishment when acts were committed against younger (prepubescent) victims, however the 
non-contact offender scenario did not meet this prediction. The varying effect for victim age in the non-contact offender scenario could possibly be due to the phrasing of the vignettes, which will be later discussed in more detail later.

The current study hypothesised that those who dehumanised offenders to a greater extent would experience more moral outrage, increased support for punishment and reduced support for offender rehabilitation (hypothesis 5). This prediction was based on the findings of Bastian et al. (2013) who found that dehumanisation and moral outrage can predict punishment independent of the type and severity of crime. The current study also found dehumanisation and moral outrage to be predictors for harsher forms of punishment (hypothesis $5 \mathrm{a} \& 5 \mathrm{~b}$ ). A negative relationship between rehabilitation and dehumanising attitudes was also found, indicating that participants who dehumanised the offender were less likely to support the offender participating in rehabilitation (hypothesis $5 \mathrm{c}$ ) possibly because those who dehumanise child sex offenders perceive them to be less reformable.

The current study attempted to address for the first time whether dehumanising attitudes have a role in preference between the RNR and GLM approaches to rehabilitation (hypothesis 6). No significant effect was found for dehumanisation, however moral outrage, punishment and rehabilitation were found to have significant bivariate relationships with RNR/GLM preference. Individuals who experienced more moral outrage and supported a more punitive response to sex offenders were less likely to favour a GLM approach, whereas those who supported offender rehabilitation were more likely to favour a GLM approach. The current study therefore suggests that there is scope for further research to investigate the role of attitudes in RNR/GLM preference.

\section{Study 2}

Study 2 was undertaken with the general aim of investigating: (A) dehumanising attitudes of participants towards child sex offenders, (B) support for rehabilitation of child sex offenders, and (C) support for the creation of a sex offender registry in New Zealand and support for post-release monitoring in general. Three focus groups were held containing a combined total of 22 participants to allow for further discussion on the topic. Some participants responded to an invitation included in the online survey and others contacted the researcher after seeing the study advertised on various social media and university sites. After all three focus groups were transcribed the data was uploaded to Nvivo 10 for thematic coding analysis of dehumanising attitudes of participants displayed toward child sex offenders. Two case 
studies were presented to participants, the first was Stuart Murray Wilson - or the 'Beast of Blenheim' as the New Zealand media refers to him -the second was a vignette from the online survey read aloud (see Appendix C) involving child pornography offenses committed by a 30 year old male who collected 500 nude images of children ages 7 and below over a period of months before the collection was discovered on his computer by a friend. After being presented with the case study, the researcher asked questions relating to the punishment and rehabilitation of the offender including questions relating to support of post-release monitoring.

\section{Dehumanisation}

'Beast of Blenheim' case study. Participants displayed dehumanising attitudes towards offenders which deprived them of UH characteristics, leading to support for comparisons to subhuman beings such as 'beasts' and further contributing to animalistic dehumanisation of the offender. Referring to out-group members (such as child sex offenders) as animal or beastlike is a form of animalistic dehumanisation (Haslam, 2006) and a denial of UH characteristics because it portrays others as lacking refinement, self-control, civility, intelligence, and rationality (Haslam \& Loughnan, 2014). The example of New Zealand child sex offender Stuart Murray Wilson - referred to as 'the Beast of Blenheim' in the New Zealand media (3News, 2014) - was presented to participants alongside questions regarding support for use of the term 'beast' for the offender, support for post-release monitoring, and support for rehabilitation. The 'Beast of Blenheim' case study provided an example of a New Zealand child sex offender case on which to base discussion relating to offender punishment and rehabilitation in New Zealand. Viki et al. (2012) found that dehumanising attitudes lead to support for social exclusion of the offender, therefore it was expected for the current study that participants who held dehumanising attitudes towards child sex offenders would be more likely to support forms of punishment such as sex offender registration.

\section{Animalistic dehumanisation and denial of uniquely human characteristics.}

Dehumanising attitudes supported the belief that child sex offenders held different characteristics from the rest of humanity and supported use of the term 'beast' amongst other dehumanising terms such as 'freak' (Participants B \& X):

I think that beast is a good title, even though the media made it. I think that's a good connotation for child sex offending (Participant Z)

... Yeah, but he's a freak, really. It's helpful to think he's a freak. (Participant B) 
I agree with what these guys are saying, it makes them different from everyone else, he's like an animal or like a beast, he doesn't behave to the laws that everybody else does so we separate him (Participant S)

Some participants made specific animal-like comparisons to describe the uncontrollable and unpredictable nature of child sex offenders:

... I'm still quite confident that there are some things that you cannot fix, like if a dog bites someone and gets a taste for blood, they're always gonna have that taste for blood [regarding paedophilia] (Participant L)

I can remember the first time I heard it, it was on the radio, and I thought oh my god there's a wild animal on the loose! We've got a wolf or something in New Zealand! It was like oh there's something completely uncontrollable that's gone on a rampage, and that whole thing of fear. . I thought there was a wild animal in Blenheim (Participant $\mathrm{N})$

The 'Beast of Blenheim' case study included the information that Wilson had refused to participate in a rehabilitation program whilst in jail and therefore was released with stringent parole conditions placed on him. Rogers et al. (2011) examined attitudes towards offenders who had chosen to participate in an auto-mechanics course whilst incarcerated rather than a rehabilitation program. This research found that attitudes were more negative towards offenders who refused to participate in rehabilitation, therefore the current study investigated whether participants would display the same attitudes towards Wilson's refusal to participate in rehabilitation. This refusal to participate in rehabilitation led participants to perceive that Wilson was lacking in UH characteristics such as the higher cognitive functioning needed to generate empathy and remorse for his offenses (Haslam \& Loughnan, 2014). Denial of UH characteristics is a form of animalistic dehumanisation because it denies traits specific to the higher cognitive functioning of human beings such as consciousness, agreeableness, and openness to experience (Haslam, 2006). Self-control is another UH trait, and when offenders are perceived to be lacking characteristics such as these it is expected that support for postrelease monitoring will increase. Participants noted that use of the term 'Beast' was justified toward Wilson for his lack of remorse and empathy (UH traits) therefore displaying animalistically dehumanising attitudes:

If he were to be unrepentant after an opportunity for rehabilitation, or to say I don't need rehabilitation, because I think these kids would consent... a lot of things that you hear from unrepentant sex offenders is that the kids consented, the kids led me on, exactly the sort of things that regular adults who commit sexual assault would say only it's about children. It's about lack of understanding and empathy. Which is demonstrated by his unrepentance. (Participant D) 
Given his history and how he shows no remorse, and doesn't want any help and doesn't want to change. Someone like that I feel like yeah he deserves to be known because he poses such a risk. I think it gets more questionable when people don't pose as much of a risk (Participant $\mathrm{M}$ )

Participants also noted that this lack of remorse and empathy (UH characteristics) provided justification for animalistically dehumanising terms such as 'beast', which likened Wilson to an uncontrollable subhuman being:

I was just going to say that calling him a beast also emphasizes his lack of empathy and remorse for what he's done. (Participant B)

I feel that the reason he would be referred to as a beast whereas other cases wouldn't is because he showed no remorse and it was repeat offending. Again and again. It's obviously quite intentional. (Participant L)

This lack of remorse and empathy seemed to increase perceived moral distance between participants and offender. Removal of UH characteristics such as the higher cognition needed to generate empathy led participants to dehumanise the offender more. The current study aimed to investigate if dehumanising attitudes were related to an increase in support for punishment whilst creating a reduction in support for rehabilitation. Although the focus groups did not aim to address a specific set of hypotheses, findings contribute support for the expectation that participants who dehumanised the offender to a greater extent would favour harsher forms of punishment such as post-release monitoring. One participant stated that the uncontrollable nature of their sexual urges justifies close monitoring to protect children from further sexual victimisation: "totally, in that situation I still think they should be on a registry afterwards. I think if you still have the urge to do it. . I would want to know if there was a paedophile living next to me and my children, so I'd know to keep them away from him (Participant D)" Another participant believed that a lack of remorse and empathy reflect a diminished state of self-control therefore reflecting a need for post-release monitoring: "If he's completely unrepentant, I haven't done anything wrong, then yes." Participants who believed that offenders posed a highrisk of reoffending due to a lack of self-control (UH characteristics) were more likely to support social exclusion of the offender post-release monitoring:

Released from prison? Eventually they'll get released. I mean they shouldn't, but they will, and they still should be tracked for the rest of their lives. I think they're likely to do it again. They're a risk, and it's not worth being sorry, y'know. I think there's certain cases that should be tracked. And if not locked up forever, I'd like to know where they were. . . I think overall with a sex offender registry for those who repeat [offend] really really badly, the list would be fine, and if I was a parent I would like to know who was living in my neighbourhood, to protect my kids. I'm thinking if you've got kids most 
people would agree. Especially around schools. . I think with a repeat predator they can tell and those people should be put on the registry (Participant Z)

It's a natural response to uhm, something like that, compared to something like burglary, it's engrained in us. I think it's part of human nature... their mind is too far gone to rehabilitate, to the point that I wouldn't have them in my area (Participant Z) If I saw him on the street I wouldn't want to talk to him. But if he'd come out and accepted it and was remorseful and he'd gone to treatment and what-not, they conversation well...I'd just say hello. (Participant Z)

These statements reinforce the idea that degrees of dehumanisation and attribution of UH characteristics varied between participants, because somebody who sexually offended once was not necessarily perceived as uncontrollable in nature forever. These quotes also reflect that some participants recommended that harsher forms of punishment - such as post-release monitoring - be reserved for repeat offenders who are perceived as the most uncontrollable (the most lacking in UH characteristics) and therefore believed to pose the most risk of reoffending. It may require repeat offending and ongoing denial of remorse and empathy to build dehumanising attitudes and gain the perception that post-release monitoring is necessary.

Child pornography offender case study. Participants were presented with a case study from the online survey (see Appendix C) involving an offense committed by a 30 year old male involving the collection of 500 nude images of children ages 7 and below. The collection was discovered by a friend of the offender one day when they accessed his computer. This offense was presented alongside questions regarding support for post release monitoring, support for rehabilitation, and support for terms such as use of the word 'beast' toward the offender.

Participants throughout study 2 displayed less dehumanising attitudes towards a noncontact offender and were less likely to withhold attribution of UH characteristics from the offender. Participants did not support use of dehumanising terms such as 'beast' towards the offender, displaying less animalistic dehumanisation of the offender than when presented with the 'Beast of Blenheim' case. What remained similar was the emphasis on need for remorse and acknowledgement required from the offender:

No, I wouldn't call anybody a beast, I personally think no acknowledgement, no remorse, I would question that he might still be quite a dangerous person to be around, or for children and certain other individuals to be around. (Participant $\mathrm{C}$ ) My first thought would be, has he acknowledged what he's done? Like "it wasn't my images someone must have borrowed my computer one day"? (Participant D) 
Participants were more likely to attribute UH qualities such as higher cognition to the noncontact offender, suggesting that the offender could be reasoned with or rehabilitated rather than punished:

Well I think it would be more constructive to give the guy some kind of education and support like you suggested just now, I don't actually see much benefit in sticking him in prison and putting him on a ... whatever you call it...list... unless you could guarantee that if he had some kind of punitive sentence he would also be receiving some helpful training/counselling etc. and I don't know if that's possible (Participant A)

... What you've got here is the whole underage situation clearly that has to prevail. So he has to in some way be punished and I'd say if it were possible to make him aware of what he's done and definitely not imprison him I think that would be way over the top, but I think if you could in some way re-educate him as such that he saw. (Participant B)

Previous studies have shown that type of offense can determine severity of punishment and dehumanisation of the offender (Bastian et al., 2013), therefore the current study suggested that non-contact offenders would receive less support for harsher forms of punishment including post-release monitoring. The majority of participants throughout study 2 reported that placing a child pornography offender on a registry was too harsh a form of punishment for a noncontact offense, "to me it seems over the top. For going in and looking at your computer" (Participant D), concern was expressed that the offender had only viewed pornography but would be registered alongside offenders who commit sexual assault - "I agree that he's a somewhat dangerous person, but where do we draw the line? With him not being as dangerous as others?" (Participant H). Participants also questioned if punitive approaches could have any effect on an offender who viewed child pornography, "I think that any change in behaviour has to come from him working inside rather than external forces working on him" (Participant Z).

Overall the majority of participants expressed a lack of support for placing a non-contact offender on a registry:

Putting someone like that on the registry is going to make it even harder to rehabilitate them because it will drive people sort of underground because their isolated from society, obviously watching child pornography in a way does condone actions against children, but I think most people can separate that from themselves actually offending. (Participant X)

I think it's labelling - he hasn't necessarily done anything wrong, it's still distorted and disgusting, but it's kind of like thinking about robbing a bank and being imprisoned for thinking about robbing a bank. Seems like it predicts or assumed he's going to do something when he might not - sort of think about it like that, they're also not seeing the rehabilitation approach. They're thinking "it's disgusting let's stop it" but not how did it start, it seems kind of redundant to me. (Participant X) 
The only support received for registration of a child pornography offender related to a lack of knowledge regarding paedophilia: participants that were unsure if either rehabilitation or punishment could: (A) prevent the offender from continuing to view pornography and (B) prevent them from committing a contact offense in the future were more likely to lend support to post-release monitoring, "I think the thoughts are just as dangerous as the action though...in that situation I still think they should be on a registry afterwards. I think if you still have the urge to do it." (Participant H)

Consideration of the offense. Due to the free-flowing nature of focus group discussion, conversation at times related to general consideration of child pornography offenses. Multiple participants questioned the relationship between child pornography and child sexual offending (e.g. are those who view child pornography more likely to commit a sexual offense against a child?) Some participants worried that viewing pornography increased the risk of an offense occurring: "I don't know how you can tell whether that is typical behaviour of someone who then goes on to abuse children in that age group or whether it's relatively harmless..." (Participant B). Other participants debated that pornography provided an outlet for fantasy: "People watch crime and violence on the TV and internet but don't go and actually kill someone, it's the same as child pornography, you can watch it and not do anything." (Participant B). Participants began to provide support for registration of a child pornography offender and withdraw support for rehabilitation when they perceived that viewing child pornography would lead to desensitization and the need to commit a contact offense to provide further stimulation:

It's just 500 pictures though, if he'd done it once it's like maybe we can rehabilitate this guy, but like 500 pictures is kinda like...it kinda stopped him but it's like he's in stage 1 , the next stage is he's gonna go and find an innocent little girl or something, but stage 1 is to have all these pictures. (Participant M)

Others debated that a non-contact offense did not warrant a harsh form of punishment such as registration, and whether registration could have any preventative effect on future offending:

What worries me about so called "sex crimes" is that they can span so many things I mean this guy has looked at some images on the computer, which is a bloody sight better than going out and assaulting children. If it stops him going out and assaulting children it's better that he continues to do so (Participant D)

I probably would put him in an intervention or community service or something, something that might be beneficial, because he may not be harming anyone just viewing images and there might be a million other people that are doing the same thing as well (Participant $\mathrm{H}$ ) 
Other participants questioned the nature of internet pornography and expressed concern that physically mature minors were often involved in pornography unbeknownst to the viewer, creating potential for viewing child pornography accidentally which could result in accidental registration for members of the public who pose no risk of sexual offending. The vignettes included in the survey (see Appendix C) and the description read aloud in the focus groups described an offender who had a collection of over 500 images so that question of intent for offending could be eliminated. Participants recognised that the offender displayed clear intent but stated that "Every male in this room without knowing it has probably looked at an underage girl on the internet and just don't know it" (Participant B) because "there's this grey-black underbelly to the internet, which we have no idea how it even functions, but those people who seek it can find it" (Participant D). One participant concluded that the amount of images was a good way to decipher intent, and the example offense (500 images) displayed fair intent to commit the offense, "I think it's $100 \%$ level of intent. You could click on something and it could take you to literally anything. I torrent stuff” (Participant A): “yeah, there's intent. And even though he hasn't actually committed a crime against anyone, he has endorsed the trade of child pornography" (Participant M).

Also mentioned in the consideration of the offense by participants was: (A) the context of the images: and (B) the nature of the victim. Consideration of the context of the offense related to where and when the nude images of the children were taken (for example if the images were of children bathing or swimming vs. children posed in sexual positions) and relationship to the victim (family members, caregivers or anonymous). Participants questioned if direct exploitation and harm to children was committed in order to obtain the images, or if the pornography had involved anonymous victims in a neutral setting. It seemed that for participants the context of the images could greatly mediate level of punishment recommended for the offender. Images of posed, underage victims were also recommended to result in harsher forms of punishment also because they could potentially relate to the endorsement of the sex trafficking trade:

Is it children in paddling pools? In back gardens? That somebody's photographed with a long lens? Or is it children who have been made to pose? It's different. (Participant A)

I would think well are these images his nephews and nieces? Or where from? And then kind of if you're looking at 500 images of children you might look form an investigative point of view you might be looking at the power points at stuff to see if you could locate countries. Because it's worldwide. (Participant B) 
I would say because of the emotional scarring that is perpetrated on a child that no counselling for that child can ever fix. The nature of the victim. These are photographs, who knows if the children knew they were being photographed even, they could be kids in paddling pools or in back gardens, that's why I'd want to know the nature of the pictures (Participant C)

Summary: type of offense. Overall, throughout study 2 participants were more likely to support harsher forms of punishment including post-release monitoring for a contact offender such as Stewart Murray Wilson or the 'Beast of Blenheim'. Participants generally regarded post-release monitoring to be too harsh of a punishment for a non-contact child pornography offender. Rehabilitative efforts including counselling and forms of education were recommended more often for the non-contact offender, implying that participants regarded non-contact offenders to be more reformable. The child pornography scenario generally generated less dehumanisation and more discussion surrounding consideration of the offense, including the context of the images and the relationship between viewing pornography and committing a sexual offense.

Participants also did not support use of terms for the offender such as 'beast', whereas contact offenders were animalistically dehumanised and recommended various dehumanising labels such as 'freak' or 'beast'. UH characteristics such as empathy and remorse were found to mediate recommendations for punishment such as post release monitoring: the less remorse displayed, the more participants regarded the offender to be uncontrollable and to pose a highrisk of re-offending.

Post-release monitoring. The current study aimed to investigate dehumanising attitudes and their role in support for social exclusion and post-release monitoring. Focus groups created an opportunity for in-depth discussion around the possible creation of a sex offender registry in New Zealand. It has already been mentioned that use of the registry was supported more for a contact offender - such as the Beast of Blenheim - than a non-contact child pornography offender. The discussion created a free-flowing conversation that generated other ideas, such as use of the registry as a threat for repeat offenders:

I am definitely down the rehab avenue, but I do think that this could potentially be the use of the register as a threat, if you do not actively participate in ongoing counselling etc. then you might end up on a register and you will be tarred for life, so use the register almost as a consequence of actions (Participant F)

Others noted the harmful effects the registry may have due to infrahumanisation: perceived distance and prejudice toward the out-group has been known to underlie justification for severe 
and cruel forms of treatment (Bastian et al., 2013) therefore a community that rejects the integration of child sex offenders may react violently:

I think that the society we live in now, you would end up with people going round shooting people and god knows, setting their houses on fire (Participant B)

...Or someone goes round and shoots the person that's on the list (Participant D)

I just think you'd have murder and mayhem, I really do because people even sometimes without really understanding they just go "that's the label! You bastard! You're gonna get your throat slit tonight!" and that's not helping. It's the breakdown of society. (Participant N)

Some participants suggested that a registry should be created but only made available to certain sources:

As far as a registry goes, I think there should be a registry available to the police myself, if say schools are employing teachers, anyone that comes into contact with young children and parents, I think they should all have one to make a police check easier, really because I think these kids need to be protected (Participant X)

Whereas others had a problem with broad and homogeneous application of registration for a range of offenses with differing qualities, debating the idea that the 'Beast of Blenheim' and a child pornography offender would be placed on the same registry:

But we treat them under the same sexual offending umbrella, it gets a bit confusing (Participant Z)

The other thing is he's been thrown in with all the real bad guys. I mean there's no half yellow one saying "he's not as bad as this guy", they're all just deemed as real bad guys (Participant M)

There was certainly a link between those who dehumanise child sex offenders by withdrawing UH characteristics (such as remorse, empathy, and self-control) and support for registration policies:

If he's completely unrepentant, I haven't done anything wrong, then yes. (Participant $\mathrm{H})$

I think with a repeat predator they can tell and those people should be put on the registry (Participant Z)

I agree with him given his history and how he shows no remorse, and doesn't want any help and doesn't want to change. Someone like that I feel like yeah he deserves to be known because he poses such a risk (Participant D)

The topic of support of sex offender registration therefore provided scope to assess: (A) dehumanising attitudes of participants and (B) denial or attribution of $\mathrm{UH}$ characteristics to the 
offender. UH characteristics are related to support for sex offender registration because participants who perceived offenders to be lacking in UH qualities also perceived them to be lacking in higher cognition and self-control, therefore perceiving them as high-risk for reoffending, justifying monitoring after release. These findings could suggest directions for future study. Questions relating to support for post-release monitoring could be adjusted to include assessment of $\mathrm{UH}$ characteristics to further investigate this relationship.

Infrahumanisation and UH Characteristics. So far the results of study 2 have found that UH characteristics play a role in support for punishment and rehabilitation which could also be referred to as a form of infrahumanisation, during which UH characteristics and secondary emotions unique to human beings are reserved for in-group members and denied to more distant out-group members (Haslam, 2006) such as child sex offenders. So far it has been observed throughout study 2 that whether participants perceive that the offender holds UH characteristics - such as the higher cognition needed to govern self-control and generate empathy - can influence preferences for punishment and rehabilitation of the offender. This could be because displaying UH characteristics provides evidence that the offender has the cognitive capability to control risk of re-offending and change making rehabilitation possible. The belief that sex offenders are not capable of change reflects denial of UH characteristics and the belief that they hold a mental state different to the rest of the community, reflecting infrahumanisation.

Infrahumanisation and Paedophilia. During the focus group evidence was found to support infrahumanisation (the reservation of UH and other secondary emotions unique to human beings for in-group members (Haslam, 2006) regarding paedophiles (the diagnostic term for those with 'paedophilic disorder' or exclusive sexual attraction towards prepubescent children (American Psychiatric Association, 2013; Durrant, 2013). Because paedophiles have a sexual preference considered to be taboo and morally reprehensible by the majority of the community participants regarded these offenders as holding different, unchangeable characteristics from the rest of society:

The topic of sex is kind of taboo almost, and sexual offending is regarded as different to other offenses. Reminds me of Freud. So there's 'normal sex' and sex that kind of deviates from that is 'unnatural', so you'd regard sexual offending as kind of beyond human so the beast aspect (Participant C)

I think it helps to put him aside, like he's not one of us. No one talks to their 5-year old, "I wonder what you'll do when you grow up? Maybe you'll be like the beast of 
Blenheim?" I mean we don't want to think that, do we. They're quite separate. (Participant M)

I think there's a lot of fear that if we understand the people who do it will somehow be seen as okay, so we keep that really strong separation. (Participant A)

The nature of the victim greatly impacted the process of infrahumanisation for participants. They were asked if they would use the term 'beast' towards someone who committed a sexual offense against an adult and if they would equally support registration of adult sex offenders. Most participants noted that crimes against children (both contact and non-contact) bothered them more and showed more support for exclusion of child sex offenders from the community:

I think to me the difference is the level of vulnerability. An adult is much more able to say "this is wrong, I don't want it", scream for help etc., whereas a child has got no understanding of that kind of thing, so the power imbalance, whereas if you've got two adults you've got far more of an even balance of power, but with a child and an adult they are...so vulnerable. And I think as a society perhaps the idea of the register is coming from, to me, a misguided idea that we want to protect the most vulnerable in our society, which is a worthy kind of idea, but to me it's the wrong way of going about it (Participant F)

I would say because of the emotional scarring that is perpetrated on a child that no counselling for that child can ever fix. The nature of the victim. (Participant D)

... And then you see them as adults, and that's never ever forgotten because they've been hurt. These are photographs, but again who knows if they've been made to pose that way, very emotionally damaging. My thing with child sex offending is that I'm not sure how or if children ever recover. (Participant A)

Because child sex offenders were regarded as so unchangeable and different from everyone else this led some participants to question whether this type of offending behaviour could benefit at all from rehabilitation:

I'm not sure you can cure paedophiles (Participant A)

... Can you stop a . . . it's a sexuality thing, you can't manipulate someone's sexuality, and you can't stop a paedophile being a paedophile any more than you can stop a gay person being gay. You can repress it. You can't cure it (Participant B)

I think it's very hard for people to change their sexual orientation. I'm heterosexual, if you put me through a program to not fancy women anymore, you'd have a pretty hard job right. So if you're someone who fancies sex with underage people, it's gonna be very hard to change (Participant A)

Participants also noted that using the terms such as 'beast' for child sex offenders reflected the view that offenders possessed different, sub human characteristics from the rest of society. Referring to offenders as subhuman was also noted by participants as a method of separation from those who commit acts considered to be immoral - "People don't want to 
empathise with sex offenders because they think they could never be a sex offender. Right?" (Participant H) - leading to a withdrawal of UH characteristics from the offender and furthering the process of infrahumanisation. Those who did not support use of the term 'beast' did still recognise the function of the term:

'Beast of Blenheim' creates the old moral panic situation.... why do they call him a beast? I guess it relates to that certain situation where he did things that are immoral so it's easy to give him the term 'beast' and not consider him human-like. So it sort of easily differentiates everyone that says normal from beast who is not normal (Participant F)

It reinforces that idea of "I am normal and he's not" to make that sort of comparison in society, rather than trying to accept them and rehabilitate them (Participant B)

Many participants noted the media as the source of dehumanising titles such as 'beast' and a factor that increases the perceived moral distance between child sex offenders and the rest of the community:

"They get made as beasts so we see them as beasts" (Participant M)

We hear these little words after people's names, little epithets it makes an interesting story. I bet no one here could remember his name without prompting right? Probably very unlikely. But seeing someone as a beast it mythologises them, makes sort of this monster that everybody in society can gather round and hate and watch true crime documentaries about (Participant $\mathrm{H}$ )

I think it's unhelpful, I think the journalists [and] their administrative group should have stopped it because it's unhelpful and it glorified the case. And people latched onto it, everybody loves somebody to hate because it's helpful to hate one person especially if the group all hates them ... (Participant B)

Some participants noted that the media had portrayed child sex offenders to be so different, removed, unchangeable and beast-like that they expected child sex offenders to also appear physically different from the rest of the population. This displays further support for infrahumanisation, as child sex offenders were not only assumed to have lessened cognitive abilities from the rest of the population but also assumed to be so different that they would appear physically deformed: "I thought before I heard that story that such people would stand out in some way, they don't. They really don't” (Participant N), “. . . Or at least they should look different from us, dress different from us" (Participant M).

Some discussion touched on infrahumanisation and culture: although child sex offending is widely regarded as taboo participants mentioned other areas of human history and 
popular culture containing traces of paedophilic behaviour that did not result in moral panic or exclusion from society. Whilst noting that they do not support the behaviour of child sex offenders, participants reported that there appeared to be an unfair focus in society relating to the exclusion of sexual offenders:

There's years and years and years of mythologies and pathologies to suggest that these people are just that, they're not human, they're less than human, and they don't deserve to be judged on the same criteria as humans. Whenever you hear about child sex abuse cases the media has a focus on the fact that somebody could do something so abhorrent means you must be inhuman, rather than saying "these people are human and whatever paraphilia they have, whatever sexual attraction they have to children, or whatever they did in the past, doesn't matter" because they're a monster for having done these actions (Participant X)

Summary of findings: Infrahumanisation. Study 2 found evidence that participants tended to infrahumanise child sex offenders by depriving them of self-control and other qualities unique to human beings (HU). Participants generated discussion relating to infrahumanisation and paedophilia: paedophiles have such taboo sexual preferences that participants were more likely to perceive them as distant-others, creating reluctance towards support for offender rehabilitation and reintegration. There was also some discussion regarding human history and sexual preference for children, noting that throughout history kings would marry pubescent girls and presently the media sexualises young women.

Contact Hypothesis. The current study did not aim to provide support for the contact hypothesis, but due to the nature of the sample of participants in study 2, aspects of this hypothesis could be explored. Whilst retaining anonymity, several participants identified their professions: nurses, social workers (Child Youth and Family Services - CYFS), law enforcement, primary school teachers, academics and students (both criminology and psychology students). Previous research has found that those who experience increased contact with offenders are less likely to hold prejudicial attitudes towards them (Viki et al., 2012; Willis et al., 2013a). Clinicians, law enforcement and other justice system professionals experience a high amount of contact with offenders and have been found to display less negative attitudes towards offenders as a result (Conley et al., 2011; Viki et al., 2012). Shackley et al. (2013) also found that participants who had an undergraduate or postgraduate degree had less negative attitudes than participants who only had a high school level education, suggesting that level of educational attainment can also play a role in attitudes. Shackley et al. explain that people with a higher level of education are more likely to get their information from credible sources rather than sensationalised media articles. 
Participants of study 2 included criminology and psychology students who held a level of knowledge which appeared to inform opinions towards offenders. One participant noted they had knowledge of 'rape myths' - myths relating to sexual offending - which the public may not, and this knowledge affected support for offender registration. An example of a 'rape myth' includes the belief that rape is commonly perpetrated at the hands of a stranger down a dark alleyway, often referred to as 'stranger danger' (Levenson et al., 2007a) when in fact evidence supports that offenders are often known to their victims:

Sexual victims are usually known to their offenders as well. That completely takes away what people say is good about the registry. That means you can see what people are in your neighbourhood but most likely is that they're not actually going to be offending on your children, if they do it will be on people that they know. Having a registry doesn't actually reduce the likelihood of crime happening, then what's the point in having it because it just puts more of those people at a disadvantage (Participant $\mathrm{M}$ )

I think also it comes down to that number one misconception - that sex offenders aren't strangers lurking around the corner, they're people that everyone knows. . . (Participant E)

Participants continued applying this university-level knowledge of criminology to generate opinions towards punishment and rehabilitation:

... Recidivism rates of sex offenders. While I'm aware that they are low, other people aren't, and the media feeds off the quite distorted perception that they are, and that anyone that's sexually offended in any way is going to continue to do that. Going with that thought you can see why sex offender registries just seem like a great answer (Participant M)

. . . It's almost systematic, if you listen to any person who isn't a child offender, generally they were offended [against] or saw it as a child. Those sort of contexts they start drawing in a whole bunch of different social variables, like the conditions in which these people were living in, and when they were touched and stuff like that. It's all a mix of psychology, biology, sociology it's a whole mix (Participant T)

The false assumption that child sex offenders pose high-risk of re-offending has been found throughout previous studies to underlie the creation of sex offender registries (Levenson et al., 2007a). Throughout study 2, participants who held evidence-based opinions were less likely to provide support for post-release monitoring, reinforcing the findings of other studies which have found those with higher educational attainment to hold less negative attitudes towards offenders (Shackley et al., 2013). When discussing the topic of a woman in the media who was receiving negative attention for having a relationship with a registered sex offender, one participant noted that a lack of education underlay the negative reaction from the community about the relationship and created a general reduction in support for rehabilitation: 
... Anyone having a relationship with a sex offender is something that most people think is wrong because most people think that sex offenders, especially child sex offenders, can't be rehabilitated. Which kind of ignores the fact that sexual preference for children is something that can potentially be changed, especially through having intimate relationships with someone else, I think that's just a common perception. I think just anyone in general, if they said they were dating a sex offender most people would not think that's okay because they would always think that sort of "once a sex offender always a sex offender", which isn't obviously true (Participant X)

Participants who held a higher level of knowledge regarding offending therefore did not hold the perception that child sex offenders were uncontrollable, subhuman beings which lead to increased support for prosocial approaches towards offenders such as counselling and rehabilitation.

Amongst the nurses, social workers and members of law enforcement included in the sample, participants occasionally drew upon their experiences of child sex offenders on which to base an opinion, and typically this increased level of contact had contributed to a more humanizing view of offenders:

I can just say that they are people like us, totally. There's one on every street, we say these things at work, but kind of safe to say that they are people we probably will all know somebody one of the things we're kind of always told to take into consideration is that what we know is the very tip of an ice berg, anything we don't find out they will never tell us. I bet all of us have actually got sex offenders in our social networks somewhere, some kind, and it's not the kind of thing you disclose when you're sharing lasagne (Participant D)

... I mean I can remember one time as a nurse, this particular time in a ward years ago, and there was somebody everybody knew had been convicted as a paedophile and he became sort of, 'the paedophile down in room 6', and it was like he was a label before he was a person (Participant F)

Level of contact and education were found to impact on opinions toward rehabilitation too: participants who did not hold any knowledge about offender rehabilitation would occasionally question the ability of rehabilitation to reduce sexual recidivism and withdraw their support, but often stated support for rehabilitation if the evidence could be provided:

I don't know how successful rehabilitation programs are for child sex offenders; I'd need to read some peer reviewed papers on whether it was a good idea and what it should be like, because otherwise I'm just guessing. I'm a positive person; I'd like to think it would work. (Participant B)

I certainly believe you should try. You can never entirely determine what another human being is going to do but most importantly you've got to offer them the opportunity and the facilitation if you can. The system should allow people the opportunity to put things right, to have the opportunity to seek further help without any 
difficulty at all, and yes to re-engage with society in a better way. Whether everybody can is another totally huge question, but I definitely would like to live in a society that believes you've got to try (Participant C)

Overall, participants who experienced higher contact with child sex offenders, whether it was due to their occupation or because they held a tertiary-level education, were less likely to dehumanise offenders. They were also less likely to support harsh forms of punishment for the offender such as post release monitoring, and more likely to support rehabilitation.

Summary. Study 2 did not aim to test any specific hypothesis but aimed to generate further discussion regarding the punishment of child sex offenders in New Zealand and examine the presence of dehumanising attitudes at implicit and explicit levels. The focus groups took a similar approach to the online survey of study 1 by presenting participants with offending scenarios involving a contact and non-contact sexual offense against a child. The contact offender case study presented was the Beast of Blenheim - a repeat sexual offender from New Zealand - and the non-contact offender case study was a description of a child pornography offense. Both case studies involved sexual offenses committed against prepubescent children (ages 7 and below). The case studies were presented as examples by which to examine: support for post-release monitoring, support for rehabilitation, dehumanising attitudes towards offenders, and if dehumanising attitudes of participants implicate support for either rehabilitation or punishment.

Study 2 produced findings related to animalistic dehumanisation, infrahumanisation and the contact hypothesis which had an impact on preferences for punishment and rehabilitation. Participants who held dehumanising attitudes were more likely to support harsher forms of punishment - such as post-release monitoring - whilst withdrawing support for rehabilitation of the offender. Participants were also more likely to support the animalistic dehumanisation of the contact offender via use of terms such as 'beast'. An interesting finding was that UH characteristics specifically were found to influence preference for punishment and rehabilitation: participants who did not display the UH traits of empathy, remorse and acknowledgement were preferred to be monitored more closely and believed to pose more risk of re-offending. This is possibly because offenders who are seen as lacking UH characteristics are perceived as having lower cognitive abilities and less control over their own behaviour (Haslam \& Loughnan, 2014), therefore posing higher risk of re-offense. 
Based on findings of previous studies, it was expected that that non-contact offenders would generate less dehumanising attitudes from participants, gain less support for punishment and receive more support for rehabilitation. The majority of participants perceived post-release monitoring to be too severe of a punishment for a non-contact offender and recommended a more rehabilitational approach to prevent a contact offense from occurring in the future. Non-contact offenders were also dehumanised less by participants who rejected use of the term 'beast' for someone who viewed child pornography, instead generating discussion about the offense and whether viewing pornography increases the likelihood of committing a sexual offense. Participants recommend approaches to the treatment of a child pornography offender which required higher cognitive abilities and reasoning skills, reflecting attribution of UH characteristics to the offender and the perception that he is an autonomous being who can control his own behaviour. The attribution of UH characteristics alongside displays of empathy and remorse often received support for participation in a rehabilitation program. Dehumanising attitudes of participants were strongly associated with support for punishment and reduced support for rehabilitation. The specific finding of this relationship was that qualities regarded as cognitively unique to human beings (UH - such as empathy) had the strongest influence on the attitudes of participants.

\section{General Discussion}

The current study aimed to investigate the role of dehumanisation on attitudes towards the punishment and rehabilitation of child sex offenders in New Zealand. Bastian et al. (2013) and Viki et al. (2012) found that dehumanisation predicted support for harsher punishment and less support for the rehabilitation of offenders, therefore it was hypothesised that participants who held dehumanising attitudes towards offenders would experience greater moral outrage, be less likely to support their participation in a rehabilitation program, and would be more likely to support punitive responses to offenders. Previous research (Bastian et al., 2013; Viki et al., 2012) has also found that the nature of the offence predicted the degree of moral outrage, the extent of dehumanisation and attitudes towards punishment and rehabilitation. The present study, therefore, aimed to explore to what extent the age of victims and the type of sexual offence (contact vs. non-contact) influenced responses. Viki et al. (2012) also found that participants who dehumanised offenders to a greater extent were more likely to support their exclusion from the community, therefore the current study aimed to explore how dehumanisation was related to support for the creation of a sex offender registry. The overall aim of the study was to investigate how the concept of dehumanisation can improve our 
understanding of how individuals perceive child sex offenders and what they believe is the most appropriate response from the justice system to their offending.

\section{Type of offense and age of victim}

The results of study 1 supported the prediction that participants would display more dehumanisation, experience greater moral outrage, would favour harsher punishment, and would be less likely to favour rehabilitation for an offender who committed a contact offense compared to a less harmful non-contact offense (Hypotheses 4a). Study 1 did not however provide support for the hypothesis that the same variables would be impacted by the age of the victim: offenses involving prepubescent victims did not lead to greater moral outrage, more dehumanisation, more severe punishment, or less support for rehabilitation (Hypotheses $1 \&$ 3). Study 2 found that participants who displayed more dehumanising attitudes when discussing contact offenses compared to non-contact (child pornography) offenses, tended also to support forms of punishment such as post-release monitoring for offenders, in part because they perceived contact offenders to pose a higher risk of reoffending.

The nature of the offence (contact vs. non-contact) had a significant effect on dehumanisation, moral outrage, and support for punishment and rehabilitation. Contact offenders were more likely to be dehumanised and caused higher moral outrage than noncontact offenders. Dehumanisation and moral outrage were found to predict support for harsher forms of punishment regardless of offense type, similar to the findings of Bastian et al. (2013) who found that moral outrage and dehumanisation scores could predict punishment severity independent of crime type. Bastian and colleagues compared a wider range of crime types (violent, white collar, and child molestation) than the current study, however found similar results regarding the ability of dehumanisation to impact punishment decisions. The current study also produced findings consistent with the work of Bastian et al. (2013) and Viki et al. (2012) who found that when participants were morally outraged by an offense and/or perceived the offender to be subhuman they were less likely to perceive the offender as suitable for rehabilitation. Overall it would seem that offences which are perceived as more severe or harmful generated more dehumanising attitudes and support for punitive responses to offenders. These dehumanising attitudes then align with the perception that the offender is less reformable, leading to a reduction in support for participation in a rehabilitation and increased support for more punitive responses. 
The age of the victim has been found to have varying effects on preference for punishment and rehabilitation in previous studies: Rogers et al. (2011) found that participants attitudes did become more negative as the age of the victim decreased, however participants supported rehabilitation more for offenses involving the youngest victims (age 10). The current study predicted that age would determine withdrawn support for rehabilitation because participants would be more morally outraged by an offense involving a prepubescent victim, however Rogers et al. found that participants held more negative attitudes towards offenders who did not participate in rehabilitation, suggesting that the relationship between public attitude and support for rehabilitation can be quite complex. The current study predicted that dehumanising attitudes would have a negative effect on support for rehabilitation because dehumanising attitudes contain the belief that the offender is unchangeable, has less selfcontrol, and is less reformable than other types of offenders (Haslam \& Loughnan, 2014). However other researchers - such as Bastain et al. (2013) - state that the relationship between dehumanisation, blame, and rehabilitation is far more complex. Bastian and colleagues suggest that if people perceive the individual to be mentally ill they will also perceive them to have diminished self-control and responsibility for their offending, therefore leading to support for rehabilitation over punishment whilst sustaining a dehumanising attitude. Therefore dehumanisation and support for rehabilitation can vary - regardless of the type of offense due to how responsible and reformable people perceive the offender to be.

Viki et al. (2012) hypothesised that the age of the victim would predict withdrawn support for rehabilitation, similar to the current study. Viki et al. included vignettes of a prepubescent victim (6 years old) and a victim closer to the legal age of consent (age of consent is 16 years old, the study used a victim age 15) to examine if participants produce different responses for an offense against a victim close to the legal age of consent. Similar to the current study, Viki et al. found that age of victim had no impact on preferences for rehabilitation and punishment, leading the researchers to suggest that “...offenders who commit sex offenses against children of different age groups are equally negatively evaluated" (p. 2359) This explanation could apply to the current study as well: participants were either presented with an offense involving a prepubescent victim (age 7 and below) or a pubescent victim (ages 11 to 14) and it is possible that participants perceived all victims, prepubescent or older, to be children and therefore no difference in scores for attitude in relation to victim age were found.

However, in the present study a significant interaction effect was found for age and offence type for both moral outrage and punishment scores. Non-contact offenses involving 
older (pubescent) victims were related to greater punishment and moral outrage, however contact offenses received more support for both of these factors when committed against a younger (prepubescent) child. This interesting interaction effect illustrated that the age of the victim could influence moral outrage and punishment, however not in the direction which the study predicted (that younger victims would receive higher scores for both punishment and moral outrage, regardless of offense type).

Because the non-contact offence produced unpredicted outcomes relating to victim age, the phrasing of the non-contact offense in the survey could also be considered when interpreting the lack of effect for victim age. The survey described a 30 year old male who had spent months collecting over 500 images of "nude" children. Throughout Study 2 the participants frequently noted that although the offender had definitely committed a crime by viewing child pornography, they still remained unsure of the severity of the offense because the context and nature of the images was unclear. Participants questioned whether the children in the images were forced to pose sexually or had been photographed in a neutral setting doing an activity that was perceived as sexual stimuli to the offender, such as swimming or in stimuli. Participants explained that photographs of a child in a neutral setting would equally involve violation of the law and exploitation of children, however these images were less psychologically harmful to the child (who could be unaware of being photographed in a neutral setting) compared to contexts where a child is forced to pose sexually for photographs. A better description to include in the online survey may have been "sexualised images of children" or even further clarification, "images of children posed in sexual positions", to clarify the nature of the images.

\section{Dehumanisation, punishment and rehabilitation}

Correlational and regression analysis revealed that dehumanisation correlated with moral outrage and support for punishment whereas a negative relationship was found between dehumanisation and rehabilitation, implying that participants who dehumanised the offender to a greater extent also were more likely to withdraw their support for offender rehabilitation (hypothesis 5). Regression analysis found support for dehumanisation and moral outrage as significant predictors for punishment (hypotheses 5a \& 5b) and dehumanisation as a negative predictor for rehabilitation scores (hypothesis 5c), implying that those who dehumanised the offender to a greater extent were less likely to support rehabilitation and more likely to display support for punishment. Unexpectedly, age was found to be a negative predictor for punishment. The findings of study 1 imply that dehumanisation predicts more punitive 
responses and less support for rehabilitation independently of moral outrage, liking, and other variables of the current study. Bastian et al. (2013) similarly found that dehumanisation and moral outrage were predictors for punitive responses regardless of crime type and severity of the crime. Viki et al. (2012) also found that dehumanisation predicted withdrawn support for rehabilitation and increased support for harsher forms of punishment such as castration and murder. The findings of the current study reinforce the findings of Bastian et al. (2013) and Viki et al. (2012) because similarly dehumanisation was found to play a role in preference for punishment and perceived suitability for rehabilitation.

\section{RNR/GLM}

The current study also aimed to investigate whether dehumanising attitudes of participants would predict support for an RNR based approach to offender rehabilitation (focused on the removal of deficit and risk management) opposed to a GLM based approach to rehabilitation (a holistic, strength-based approach to rehabilitation which attempts to build the individual skills of each offender). Results of study 1 revealed that dehumanisation had no significant correlational or regression effect for preference between the two approaches, leaving hypothesis 6 unsupported. No previous studies have investigated the relationship between dehumanising attitudes and preference between these two approaches to rehabilitation, therefore there were no previous findings or questions on which to base the current study. Professor Tony Ward, GLM researcher and clinical psychologist, kindly loaned his expertise to the current study by providing assessment of the RNR/GLM question included in the online survey to ensure that the descriptions accurately addressed the treatment principles of each.

The lack of effect for dehumanisation in preference for these two programs could still be partially attributed to the phrasing of the questions. Possibly the description of the RNR program did not accurately address a narrow focus on deficits and risk management, or similarly the description of the GLM may not have conveyed the holistic and strength-based approach of the model properly. It was interesting to note, however, that there were significant negative relationships between RNR/GLM preference, moral outrage, and punishment scores. This implies that participants who displayed less moral outrage and less support for punitive approaches participants were more likely to be in favour of the strength based and motivational approach of the GLM model. A positive bivariate relationship was also found between 
RNR/GLM and support for rehabilitation, implying that participants who supported rehabilitation were more likely to support a GLM model. Although no significant relationship was found between dehumanisation and RNR/GLM preference, the findings do imply that types of attitudes, such as moral outrage and attitudes towards rehabilitation and punishment can impact preference between the two approaches, however more research is required to better establish all of these findings.

The findings of the current study provide implication for future study: the role of dehumanising attitudes in preference for the RNR/GLM requires further investigation using re-phrased questions and a larger more diverse sample. By attempting to address the relationship between dehumanisation and RNR/GLM preference, the current study has still contributed to a growing body of literature addressing dehumanisation and attitudes towards punishment and rehabilitation of child sex offenders in a New Zealand context.

\section{Infrahumanisation}

Study 2 produced some interesting findings regarding UH characteristics and infrahumanisation. The reservation of $\mathrm{UH}$ qualities for in-group members and subsequent denial of $\mathrm{UH}$ qualities to outgroup members is a process known to lead to infrahumanisation (Haslam, 2006). This denial of UH characteristics can underlie justification for harsher treatment of offenders: those perceived to be lacking the secondary emotions unique to human beings - intelligence, language, and refined emotions - lie outside the boundaries of moral concern, and may be deemed worthy of harsher punishment (Leyens, Rodriguez-Perez, Rodriguez-Torres, Gaunt, Paladino, Vaes \& Demoulin, 2001). As Bastian et al. (2013, p. 1) explain, when innocents are harmed the public is eager to see the justice system deliver 'just deserts' or punishment proportionate to the moral offensiveness and severity of the offense. Children are vulnerable and innocent victims, therefore the crimes committed by child sex offenders result in higher moral outrage leading to recommendation for harsher forms of punishment including exclusion from the community (Bastian et al., 2011; Viki et al., 2012). Infrahumanisation reduces prosocial behaviour to the out-group and can possibly explain support for policies such as sex offender registration (Haslam \& Loughnan, 2014).

Throughout study 2 participants cited various UH characteristics to justify why the offender should be included or excluded from society. Remorse, empathy and acknowledgement were specific UH characteristics that received frequent mention. When an offender had acknowledged the harm caused by their behaviour and displayed remorse or empathy for their actions, participants were more likely to support participation in a 
rehabilitation program. Offenders who displayed remorse or empathy (UH traits) and participated in rehabilitation or a form of counselling received further support for reintegration back into the community after release. When offenders did not display these qualities participants reported the offender as being at a high risk of reoffending and dangerous to society, leading to withdrawn support for rehabilitation and increased support for punitive approaches such as post-release monitoring.

Haslam (2006) and Haslam \& Loughnan (2014) describe the importance of UH characteristics which can potentially explain the findings of study 2 . Uniquely human emotions require higher cognition specific to human beings in order to be generated (refinement, civility, intelligence, rationality and self-control) therefore individuals who lack these qualities are likened to subhuman, uncontrollable, animal-like beings. By not displaying remorse or empathy for their crime - particularly for child sexual offenses, which involve direct exploitation of innocents - participants possibly regarded the offender as having lessened cognitive ability to generate these emotions and subsequently less capability to be reformed via rehabilitation, leading to a perceived increase in risk of reoffending and support for harsher forms of post release monitoring. The perception of reduced cognitive performance implied poor self-control that dictated a need for distancing, monitoring and exclusion of offenders. These perceptions contributed to infrahumanisation of child sex offenders from the rest of the community, placing them outside the moral boundaries of concern and justifying harsher forms of punishment.

Similarly, offenders who displayed the uniquely human traits of remorse, empathy and acknowledgement of their offending resulted in decreased infrahumanisation from participants. By displaying the higher level of cognitive functioning needed to generate these emotions, participants regarded the offender as more human-like and similar in nature. Participants also displayed more support for these offenders receiving a form of rehabilitation or counselling. By displaying remorse and empathy, participants likely perceived the offender to hold other uniquely human traits such as self-control and rationalised thinking, contributing to the perception that the offender would benefit from rehabilitation by learning to control impulses that lead to re-offending.

\section{Rehumanisation of child sex offenders and the contact hypothesis}

The findings of Study 2 reinforce the potential predictive power of UH characteristics for rehumanisation of the offender in the eyes of the community: an offender who displays the ability to reflect on their offending and express remorse for their actions, empathy for their victims, and acknowledgement of harm caused could be more likely to be successfully 
reintegrated back into the community. The perception of shared UH characteristics reduces perceived moral distance from the offender thereby re-humanizing the offender and reducing the effects of infrahumanisation (Haslam \& Loughnan, 2014). Therefore an implication of the current study is that the higher cognition required to generate the uniquely human emotions of empathy and remorse are factors which can increase for support for rehabilitation and successful reintegration after release. Offenders who are able to display these characteristics after offending may be re-humanized in the eyes of the public, whereas an offender who withholds them is more likely to be perceived as an ongoing threat to the community.

\section{Limitations of the current study}

The current study aimed to examine the role of dehumanisation in attitudes towards child sex offenders in New Zealand, however the study used a small sample that cannot be considered representative of the general population of New Zealand. The current study provides a basis from which future research can build. For example further altering of the RNR/GLM questions could be made and presented to a wider sample to better assess dehumanising attitudes and preferences for approaches to rehabilitation in a New Zealand context.

The scale used to assess dehumanising attitudes in the online survey of Study 1 generated a reliable but relatively low Cronbach alpha score $(\alpha=.604)$, demonstrating low internal reliability of the scale for analysis. A limitation for the current study therefore arises relating to the ability of the scale to adequately access and assess dehumanising attitudes withheld by participants, suggesting that studies of the future looking to examine dehumanising attitudes towards offenders may require better developed tools or scales in order to do so.

Study 2 was advertised on the Victoria University blackboard page for a criminology course and on student-run social media site 'Vic deals' to gain participants and held on Victoria University campus. Therefore the majority of participants for the current study were students who held background knowledge of criminology, psychology or both. Education is known to reduce prejudice toward outgroup members (Shackley et al., 2013) therefore it is worth considering that participants held a large amount of background knowledge which members of the public typically do not which may have altered the discussion. Study 2 also revealed unintended findings in support of contact hypothesis, revealing that some of the participants had experienced increased contact with offenders which members of the public typically do not, which contributed to a more humanizing view of offenders and may have also altered discussion. 
The current study used online survey methodology, vignettes and focus groups to address dehumanising attitudes in a New Zealand context. The focus groups in Study 2 included use of case studies and the topic of offender registration as examples to generate discussion and assess dehumanizing attitudes, however this method should be considered before repeating in future studies. It is possible that discussion of both case studies and offender registration created too broad of a conversation for an hour-long focus group, which may have limited the depth of discussion within the sessions. Also this method and use of material could be considered too structured for an exploratory study and may have been better phrased as a discussion around the core themes of the study, from which thematic analysis would later detect key ideas.

Online survey methodology allows for a broad and anonymous sample, however it is impossible to ensure that all participants were honest about their age and residency. The online survey was advertised on Victoria University websites and the focus groups were held on Victoria University campus, therefore future studies aiming to examine attitudes in New Zealand should try to do so with less involvement with tertiary institutions to ensure a better sample of public attitudes. Future studies should also consider the phrasing of noncontact offenses and victim age within vignettes used throughout the online study to avoid the same limitations as the current study

The current study provides findings related to attitudes towards punishment and rehabilitation of child sex offenders, however there is scope for further research to build on these findings and build a more solid representation of New Zealand attitudes.

\section{Implications of the current study}

\section{Implication for policy and practice}

Rehumanisation, the contact hypothesis and community education. Study 2 produced some interesting findings related to the contact hypothesis that are relevant to the overall thesis. Participants who had worked in a professional role that involved increased contact with offenders displayed a more humanizing attitude towards them and were more likely to support the rehabilitation and reintegration of offenders. Previous findings have also supported the idea that those who experience closer contact with child sex offenders are less likely to dehumanise them (Conley et al., 2011; Viki et al., 2012). It has been established that members of the public often hold false beliefs regarding the offending rates of child sex offenders due to a lack of contact (Viki et al., 2012) which creates panic for the public, resulting in support for registration and notification policies out of fear (Kernsmith et al., 2009). The current thesis therefore provides further indication that increased contact in the form of education could reduce prejudice towards child sex offenders and aid their reintegration (Viki et al., 2012). 
Throughout the focus groups of Study 2 participants reported a lack of knowledge of offender recidivism and rehabilitation, often stating that they could not form an opinion towards offender rehabilitation programs because they did not know what a program involved and questioned if recidivism rates of child sex offenders could be reduced at all. However the majority of participants reported that if the effectiveness of rehabilitation could be proven they would support offender participation more. Public education could target these inaccurate beliefs and provide empirical evidence for approaches to rehabilitation known to reduce reoffending, such as the RNR and GLM.

Because members of the public do not often interact with sex offenders and instead typically rely on the media for information (which often includes sensationalised use of degrading terms such as 'beast'), forms of public education (such as public forums, pamphlets and announcements) have been suggested by multiple researchers as a form of increasing contact by reducing perceived distance and prejudice (Kernsmith et al., 2009; Shackley et al., 2013; Willis et al., 2010). Powell et al. (2014) found amongst a sample of Australian police professionals that officers believed it took a certain amount of specialised knowledge for successful contact with child sex offenders. Therefore it can be suggested that an effective approach to offender reintegration would involve education which provides the public with accurate information about recidivism rates and the ability of rehabilitation to effectively target and reduce these rates. Given the importance of UH characteristics, these community education forums could provide information that reinforces a more humanizing view of offenders. It could be noted to the public that offenders being released into the community have acknowledged their offending behaviour, displayed remorse and made progressive steps to prevent re-offending in the community. In fact Willis et al. (2014) found that the GLM was more successfully implemented when meetings were held with professionals, family members and friends of the offender to discuss rehabilitative aims before the offender was released. Community education also presents an opportunity to inform the public on the process of the justice system for releasing offenders (such as parole conditions and ongoing checks) which allows law enforcement to know the whereabouts of offenders should any offending occur in that area, possibly eliminating the need for an offender registry to be made publically available. This could create a sense of ease and security for the public by providing assurance that child sex offenders are released into the community with preventative measures in place to prevent further victimisation of children. Future considerations should include the recent findings of Day et al. (2014b; 2014c) relating to a need for a heavier focus on individual risk of each offender and risk management for law enforcement. These suggestions could narrow the scope of registration (if it was to be introduced in New Zealand) so that only offenders who are high 
risk and need monitoring are registered, preventing blocked opportunities for low risk offenders who pose little risk of offending in the future and could potentially become contributing members of society.

\section{Implication for further research}

Future investigation of $\boldsymbol{U H}$ characteristics. Previous studies have concluded that dehumanising attitudes can lead to reduced support for sex offender rehabilitation (Viki et al., 2012) however the findings from Study 2 suggested further investigation into the role of UH characteristics such as empathy and remorse in these preferences. Gwinn et al. (2013) investigated how UH characteristics can express and justify power in a corporate setting. Another study of UH qualities could investigate, for example, using an online survey with alternating vignettes, the response toward offenders who display remorse for their offending followed by participation in rehabilitation and an attempt to reintegrate back into the community, compared to those who deny or justify their offending behaviour and attempt to reintegrate. It would be assumed from the findings of the Study 2 that participants would view more negatively and support the exclusion of offenders who do not take responsibility for their offenses, and would assume them to hold less self-control and therefore pose a higher risk of re-offending.

Victim age. The hypothesis that offenses involving prepubescent victims would receive the most dehumanising attitudes and harshest recommendations for punishment was found to be unsupported in Study 1. Perhaps further investigation into the role of victim age in attitudes towards offenders is needed. Other studies have also found varying results when measuring attitude against victim age. Rogers et al. (2011) found that attitudes of participants became more negative as the age of the victim decreased, whereas Viki et al. (2012) found no effect for the age of victim in their study. These alternative findings suggest that a study involving a larger sample of New Zealand participants and a wider age range of victims could be helpful. For example a study that compares dehumanisation scores for offenses involving prepubescent, pubescent and adult victims could be suggested to address these alternate findings, because if no effect can be found for dehumanisation of adult sex offenders compared to child sex offenders, it may be the details of the offense that impact dehumanising attitudes more than the age of the victim. Higgins and Ireland (2009) conducted a study of this type, however they chose to compare the attitudes of male and female justice system professionals, forensic staff and members of the public in reaction to vignettes describing sex offenses against adults and children. This study produced similar findings to Viki et al. (2012) wherein victim age did not seem to affect the attitudes of participants, leading the 
researchers to suggest that participants regarded the victims as a homogenous group (children) producing no differences in findings for sexual offenses against different age groups. Higgins and Ireland (2009) did not attempt to assess dehumanising attitudes towards adult and child sex offenders, therefore there is scope to perform a study of this nature in a New Zealand context with a wider sample to investigate the role of victim age in attitudes towards child sex offenders.

Non-contact offenses. Participants in Study $1 \& 2$ discussed the treatment of a 30 year old male offender who had downloaded 500 images of nude children (categorising them as a child pornography offender). Throughout Study 2 participants reported that despite committing a child pornography offense the context of the images still played a role in attitudes towards the offender, specifically that images of children forced to pose sexually denoted more harm to the victim than images of children in a neutral setting. These findings could be considered for future studies which aim to address attitudes toward child pornography offenders. For example it would be interesting to know if participants dehumanise and recommend harsher punishment for an offender who views pornography of children in neutral settings compared to images involving children in sexualised poses. As reported by participants of study 2 , one context denotes more harm to the victim than the other, therefore it would be interesting to present both conditions to participants through an online study and see if the context of the images can also impact scores for dehumanisation, moral outrage, and support for punishment and rehabilitation.

\section{Conclusion}

The current study aimed to investigate the role of dehumanisation in attitudes towards the punishment and rehabilitation of child sex offenders in New Zealand. It was hypothesised based on previous findings that dehumanising attitudes would be impacted by the type of offense and age of victim, whilst predicting support for harsher forms of punishment (such as post-release monitoring) and leading to a reduction in support for rehabilitation. These findings overall were supported by Study 1, apart from victim age which was found to have no significant main effect on dehumanisation, moral outrage, punishment or rehabilitation.

Other studies (Viki et al., 2012), similarly found a lack of effect for the age of victim when examining attitudes towards offenders, leading researchers to suggest that sexual offenses against children are generally perceived negatively by the public regardless of the age group to which the victim belongs. Members of the public may view child sex offenders as a homogeneous group because legislative approaches, such as sex offender registration, treat them as such. Regardless of victim age, type of offense or individual level of risk for re- 
offending, child sex offenders are registered alongside one another and subjected to the same barriers to employment and housing as a consequence (Day et al., 2014c; Harkins \& Beech, 2007; Levenson \& Cotter, 2005a). The lack of distinction between typologies of child sex offenders quite likely contributes to broad negative public perceptions that did not distinguish victim age throughout the online survey and provided similar negative outcomes for all victim ages. Future studies could examine dehumanising attitudes towards offenses involving prepubescent, pubescent, and adult victims in New Zealand to better address the role of victim age in attitudes towards offending.

Study 2 allowed for further discussion regarding punishment and rehabilitation of child sex offenders, specifically discussion relating to the creation of a child sex offender registry in New Zealand. Participants regarded post-release monitoring and dehumanising terms such as 'beast' to be too harsh for a child pornography (non-contact) offenders, however both factors were endorsed more for contact offenders such as the 'Beast of Blenheim'. Overall participants expressed concern towards the homogeneous approach of sex offender registration and did not support its creation in New Zealand. Concern was expressed towards the broad nature of registration criteria that could lead to registration for members of the public who commit less severe offenses and/or pose low risk for offending such as internet pornography offenders. Previous reviews of the legislation should be considered before creating a sex offender registry in New Zealand. Registration policies can often result in public backlash such as vandalism or physical threats for registered offenders (Mercado et al., 2008) and have been established to create various forms of strain which contribute to re-offending (barriers to employment, housing, and intimate relationships with others) (Levenson \& Cotter, 2005a; $2005 \mathrm{~b}$ ). These consequences hinder the ability of registration to meet its intended legislative aim of increasing public safety (Day et al., 2014b). Perhaps these findings should be considered and if implemented in New Zealand, registration criteria should at the least be narrowed to high risk offenders as it has been in other areas of the world (Mercado et al., 2008).

Throughout study 2 participants who dehumanised offenders were more likely to support post-release monitoring policies. Dehumanising attitudes related to the belief that child sex offenders are uncontrollable, subhuman beings who require constant monitoring after release to ensure the safety of the public. Specifically, participants of study 2 animalistically dehumanised contact offenders via use of terms such as 'beast' and supported their overall exclusion from the community, contributing to infrahumanisation. Emphasis was placed on the power of UH characteristics to influence support for punishment and rehabilitation: if an 
offender displayed remorse for their offending and empathy for their victim(s) participants perceived them as more reformable and supported their rehabilitation, whereas withholding of these factors created the perception that offenders had diminished self-control and lead to support for monitoring policies. The current therefore study provides implications for future research regarding the impact of empathy and remorse (UH characteristics) on dehumanising attitudes towards child sex offenders.

Implications of these findings relate to the contact hypothesis and public education: increased contact via community education forums which relay accurate information about offender rehabilitation and its empirically established ability to reduce recidivism could dispel re-offending myths which underlie the creation of sex offender registries whilst creating a more humanizing view of offenders by describing and explaining their treatment. For example an offender who has completed a rehabilitation program using a GLM framework will have addressed personal risk factors for offending and made a Good Lives plan tailored to their personal skills to guide prosocial, non-offending behaviour after release. These aims have been found to be undermined after release via hostile and negative attitudes of the public (Willis et al., 2014). It could better uphold rehabilitative aims, create a more humanizing view of offenders, and reduce perceived need for offender monitoring if accurate information about offender rehabilitation was relayed to the public via forms of community education. Forms of education have been suggested by multiple researchers as a form of contact which can reduce prejudice towards sex offenders (Mercado et al., 2008; Opotow et al., 2005; Willis et al., 2010).

The current study also aimed to examine for the first time whether dehumanising attitudes could predict preference between the RNR and GLM frameworks for offender rehabilitation. Study 1 found that participants who dehumanised the offender were less likely to be supportive of offender rehabilitation, however dehumanising attitudes were not found to predict preference between the RNR and GLM approaches to rehabilitation. The current study has, for the first time, attempted to provide descriptions embodying the key principles of each treatment program in an online survey context to examine whether dehumanising attitudes impact preference between the two. Because this is a new approach to research, no descriptions were available on which to base survey material or prior findings on which to base predictions. Despite the unsupported prediction of the current study, there is scope for future studies to explore the relationship between dehumanisation and preference between RNR and GLM approaches to rehabilitation. The current study found that dehumanising attitudes have a role in preferences for punishment and rehabilitation of child sex offenders, however a relatively small sample comprised of mostly university students was used. The current study 
therefore provides scope and indication for areas of further study in order to better establish findings. A larger sample is needed to accurately represent the attitudes of New Zealanders and establish the role of dehumanisation in attitudes towards punishment and rehabilitation. Certainly the findings regarding public attitudes towards post-release monitoring should be considered in relation to the creation of an online registry in New Zealand as no other studies can be retrieved to date which address these attitudes. The small sample of the New Zealand public used in Study 2 preferred that only high-risk offenders be registered so that harsh consequences are not placed unfairly on others. Other researchers have echoed this preference throughout reviews of notification polices (Day et al., 2014b; Day et al., 2014c), therefore this should be considered before implementing the same legislation in New Zealand. 
Dehumanisation and child sex offenders: a New Zealand study

\section{Appendices}




\title{
Appendix A
}

\author{
VICTORIA UNIVERSITY OF WELLINGTON \\ Te Whare Wānanga o te Ūpoko o te Ika a Māui
}

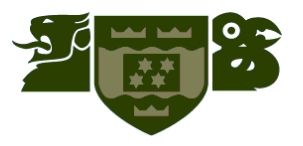

Information about the current study:

\section{The role of dehumanisation in attitudes towards the punishment and rehabilitation of child sex offenders}

I am a MA (Masters) student in criminology at Victoria University of Wellington. As part of this degree I am undertaking a research project leading to a research thesis. The project that I am undertaking explores attitudes towards the punishment and rehabilitation of child sex offenders. This research has been approved by the Victoria University of Wellington human ethics committee.

I am inviting any individual aged 18 or over who would like to complete this survey. You must also be a New Zealand resident or citizen. You will be presented with an example of a sexual offence against a child then be asked a number of questions about the offender and about your attitudes towards the punishment and rehabilitation of this offender. The survey should take no longer than 10 minutes to complete.

Discussion of child sex offenders can be distressing to some therefore participation of only those 18 years of age and older is suggested. At no point are you required to reveal personal information or experience. For those who feel any personal distress after participating in the study, a list of available New Zealand counselling services will be provided after the survey.

Your responses will form the basis for my thesis and the results of the study may be submitted for publication in scholarly journals.

The survey is completely anonymous, and you will not be asked to give your name or any other identifying information. Completion of the survey is taken as consent to your participation. At the end of the survey there will be some information about how to contact the researchers for a summary of the research findings. Do not hesitate to contact us regarding questions or concerns over the questionnaire.

Once again, thank you for your assistance in this research.

Charis Dixson

MA student, Institute of Criminology, Victoria University of Wellington

Charis.Dixson@vuw.ac.nz

Supervisor

Dr Russil Durrant

Senior Lecturer for Victoria University

Institute of Criminology

russil.durrant@vuw.ac.nz 


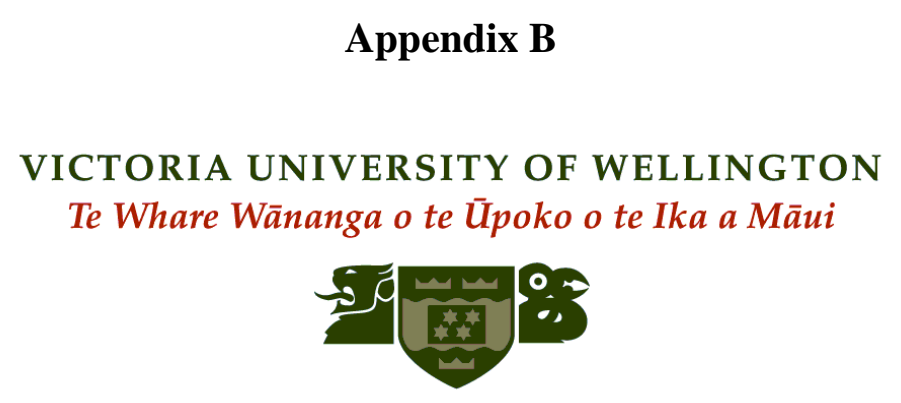

Please specify the following:

Age:

Gender:

Ethnicity:

Survey Questions

1. To what extent do you feel the following emotions when considering the crime that you just read about?

Anger

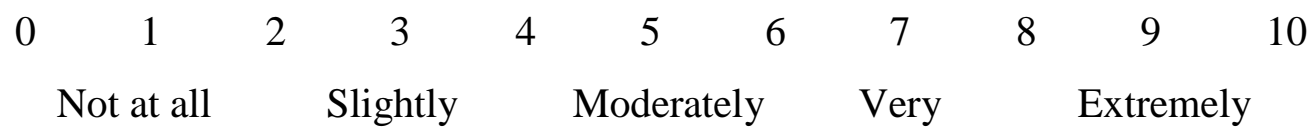

Disgust

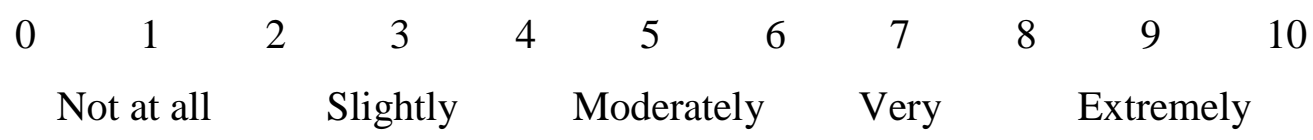

Contempt

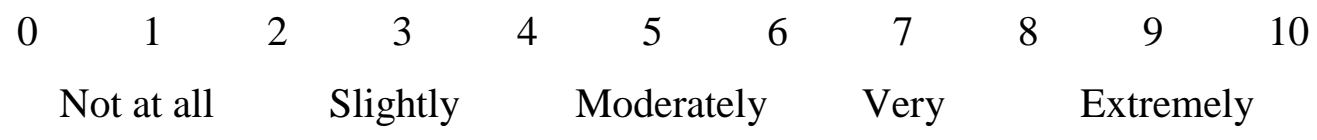

2. How much do you respect the offender that you just read about?
1. Not at all
2. Slightly
3. Moderately
4. Very
5. Extremely 
3. How much do you like the offender that you have just read about?

1. Not at all

2. Slightly

3. Moderately

4. Very

5. Extremely

4. Did the offender that you have just read about leave a positive impression on you?

1. Not at all

2. Slightly

3. Moderately

4. Very

5. Extremely

5. I felt like the person in the story was open minded, like they could think clearly about things.

$\begin{array}{lllllll}1 & 2 & 3 & 4 & 5 & 6 & 7\end{array}$

Strongly disagree

Strongly Agree

6. I felt like the person in the story was emotional, like they were responsive and warm.

$\begin{array}{lllllll}1 & 2 & 3 & 4 & 5 & 6 & 7\end{array}$

Strongly disagree Strongly Agree

7. I felt like the person in the story was superficial, like they had no depth.

$\begin{array}{lllllll}1 & 2 & 3 & 4 & 5 & 6 & 7\end{array}$

Strongly disagree Strongly Agree

8. I felt like the person in the story was mechanical and cold, like a robot.

$\begin{array}{llllllll}1 & 2 & 3 & 4 & 5 & 6 & 7\end{array}$

Strongly disagree $\quad$ Strongly Agree

9. I felt like the person in the story was refined and cultured.

$\begin{array}{lllllll}1 & 2 & 3 & 4 & 5 & 6 & 7\end{array}$

Strongly disagree Strongly Agree 
10. I felt like the person in the story was rational and logical, like they were intelligent. $\begin{array}{lllllll}1 & 2 & 3 & 4 & 5 & 6 & 7\end{array}$

Strongly disagree

Strongly Agree

11. I felt like the person in the story lacked self-restraint, like an animal.

$\begin{array}{llllllll}1 & 2 & 3 & 4 & 5 & 6 & 7\end{array}$

Strongly disagree

Strongly Agree

12. I felt like the person in the story was unsophisticated.

$\begin{array}{llllllll}1 & 2 & 3 & 4 & 5 & 6 & 7\end{array}$

Strongly disagree

Strongly Agree

13. Do you think the offender that you have just read about should receive a prison sentence for his crime?

1. Not at all

2. Receive a fine

3. Community sentencing

4. Less than one year prison sentence

5. 1-5 year prison sentence

6. 6-10 year prison sentence

7. 11-15 year prison sentence

8. Life imprisonment without parole

14. How severe do you think the punishment for this crime should be?

$\begin{array}{lllllllllll}0 & 1 & 2 & 3 & 4 & 5 & 6 & 7 & 8 & 9 & 10\end{array}$

Not Severe $\quad$ Moderately Extremely severe

15. How likely do you perceive that the offender will commit a similar offense within 5 years of completing their sentence (without rehabilitation)?

$\begin{array}{lllllllllll}0 & 1 & 2 & 3 & 4 & 5 & 6 & 7 & 8 & 9 & 10\end{array}$

$\begin{array}{lll}\text { Not at all } & \text { Moderately } & \text { Extremely }\end{array}$

16. How suitable do you think that the offender that you have just read about would be for a rehabilitation program?

\begin{tabular}{llllllllllc}
0 & 1 & 2 & 3 & 4 & 5 & 6 & 7 & 8 & 9 & 10 \\
Not at all & \multicolumn{1}{c}{ Moderately } & & & & Extremely
\end{tabular}


17. How effective do you think a rehabilitation program would be in reducing the likelihood of this individual offending again?

1. Not at all

2. Slightly

3. Moderately

4. Very Effective

5. Extremely

18. To what extent do you support the offender's participation in a rehabilitation program?

$\begin{array}{lllllllllll}0 & 1 & 2 & 3 & 4 & 5 & 6 & 7 & 8 & 9 & 10\end{array}$

Not at all Moderately Extremely

19. How likely do you perceive that the offender will commit a similar offense within 5 years of completing rehabilitation?

\begin{tabular}{llllllllllc}
0 & 1 & 2 & 3 & 4 & 5 & 6 & 7 & 8 & 9 & 10 \\
Not at all & \multicolumn{1}{c}{ Moderately } & & & & Extremely
\end{tabular}

20. In thinking about your political attitudes, which of the groups below would you most identify with? (circle ONE number)

1. People whose views are extremely liberal

2. People whose views are very liberal

3. People whose views are moderately liberal

4. People whose views are moderate (neither liberal nor conservative)

5. People whose views are moderately conservative

6. People whose views are very conservative

7. People whose views are extremely conservative 


\section{Appendix C}

\section{Vignette 1}

Walter is a 30 year old male from Wanganui who was recently arrested and convicted for the sexual assault of a 7 year old girl. The victim lived nearby and the sexual assault occurred as the she walked the neighbourhood unsupervised one day. Walter grabbed the victim and dragged her into a nearby bathroom then removed her clothing and sexually assaulted her. The crime was interrupted when a bystander entered the bathroom. Walter has no prior convictions for sexual assault.

\section{Vignette 2}

Robert is a 30 year old male from Wanganui who was recently arrested and convicted for the sexual assault of a 14 year old girl. The victim lived nearby and the sexual assault occurred as the she walked the neighbourhood unsupervised one day. Walter grabbed the victim and dragged her into a nearby bathroom then removed her clothing and sexually assaulted her. The crime was interrupted when a bystander entered the bathroom. Robert has no prior convictions for sexual assault.

\section{Vignette 3}

James is a 30 year old male living in Wanganui who has recently been convicted for traces of child pornography on his computer. His search history revealed that Simon spent months searching for pornography containing nude images of children ages 7 and below and had built a collection of over 500 images. One day a friend accessed his computer and discovered this collection, which resulted in the eventual prosecution and classification of Simon as a child sex offender. James has no prior convictions for sexual assault.

\section{Vignette 4}

Simon is a 30 year old male living in Wanganui who has recently been convicted for traces of child pornography on his computer. His search history revealed that Simon spent months searching for pornography containing nude images of children ages 11-14 and had built a collection of over 500 images. One day a friend accessed his computer and discovered this collection, which resulted in the eventual prosecution and classification of Simon as a child sex offender. Simon has no prior convictions for sexual assault. 


\section{Appendix D}

\section{Consider the two following options of rehabilitation programs for the offender you just read about.}

Rehabilitation option 1: Focus on addressing risk factors

The offender described is suffering from a problem which effective treatment should target. In particular, the rehabilitation programme should focus on any risk factors that increase the chances of reoffending. Once the problem has either been eliminated or managed, the offender should be monitored according to his level of risk in order to prevent re-offending. This approach stipulates that therapy for child sex offenders should primarily focus on addressing psychological or social problems that are directly related to the risk of re-offending. Other needs that the offender might have which are not directly related to their offending should be given a lower priority.

Rehabilitation option 2: Focus on building strengths and capabilities

The offender described would benefit from therapy that allows them to form a plan that will enable a more successful life without harming others. Because human needs are directly associated with offending behaviour, individuals need to learn how to meet their needs in prosocial and personally meaningful ways. While this therapeutic approach considers individual risk factors that might lead to reoffending it primarily focuses on the wider range of needs offenders might have. More specifically, the rehabilitation programme entails working with the offender to develop projects that are personally motivating such as training for future employment opportunities or learning how to establish and maintain intimate relationships.

Select your preference for treatment:

Option 1:

Option 2: 


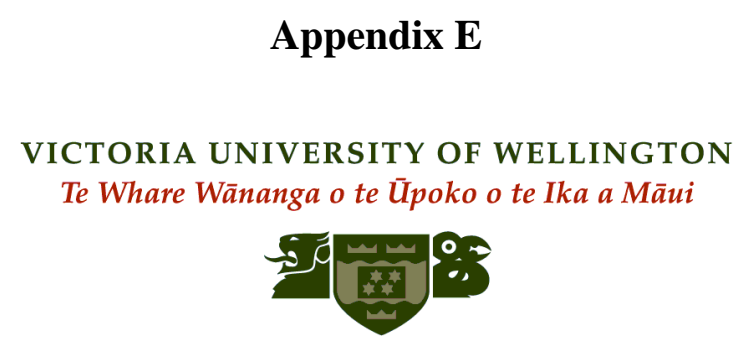

Information Sheet

Attitudes Towards the Punishment and Rehabilitation of Child Sex Offenders: A New Zealand Study

Researcher: Charis Dixson, School of Social and Cultural Studies, Victoria University of Wellington.

I am a Masters student in Criminology at Victoria University of Wellington. As part of this degree I am conducting a research project that will contribute to a thesis. My research examines the attitudes held towards child sex offenders by the New Zealand public. In particular, I am interested in attitudes that relate to punishment and rehabilitation. The project has the overall aim of improving our understanding of public attitudes towards the punishment and rehabilitation of child sex offenders in New Zealand. The study has received approval from the Victoria University Human Ethics Committee.

I am inviting members of the New Zealand public to participate a focus group to discuss the topic. Due to the nature of this topic, it is suggested that participants should be of 18 years or older. This study aims to examine New Zealand attitudes, therefore it is also requested that participants must be either permanent residents or citizens of New Zealand.

\section{About the Focus Group}

If you agree to take part in this research, you will be sent details of the time/place of the focus group that you will attend. The focus group will comprise 8-10 other people, the session will be facilitated by me, and there may also be a research assistant in attendance to ensure your comfort.

During the focus group, you will be asked a number of questions about your attitudes towards child sex offenders and your beliefs and the appropriateness of various forms of punishment and rehabilitation. The focus group will take a maximum of one hour of your time.

Discussion of child sex offenders can be distressing to some therefore participation of those 18 years of age and older is suggested for the online survey and required for attendance of focus 
groups. At no point are you required to reveal personal information or experiences during the focus group. For those who feel any personal distress after participating in the study, a list of available New Zealand counselling services will be provided.

\section{Focus Group Ground Rules}

The focus group will follow several rules:

- I am interested in what you think, so would like everyone to participate;

- I may ask your opinion if I haven't heard from you on a topic;

- Please respect each other's opinions - there are no right or wrong answers, and I want to hear a wide range of views;

- The sessions are confidential - please do not discuss other participants or their responses once the focus group has ended. While I hope that everyone will follow this confidentiality agreement, be aware that I cannot guarantee confidentiality from others in the group;

- The focus group will be recorded however your responses will remain anonymous and no names will be mentioned in any future publications.

\section{Consent}

Your participation is completely voluntary. If you do agree to take part, you will be asked to sign a consent form. Please be aware that:

- You do not have to answer any question that you do not want to;

- You may withdraw from the focus group at any time, and any comments that you make during the focus group will not be used in the final research. If you do decide to withdraw from the study after the focus group is complete you need to contact the researcher within one month of the completion of the focus group. However, please note that if you do decide to withdraw it will not be possible to eliminate your comments from the audio recording until it is erased at the end of the project.

\section{Confidentiality}

If you agree to take part in this research:

- Your name will not appear on any focus group data. Details of your name and contact details will be stored in a separate place from focus group data;

- All information will be held in a secure place, accessed only be myself and my supervisor, Dr Russil Durrant;

- All digital recordings will be erased when this project ends (anticipated to be 30 June 2015). All other information will be destroyed three years after completion. 


\section{Feedback}

Following the focus group, you can request a summary of the research to be sent to you at the end of the project.

\section{What will happen to my responses?}

Responses will form the basis of my research project and will be put into a written report on an anonymous basis. It will not be possible for you to be identified personally, only grouped responses will be presented in this report. All material collected will be kept confidential. No other person beside me and my supervisor [Dr Russil Durrant] will see the questionnaires or transcripts of focus groups. The thesis will be submitted for marking to the School of Social \& Cultural Studies and deposited in the University Library. It is intended that one or more articles will be submitted for publication in scholarly journals.

\section{Contacting Me}

If you would like any further information on this project, you can contact me directly at:

Charis Dixson

Phone: 0273460023

E-mail: Charis.Dixson@vuw.ac.nz

or my supervisor:

Dr Russil Durrant

Senior lecturer for Victoria University

Phone: 4639980

Email: Russil.durrant@vuw.ac.nz

Thank you for your participation and time.

Sincerely,

Charis 


\section{Appendix F}

VICTORIA UNIVERSITY OF WELLINGTON

Te Whare Wānanga o te Ûpoko o te Ika a Māui

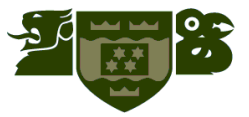

\section{CONSENT TO PARTICIPATE IN RESEARCH}

\section{"Attitudes towards the Punishment and Rehabilitation of Child Sex Offenders: A New}

\section{Zealand Study"}

I have been given and have understood an explanation of this research project. I have had an opportunity to ask questions and have them answered to my satisfaction. I understand that I may withdraw myself (or any information I have provided) from this project without having to give reasons, up to one month after the completion of the focus group. If I do decide to withdraw from the study I understand that any comments that I make during the focus group will deleted from completed transcripts and will not be used in any form. However, my comments will not be able to be deleted from the audio recording until it is erased on the completion of the study in June 2015.

I understand that any information I provide will be kept confidential to the researcher, and the supervisor [Dr Russil Durrant]. I understand the published results will not use my name, and that no opinions will be attributed to me in any way that will identify me. I understand that the data I provide will not be used for any other purpose or released to others without my written consent.

$\square$ I would like to receive a summary of the results of the research when it is completed

$\square$ I agree to abide by the ground rules of the focus group provided in the information sheet

$\square$ I agree to take part in this research.

\section{Signed:}

\section{Name of participant:}

Date:

Contact details if a summary of the research is desired: 


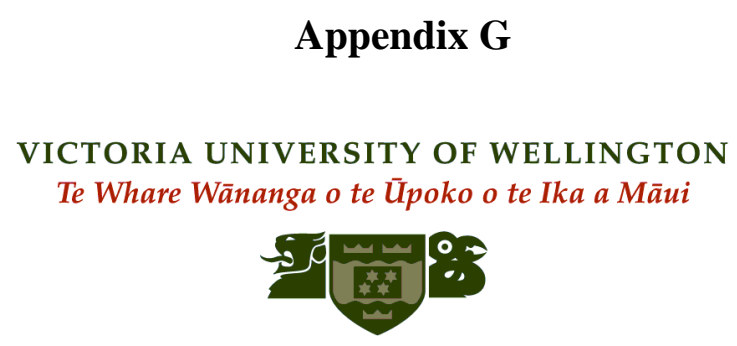

Focus Group Interviewer Guide

\section{Start by:}

- Thanking participants for their time and attendance

- Introducing yourself and your supervisor, explain your research topic and aims

- Read through the focus group rules aloud and make sure participants acknowledge that by signing the consent forms they are agreeing to adhere to the rules of the group

- Indicate again the nature of content and make clear to participants that: (a) if they feel uncomfortable they are welcome to leave at any time however their participation until that point will be included in the study (anonymously): and (b) at no point will there be any discussion of personal experiences or information.

- Collect consent forms

- Explain to them what a sex offender registry is and that one is being developed for NZ/ also explain that they have the intended aim of deterring future offending and increasing public safety.

\section{Case Study 1: The Beast of Blenheim \\ Stewart Murray Wilson}

○ Served 18 years for sexual crimes against 16 females, mostly minors

- Could not participate in the 'Kia Marama' rehabilitation program whilst in the prison because he refused to accept responsibility for his crimes

- Because of his continued denial he completed a sentence and was released without rehabilitation

- Had some of the harshest parole restrictions in NZ placed on him

- Had to live on the grounds of Wanganui prison in a small house

- And wear an ankle bracelet

o No internet access whatsoever

- He eventually violated these conditions with a phone call and was put back in jail 
Q: The media and the public are both of the perspective that this person is a beast, what do you think of the comparison of this person to a 'beast'?

Q: Why do you think we refer to child sex offenders in this way? As 'beasts'?

Q: Do you think rehabilitation is possible for people like Wilson ['the beast']? Why/why not?

Q: What qualities would a good rehabilitation program have for an offender such as Wilson?

Q: Do you think offenders like Wilson should be allowed to reintegrate back into the community after release?

Q: Do you feel that Wilson should be placed on a sex offender registry if he was released?

\section{Case Study 2: Non-contact (child pornography) offender:}

(Read vignette aloud to participants)

James is a 30 year old male living in Wanganui who has recently been convicted for traces of child pornography on his computer. His search history revealed that he spent months searching for pornography containing nude images of children ages 7 and below and had built a collection of over 500 images. One day a friend accessed his computer and discovered this collection, which resulted in the eventual prosecution and classification of James as a child sex offender. James has no prior convictions for sexual assault.

Q: James would qualify be placed on a registry then tracked and monitored for life, do you believe this is a fair response to his offense?

Q: Would you be distressed living next door to an offender like James, considering that he has never physically harmed anybody?

Q: Would you feel safer living next door to him with/without rehabilitation?

Q: Should James be allowed back into the community and resume work at his old job after serving a sentence? Why/ why not?

Q: What do you think the correct response for offenders such as James would be?

Q: Would you refer to James as a 'beast' or 'monster' like people did Wilson? Why/why not? 


\section{Conclude with some registry questions:}

- REGISTRY Q'S:

- Q: Do you support the creation of a sex offender registry in NZ? If you do not support it, what response from the criminal justice system would you like to see instead?

- Q: Which option do you prefer in regards to the treatment of sex offenders: punishment or rehabilitation? Why? 


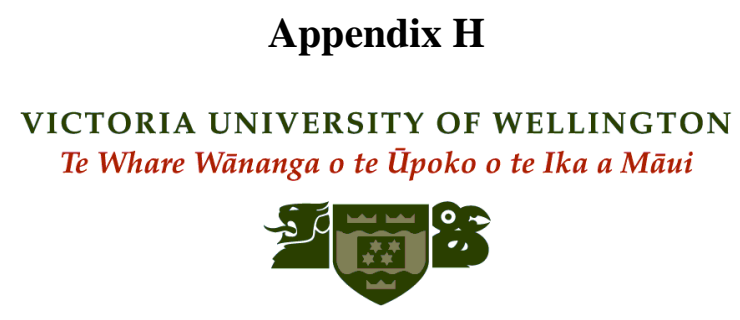

Counselling Services Available in NZ

If the content of this study has caused you any personal distress the following counselling services are available for help and support.

\section{Wellington Help}

This organisation provides a 24 hour hotline to help victims and their families recover from sexual abuse as well as counselling and referrals.

Web address: www.wellingtonhelp.org.nz

24 hour Phone service: 044997532

Victims Information Organisation:

This organisation helps victims and families by providing support for both the emotional and practical effects of crime:

Web Address: http://www.victimsinfo.govt.nz/

24 hour source of information and support for victims of any crime type:

0800842846

And a victims of crime information line that provides support services and information about the criminal justice system:

0800650654

Wellington Rape Crisis

Office phone: 048018973

National hotline for crisis centres: 0800883300

Wairarapa Rape and Sexual Abuse Collective 
This organisation provides a national 24 hour helpline for victims of sexual abuse and their families and are a smaller branch of the wider 'Rape Crisis' organisation.

E-mail: Rape.crisis@xtra.co.nz

24 hour helpline: 0800883300

Wellington Sexual Abuse Help Foundation

Web address: $\underline{\text { www.wellingtonhelp.org.nz }}$

Phone:_04 4997532

\section{Male Survivors of Sexual Abuse Trust}

This organisation facilitates support groups around New Zealand for male survivors of sexual abuse.

Web address: www.survivor.org.nz

Phone/Fax: +64 (03) 3776747 


\section{References}

3News (2014) 'Beast of Blenheim Stewart Murray Wilson handed more jail time', http://www.3news.co.nz/nznews/beast-of-blenheim-stewart-murray-wilson-handed-more-jailtime-2014112111\#axzz3T7XbXb18, website accessed 01/01/2015.

American Psychiatric Association (2013) DSM-5 Paraphilic Disorders. Accessed from: http://www.dsm5.org/Documents/Paraphilic\%20Disorders\%20Fact\%20Sheet.pdf， accessed on $16 / 05 / 2015$

Andrews, D., Bonta, J. \& Hoge, R. (1990) Classification for effective rehabilitation: rediscovering psychology. Criminal Justice and Behaviour. 17: 19-52.

Andrews, D., Bonta, J. \& Wormith, J.S. (2011) The Risk-Need-Responsivity (RNR) model: does adding the Good Lives Model contribute to effective crime prevention? Criminal Justice and Behaviour. 38: 735-755.

Bain, P., Park, J., Kwok, C. \& Haslam, N. (2009) Attributing human uniqueness and human nature to cultural groups: distinct forms of subtle dehumanisation. Group Processes \& Intergroup Relations. 12: 789-805

Bandura, A. (1999) Moral disengagement and the perpetration of inhumanities. Personality and Social Psychology Review. 3:193-209.

Bandura, A., Barbaranelli, C, Caprara, G \& Pastorelli, C (1996) Mechanisms of moral disengagement in the exercise of moral agency. Journal of Personality and Social Psychology. 71: 364-374.

Bastian, B., Denson, T. \& Haslam, N. (2013) The roles of dehumanisation and moral outrage in retributive justice. Plos One. 8: 1-10.

Bastian, B., Laham, S., Wilson, S., Haslam, N., \& Koval, P. (2011) Blaming, praising, and protecting our humanity: the implications of everyday dehumanisation for judgements of moral status. British Journal of Social Psychology. 50: 469 - 483.

Blumenthal, S., Gudjonsson, G. \& Burns, J. (1999) Cognitive distortion and blame attribution in sex offenders against adults and children. Child Abuse and Neglect. 23: 129- 143.

Brown, S. (1999) Public Attitudes towards the treatment of sex offenders. Legal and Criminal Psychology. 4: 239-252.

Cann, J., Friendship, C. \& Gonza, L. (2007) Assessing crossover in a sample of sexual offenders with multiple victims. Legal and Criminological Psychology. 12: 149-163. 
Conley, T., Hill, K., Church, W., Stoeckel, E. \& Allen, H. (2011) Assessing probation and community correction workers' attitudes towards sex offenders using the attitudes towards sex offenders (CATSO) scale in a rural state. Sexual Addictions and Compulsivity. 18: 75-85.

Costello, K. \& Hodson, G. (2009) Exploring the roots of dehumanisation: the role of animal-human similarity in promoting immigrant humanization. Group Process and Intergroup Relations. DOI: $10.1177 / 1368430209347725$

Day, A., Boni, N., Hobbs, G., Carson, E., Whitting, L. \& Powell, M. (2014a) Professional attitudes to sex offenders: implications for multiagency and collaborative working. Sexual Abuse in Australia and New Zealand. 6: 12-19.

Day, A., Carson, E., Boni, N. \& Hobbs, G. (2014b) The management of sex offenders in the community; from policy to practice. Australian Journal of Social Issues. 49: 249-264.

Day, A., Carson, E., Newton, D. \& Hobbs, G. (2014c) Professional views on the management of sex offenders in the community. Journal of Offender Rehabilitation. 53: 171-189

Durrant, R. (2013) An introduction to criminal psychology. Routledge: Great Britain.

Dutton, D., Boyanowsky, E. \& Bond, M. (2005) Extreme Mass Homicide: From Military Massacre to Genocide. Aggression and Violent Behaviour. 10: 437-473.

Esmeir, S. (2006) On making dehumanisation possible. PMLA. 121: 1544-1551.

Ferguson, K. \& Ireland, C. (2006) Attitudes towards sex offenders and the influence of offense type: a comparison of staff working in a forensic setting and students. The British Journal of Forensic Practice. 8: 10-19.

Field, A. (2009) Discovering statistics using SPSS. $3^{\text {rd }}$ edition. Sage publishing. London. England.

Fisher, D., Beech, A. \& Browne, K. (1999) Comparison of sex offenders to non-offenders on selected psychological measures. International Journal of Offender Therapy and Comparative Criminology. 43(4): 473-491.

Goff, P., Eberhardt, J., Williams, M. \& Jackson, M. (2008) Not yet human: implicit knowledge, historical dehumanisation, and contemporary consequences. Journal of Personality and Social Psychology. 94 (2) 292-306.

Greenberg, D., Bradford, J. \& Curry, S. (1993) A comparison of sexual victimization in the childhoods of paedophiles and hebephiles. Journal of Forensic Sciences. 38 (2): 432-436.

Gwinn, J., Judd, C. \& Park, B. (2013) Less power=less human? Effects of power differentials on dehumanisation. Journal of Experimental Social Psychology. 49: 464-470.

Hackel, L., Looser, C. \& Bavel, J. (2014) Group membership alters the threshold for mind perception: the role of social identity, collective identification, and intergroup threat. Journal of Experimental Social Psychology. 52: 15-23. 
Hanson, R., Harris, A., Helmus, L. \& Thornton, D. (2014) High-risk offenders may not be high risk forever. Journal of Interpersonal Violence. 29: 2792-2813. doi: 10.1177/0886260514526062

Hanson, R. \& Morton-Bourgon, K. (2004). Predictors of sexual recidivism: An updated meta-analysis. Ottawa: Public Safety and Emergency Preparedness Canada.

Hanson, R. \& Morton-Bourgon, K (2005) The Characteristics of persistent sexual offenders: a metaanalysis of recidivism studies. Journal of Consulting and Clinical Psychology. 73: 1154-1163.

Harkins, L. \& Beech, A. (2007) A review of the factors that can influence the effectiveness of sexual offender treatment: risk, need and responsivity and process issues. Aggression and Violent Behaviour. 12: 615-627.

Haslam, N. (2006) Dehumanisation: An integrative review. Personality and Social Psychology Review. 10: 252-264.

Haslam, N. \& Loughnan, S. (2014) Dehumanisation and infrahumanisation. Annu. Rev. Psychol. 65: $399-423$.

Haslam, N., Loughnan, S., Reynolds, C. \& Wilson, S. (2007) Dehumanisation: a new perspective. Social and Personal Psychology Compass. 1(1): 409-422.

Heflick, N., Goldenberg, J., Cooper, D. \& Puvia, E. (2011) From women to objects: appearance on focus, target gender and perceptions of warmth, morality and competence. Journal of Experimental Social Psychology. 47: 572-581

Higgins, C. \& Ireland, C. (2009) Attitudes towards male and female sex offenders: a comparison of forensic staff, prison officers and the general public in Northern Ireland. British Journal of Forensic Practice. 1(1) 14-19.

Hogue, T.E. (1993) Attitudes towards prisoners and sexual offenders. In N.C. Clark \& G. Stephenson (eds), DCLP occasional papers: sexual offenders (27-32). Leicester: British psychological society.

Hogue, T. \& Peebles, J. (1997) The influence of remorse, intent, and attitudes towards sex offenders on judgements of a rapist. Psychology, Crime and Law. 3: 249-259.

Johnson, H., Hughes, J. \& Ireland, J. (2007) Attitudes towards sex offenders and the role of empathy, locus of control and training: a comparison between a probationer police and general public sample. The Police Journal. 80: 28-54.

Kear-Colwell, J. \& Pollock, P. (1997) Motivation or confrontation: which approach to the child sex offender? Criminal Justice and Behaviour. 2 (1): 20-33. 
Keenan, T. \& Ward, T. (2000) A theory of mind perspective on cognitive, affective, and intimacy deficits in child sexual offenders. Sexual Abuse: a Journal of Research and Treatment. 12 (1): 49-60

Kernsmith, P., Craun, S. \& Foster, J. (2009) Public attitudes toward sexual offenders and sex offender registration. Journal of Child Sexual Abuse. 18: 290-301.

Kjelsberg, E. \& Loos, L. (2008) Conciliation or condemnation? Prison employees and young peoples' attitudes towards sexual offenders. The International Journal of Forensic Mental Health. 7: 95-103.

Ladegaard, H. (2013) Demonising the cultural other: legitimising dehumanisation of foreign domestic helpers in the Hong Kong press. Discourse, Context and Media. 2: 131-140.

Levenson, J., Brannon, Y., Fortney, T. \& Baker, J. (2007a) Public perception about sex offenders and community protection policies. Analyses of Social Issues and Public Policy. 7: 1-25.

Levenson, J. \& Cotter, L. (2005a) The effect of Megan's law on sex offender reintegration. Journal of Contemporary Criminal Justice. 2: 49-64.

Levenson, J. \& Cotter, L. (2005b) The impact of sex offender residence restrictions: 1,000 feet from danger or one step from absurd? Int J Offender Ther Comp Criminol. 49: 168-178.

Levenson, J., D'Amora, D. \& Hern, A. (2007b) Megan's law and its impact on community re-entry for sex offenders. Behavioural Sciences and the Law. 25: 587-602.

Leyens, J., Rodriguez-Perez, A., Rodriguez-Torres, R., Gaunt, R., Paladino, M., Vaes, J. \& Demoulin, S. (2001) Psychological essentialism and the differential attribution of uniquely human emotions to ingroups and outgroups. European Journal of Social Psychology. 31: 395-411.

Livingstone Smith, D. (2011) Less Than Human: why we demean, enslave and exterminate others. St Martin's press, New York.

Loughnan, S., \& Haslam, N. (2007). Animals and androids: Implicit associations between social groups and nonhumans. Psychological Science. 18: 116-121.

Loughnan, S., Haslam, N. \& Kashima, Y. (2009) Understanding the relationship between attribute- based and metaphor - based dehumanisation. Group Processes and Intergroup Relations. 12: 747-762

Marshall, W.L. (1996) The sexual offender: monster, victim or everyman? Sexual Abuse: A Journal of Research and Treatment. 8: 317-335 
Mercado, C., Alvarex, S. \& Levenson, J. (2008) The impact of specialized sex offender legislation on community re-entry. Sexual Abuse: A Journal of Research and Treatment. 20: 188-205.

Moller, A. \& Deci, E. (2009) Interpersonal control, dehumanisation, and violence: a self-determination theory perspective. Group Processes \& Intergroup Relations. 1-13. DOI: $10.1177 / 1368430209350318$

Neutze, J., Grundmann, D., Scherner, G. \& Beier, K. (2012) Undetected and detected child sexual abuse and child pornography offenders. International Journal of Law and Psychiatry. 35: 168175.

Olver, M. \& Wong, S. (2013) Treatment programs for high risk sexual offenders: program and offender characteristics, attrition, treatment change and recidivism. Aggression and Violent Behaviour. 18: 579-591.

Opotow, S. (1990) Moral Exclusion and injustice: an introduction. J. Soc. Issues Policy Rev. 4: 1-20.

Opotow, S., Gerson, J. \& Woodside, S. (2005) From moral exclusion to moral inclusion: theory for teaching peace. Theory into Practice. 44:4, 303-318. DOI:10.1207/s15430421tip4404_4

Petrosino, A .\& Petrosino, C. (1999) The public safety potential of Megan's Law in Massachusetts: an assessment from a sample of criminal sexual psychopaths. Crime \& Delinquency. 45: 140-158.

Powell, M., Andrew, D., Mairi, B., Vess, J. \& Graffam, J. (2014) Australian police officers' perceptions of sex offender registries. Policing and Society. 24:120-133.

Rogers, P., Hirst, L. \& Davies, M. (2011) An investigation into the effect of respondent gender, victim age, and perpetrator treatment on public attitudes towards sex offenders, sex offender treatment and sex offender rehabilitation. Journal of Offender Rehabilitation. 50: 511-530.

Rudman, L. \& Mescher, K. (2012) Of animals and objects: men's implicit dehumanisation of women and likelihood of sexual aggression. Personality and Social Psychology Bulletin. 38: 734-746.

Sample, L. \& Bray, T. (2006) Are sex offenders different? An examination of rearrest patterns. Criminal Justice Policy Review. 17: 83-102.

Sanghara, K. \& Wilson, J. (2006) Stereotypes and attitudes about child sexual abusers: a comparison of experienced and inexperienced professionals in a sex offender treatment. Legal and Criminological Psychology. 11: 229-244.

Shackley, M., Weiner, C., Day, A. \& Willis, G. (2013) Assessment of public attitude towards sex offenders in an Australian population. Psychology, Crime \& Law. 20: 553-572.

SST (Sensible Sentencing Trust) (2014) www.sst.org, accessed on 01/05/2014 
Viki, G., Fullerton, I., Raggett, H., Tait, F. \& Wiltshire, S. (2012) The role of dehumanisation in attitudes toward the social exclusion and rehabilitation of sex offenders. Journal of Applied Social Psychology. 42: 2349-2367.

Ward, T. \& Brown, M. (2004) The Good Lives Model and conceptual issues in offender rehabilitation. Psychology, Crime \& Law. 10: 243-257.

Ward, T. \& Gannon, T. (2006) Rehabilitation, etiology and self-regulation: the comprehensive good lives model of treatment for sexual offenders. Aggression and Violent Behaviour. 11: 77-94.

Ward, T., Gannon, T. \& Birgden, A. (2007a) Human rights and the treatment of sex offenders. Sex Abuse. 19: 195-204.

Ward, T., Gannon, T. \& Mann, R. (2007b). The good lives model of offender rehabilitation: clinical implications. Aggression and Violent Behaviour, 12, 87-107.

Ward, T. \& Keenan, T. (1999) Child molesters' implicit theories. J Interpers Violence. 14: 821-838.

Waytz, A. \& Epley, N. (2012) Social connection enables dehumanisation. Journal of Experimental Social Psychology. 48: 70-76.

Welchans, A. (2005) Megan's Law: evaluations of sex offender registries. Criminal Justice Policy Review. 16: 123-140.

Willis, G., Levenson, J. \& Ward, T. (2010) Desistance and attitudes towards sex offenders: facilitation or hindrance? Journal of Family Violence. 25: 545-556.

Willis, G., Malinen, S. \& Johnston, L. (2013a) Demographic differences in public attitudes toward sex offenders. Psychiatry, Psychology \& Law. 20: 230-247.

Willis, G., Prescott, D. \& Yates, P. (2013b) The Good Lives Model in theory and practice. Sexual Abuse in Australia and New Zealand. 5: 3-9.

Willis, G. Ward, T. \& Levenson, J. (2014) The Good Lives Model (GLM) an evaluation of GLM operationalization in North American treatment programs. Sex Abuse. 26: 58-81

Whitting, L., Day, A. \& Powell, M. (2014) The impact of community notification on the management of sex offenders in the community: an Australian perspective. Australian and New Zealand Journal of Criminology. 47(2) 240-258.

Yang, B. \& Ahn, O. (2007) The process of change in the sexual attitudes of sexual offenders in Korea. Asian Nursing Research. 1 (2) 95-105. 
Zhang, H., Chan, D., Teng, F. \& Zhang, D. (2015) Sense of interpersonal security and preference for harsh action against others: the role of dehumanisation. Journal of Experimental Social Psychology. 56: 165-171.

Zimbardo, P. (1973) On the ethics of intervention in human psychological research: with special reference to the Stanford prison experiment. Cognition. 2(2) 243-256.

Zimbardo, P. (2007) The Lucifer Effect: how good people turn evil. Random house publishing: London. 